\title{
Evaluating the corollary of the interdependency of rock joint properties on subsurface fracturing
}

\author{
Kenneth Imo-Imo Israel Eshiet ${ }^{1}$, Yong Sheng ${ }^{2}$, Dongmin Yang ${ }^{3}$ \\ ${ }^{1,2}$ School of Architecture and Built Environment, Faculty of Science and Engineering, \\ University of Wolverhampton, Wolverhampton, United Kingdom \\ ${ }^{3}$ School of Engineering, The University of Edinburgh, Edinburgh, United Kingdom \\ Email: $\underline{1}$ K.Eshiet@wlv.ac.uk; ${ }^{1}$ kenieshiet@yahoo.com; ${ }^{2}$ Y.Sheng2@wlv.ac.uk; \\ 르ongmin.Yang@ed.ac.uk
}

\begin{abstract}
The characteristics of structural discontinuities in the subsurface environment often play a key role in the overall behaviour of such systems and their response to externally imposed conditions. Rock joints are one of such features that constitute the heterogeneity of rock masses. Akin to other forms of discontinuities, the characteristics of rock joints affect the performance of their parent rock masses, which are constituents of rock formations. The fracturing process is one of such key geomechanical phenomena that is inevitably influenced by pre-existing joints. A numerical technique implemented via a discrete element method (DEM) is herein adopted to evaluate two fundamental properties that control the shear and dilatancy responses of discontinuities. Though these properties are also assessed in isolation, their inter-dependency, which is a dominant factor, is investigated.

As joint frictional resistance increases, it escalates the potential of the joint to attenuate the rate of fracture growth. On the other hand, an increase in joint dilatancy increases the intensity of fracturing. The impact of joint frictional resistance is more pronounced at high friction magnitudes and in this range the predominant influence of joint friction overwhelms any effect of joint dilatancy. Contrarily, at low joint frictional resistance, contributions from even a small magnitude of joint dilatancy increases the degree of fracturing. The inter-relationship between joint friction and dilatancy has influencing implications that govern the performance of rock masses. An inquiry into their combined contributions provides information prerequisite for a more accurate estimation and appraisal of fracture behaviour in underground systems.
\end{abstract}

Keywords: rock joint, joint frictional resistance, joint dilatancy, fracturing, flow through porous media, subsurface 


\subsection{Introduction}

\subsection{Background}

Discontinuities embedded in rock masses have a bearing on their structural integrity and performance. At the macro scale, this effect is markedly evident. Incidence of discontinuities, which may occur as weak regions, therefore have a pronounced effect on the macro-structure and microscale characteristics. Different aspects of this phenomenon have been examined; an essential facet being how it affects the fracturing process (e.g., Casas et al., 2006, Zhang and Jeffrey, 2006 , Thiercelin and Makkhyu, 2007, Athavale and Miskimins, 2008, Zhang and Jeffrey, 2008, Philipp et al., 2009, Chuprakov et al., 2010).

Joints are marked areas of weaknesses that immensely contribute to the overall behaviour of the rock mass. In some instances, the form the divide between rocks with dissimilar material properties. Their complex characteristics transcend connecting rock sections and the radial area of influence. Their strength is considerably lower than adjoining rock sections and their presence introduces zones of anisotropy (Ivars et al., 2011). Thus, their existence determines the whole rock behavior. Where there is a co-existence of two or more joints, other factors pertaining to joint network add to the complexity of system.

The mechanical properties and behaviour of joints have a corresponding consequence on the integrity of a rock mass (Cai and Horii, 1992, Kulatilake et al., 2001). The gravity of this effect is more conspicuous if evaluations conducted on large scales and the joints are present in considerable numbers. Therefore, joint density, location, geometry and distribution play an important role (Kachanov et al., 2010). The combination of all these components makes it difficult to understand adequately the resulting phenomena. Until recently, predictions of rock joint performance has been on the premise of several assumptions. For instance, in DEM models, joint planes can be produced by zeroising the strength of contact bonds along the plane (Kulatilake et al., 2001); and in continuum-based models, joints have been represented as thin-layered or zero-thickness interfaces (Wang et al., 2003, Priest, 1993, Desai et al., 1984). Improved interpretations are possible if underlying governing processes are understood.

Several models have been proposed, both for joints (e.g., Saadat and Taheri, 2020, Saadat and Taheri, 2019, Johansen, 2016, Lei et al., 2016, Lambert and Coli, 2014, Park and Song, 2009, Ohnishi et al., 1996, Plesha, 1987, Plesha, 1995, Wang et al., 2003, Amadei and Saeb, 1990) and for rock masses with high densities and distribution of embedded joints and cracks (e.g., Cai and Horii, 1992, Lehner and Kachanov, 1996, Kachanov et al., 1990, Kachanov, 1982a, Kachanov, 1982b, Kachanov, 1982c, Kachanov, 1980). These joint models are typically formulated with primary emphasis on one 
or a combination of the following characteristics: compressive tensile, and shear strength, frictional resistance, dilation, roughness/asperity, matedness, scaling effect, and post-yield responses (softening and hardening). For example, the conceptual model developed by Johansen (2016), and Johansen and Stille (2014) is based on the adhesive theory of friction and an idealisation of surface roughness using fractal theory, where changes in size of contact points and dilation angles due to variations in scale and matedness is taken into consideration. Lei et al. (2016) presents a joint empirical constitutive model, which couples normal, shear and dilatant responses by relating the normal, shear and dilatational displacement. The cohesive model formulated by Saadat and Taheri $(2019,2020)$ introduces a gradual softening phase in the shear behaviour that enables a more accurate representation of joints. Inclusion of these post-yield softening mechanisms at the contact level is shown to be particularly more representative of clay-infill joints (Saadat and Taheri 2019) and joints in polycrystalline rocks (Saadat and Taheri 2020).

Although the presence of joints determines the behaviour of the rock mass, this effect is reciprocal. External conditions, and the material properties and other characteristics of host rocks alter the responses of joints. This is exemplified during cyclic loading, whether shearing or normal to the joint interface, which causes a largely different impact as compared to monotonic loading (Han et al., 2020, Maciejewski et al., 2020, Li et al., 2019). During cyclic shearing, a granulate fraction as a result of abrasion of asperities is created at the interface (Maciejewski et al., 2020). The granulate fraction occurs as a newly formed interfacial layer which further contributes to the joint behaviour. With respect to rock mass, the joint geometry parameters such as orientation, density, size and distribution affect rock strength and mode of failure (Kulatilake et al., 2001).

Whereas the definition of joints does not include induced/artificial fractures, as can be caused by hydraulic fracturing operations, this work investigates the relationship between conditions that instigate hydraulic fracturing and fracture growth, and changes in joint morphology. The performance of joints with respect to the onset, mode and proliferation of fractures together with the reciprocal effect of propagating fractures, especially those approaching the expanse of joints is critical to understanding the interactive relationships between these two rock features. Knowledge of these processes is beneficial in the drive towards a more efficient subsurface management. Previous findings include an increase in fracture spacing with layer thickness, in layered formations (Tang et al., 2008, Ji and Suruwatari, 1998, Ji et al., 1998, Wu and Pollard, 1995, Ladiera and Price, 1981, Narr and Suppe, 1991, Huang and Angelier, 1989); the tendency of tensile fractures to grow normal to the plane separating layers especially in stiffer, brittle rocks (Schopfer et al., 2011) as well 
as an inverse and proportional correlation between fracture spacing and vertical normal stress, and fracture spacing and tensile strength, respectively (Schopfer et al., 2011).

Tensile strength, shear strength and cohesion are key properties that govern the behaviour of bonded joints. Joint strength is also affected by joint roughness, stiffness of the contacting planes and the presence of infills. The characteristics and effect of infills are described in Indraratna et al. (2008), Trivedi (2010) and Zare et al. (2008). According to Indraratna et al. (2008), infills decrease the frictional resistance, decrease the shear strength and if they exist in substantial amounts may determine the whole behaviour of the joint.

The Discrete Element Method (DEM) is the numerical technique preferred in this work to derive linkages and correlations between joint behaviour in rocks and related hydraulic fractures. Other techniques such as Boundary Element Methods (BEM) and Finite Element Methods (FEM) can also be used to model fracturing events (Welch et al., 2015). Nonetheless, DEMs are better at representing fracture nucleation and propagation, which occur during bond breakages and parting of particles. Unlike FEM and BEM models, the DEM approach negates the need for pre-embedded cracks to define the onset of fracturing. In FEMs, fractures are represented as discontinuous elements, with thin or zero effective thickness, which are integrated into the rock domain (Cacace and Blocher, 2015, Segura and Carol, 2008, Segura and Carol, 2004, Jacquey et al., 2017). The behaviours of fractures, the rock matrix and fluid are treated via separate continuum formulations with given distinctive characteristics (e.g., Mohammadnejad and Khoei, 2013). The main constraint of DEM is the massive computational requirements for large models, making it more suitable for small-scale problems.

\subsection{Relevance and engineering applicability of study}

The frictional properties of rock joints and other discontinuities such as induced and naturally occurring fractures are integral to its shear strength. There are inter-relationships involving frictional resistance, dilatancy, wall compressive strength and asperities of discontinuities. Rock dilatancy prefigures fracturing and can be used as a precursor and indicator of the tendency and extent of rock damage. The rate of dilation of rock discontinuities decreases with degradation of asperities (Kamonphet, 2015, Hossaini, 2014, Roko, 1997), and there is also a link between the dilatancy and frictional resistance of discontinuities. In some cases, the applicability of these interlinking phenomena in the actual environment can be observed. For example, the shear strength of discontinuities, which are less susceptible to changes in dilation is reported by Kamonphet (2015) to be independent to cyclic shear loading. Under many other conditions, these dependencies are not well established. 
In rock masses, the characteristic of embedded discontinuities is influenced by interactions of the controlling properties. These in turn govern the rock mass behaviour-much like the fracturing process-especially when it is subjected to external loadings akin to fluid injection, shear, and uniaxial and triaxial compression. Generally, joint shear strength is an important property usually considered when designing foundations, tunnels and other related engineering structures; in slope stability analyses; and subsurface exploration and production of energy resources. Thus, the principal objectives of this investigation is

- to establish the inter-relationship of the main joint properties such as the shearing resistance and dilatancy,

- to ascertain the contributions from these properties to joint displacement and strength, and

- to define the ramifications of the interacting phenomena on the fracturing process.

The peculiarity of this work is further demonstrated through the combination of various techniques, executed by

- modelling the joint as unbonded,

- integrating the concept of joint dilatancy in the smooth-joint model,

- applying the Pouseuille's equation for fluid flow through porous media, and

- incorporating the DEM embedded fluid flow algorithm and fluid-solid coupling-described in Eshiet and Sheng (2014) - with the smooth-joint model.

Eshiet and Sheng (2017) focuses on the singular effect of rock joint frictional strength on the fracturing process governed by fluid pressure. This study significantly extends the work presented in Eshiet and Sheng (2017) by accounting for dilatancy, which is treated on one hand as a separate but intrinsic rock property, and on the other hand, interactive with interdependencies involving other mechanical properties of rock and rock joints.

A key feature of joint interfaces is the asperity. This governs the frictional sliding of the joint as well as its dilation. The major (large) and minor (small) asperities control the Interfacial dilation and sliding respectively (Maciejewsk et al., 2020). The joint roughness coefficient (JRC) is an index of the existence of asperities, and is used to characterise the interfacial morphology of joints (Barton, 1973; Barton and Choubey, 1977). Here, JRC is implicitly applied as described by Barton's formulation (Barton, 1973), where the dilation angle is determined to be a function of JRC. 


\subsection{The joint and smooth-joint contact model}

The smooth-joint model (Itasca, 2008) is used to define the characteristics of a rock joint or any form of discontinuity. In this case, the rock joint is modelled by designating smooth-joint models to every inter-particle contact of particles located at opposite sections of the joint (Figure 1), implying that the smooth joint actually occurs at contacts. Each joint comprises two opposing planar and parallel surfaces and the orientation of the plane is described by the unit-normal vector $\left(\hat{n}_{j}\right)$ and angle of dip $(\theta)$. Each qualified pair of particles with their contact is linked with the corresponding joint surface. The dot product of the unit normal vectors for the contact $\left(\hat{n}_{c}\right)$ and joint $\left(\hat{n}_{j}\right)$ are used to identify the location of each particle with respect to the joint surface. For instance, considering Figure 1, Particle 1 is located in Section 2 if $\hat{n}_{c} \cdot \hat{n}_{j} \leq 0$. The joint unit normal vector $\left(\hat{n}_{j}\right)$ is given by

$$
\hat{n}_{j}=[\sin (\theta), \cos (\theta)]
$$

Where, $\theta$ is the joint dip angle.

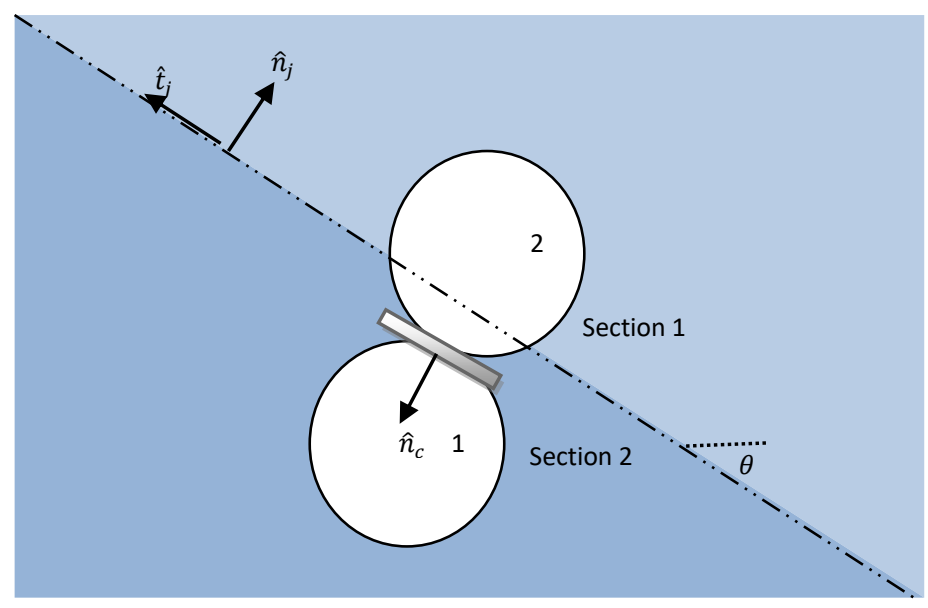

Figure 1. Orientation of Joint and Smooth-Joint Contact (Eshiet and Sheng, 2017)

In assigning the smooth-Joint model, the original contact model is replaced. The original contact model is a bonded linear model, implying the presence of a contact bond at each contact. The linear model defines the contact stiffness, and the sliding and contact bond performance. The contact stiffness is derived from each contacting pair of particles assuming that they act in series, consisting of shear and normal components. For the linear model, the contact normal secant stiffness is determined as (Itasca, 2008)

$$
K^{n}=\frac{k_{n}^{1} k_{n}^{2}}{k_{n}^{1}+k_{n}^{2}}
$$


Likewise, for the contact shear tangent stiffness is obtained through

$$
k^{s}=\frac{k_{s}^{1} k_{s}^{2}}{k_{s}^{1}+k_{s}^{2}}
$$

Where, $k_{n}$ and $k_{s}$ is the particle normal and shear stiffnesses respectively, and the superscripts 1 and 2 represent the contacting entities. Excluding the dip angle, the properties of the smooth-joint contact is adopted from the contacting pair of particles and the contact. For instance, the smoothjoint contact shear stiffness $\left(\bar{k}_{n}\right)$, shear stiffness $\left(\bar{k}_{s}\right)$ and friction coefficient $(\mu)$ are given as

$$
\begin{gathered}
\bar{k}_{n}=\left(\frac{k^{n}}{A}\right)+\bar{k}_{n} \\
\bar{k}_{s}=\left(\frac{k^{s}}{A}\right)+\bar{k}_{s} \\
\mu=\mu_{c}
\end{gathered}
$$

$\mu_{c}$ is the linear model contact friction coefficient.

When the smooth-joint model is activated, the increment in relative displacement between the contacting particles are resolved into normal and tangential components with respect to the joint plane $\left(\Delta d_{n} \& \Delta d_{s}\right)$, which is then used to update the total displacement. Because the smooth-joint contact - hence the joint - is unbonded in this case, the elastic part of the displacement $\Delta d_{n}^{e} \& \Delta d_{s}^{e}$ occurs when there is a gap between the pair of particles. The product of the elastic displacement and the smooth-joint stiffnesses determines the forces on the joint, given by Equation 7-8. This is updated through Equation 9-10.

$$
\begin{gathered}
F_{n}=\bar{k}_{n} A \Delta d_{n} \\
F_{s}=\bar{k}_{s} A \Delta d_{s} \\
F_{n}:=F_{n}+\bar{k}_{n} A \Delta d_{n} \\
\widetilde{F}_{s}:=F_{s}-\bar{k}_{s} A \Delta d_{s}
\end{gathered}
$$


Given a joint shear force value $\left(F_{s}\right)$, calculated using the joint normal force such that $F_{s}=\mu F_{n},\left|F_{s}\right|=$ $\left|\tilde{F}_{s}\right|$ when $\left|\tilde{F}_{s}\right| \leq\left(F_{S}=\mu F_{n}\right)$. If this condition is not fulfilled, sliding (shear displacement, $\Delta \dot{d}_{s}$ ) takes place and the joint normal force is increased via Equation 11.

$$
\begin{array}{cc}
F_{n}:=F_{n}+\bar{k}_{n} A \Delta \dot{d}_{n}=F_{n}+\left(\Delta \dot{d}_{s} \tan \varphi\right) \bar{k}_{n} A=F_{n}+\left(\frac{\left|\tilde{F}_{s}\right|-\tilde{F}_{s}}{\bar{k}_{s}}\right) \bar{k}_{n} \tan \varphi & 11 \mathrm{a} \\
\left|\tilde{F}_{s}\right|-\tilde{F}_{s}=\bar{k}_{s} A \Delta \dot{d}_{s} & 11 \mathrm{~b}
\end{array}
$$

Where $\varphi$ is the dilation angle. The pair of joints are modelled as a collection of smooth-joint contacts. These contacts are created and assigned a given set of joint properties subject to a criterion that must be satisfied.

\subsection{Model calibration}

\subsection{Rock calibration}

It is imperative that the micro-properties of the synthetic rock specimen be calibrated in order to match the mechanical behaviour of the simulated sample with actual rocks. Comparing the artificial and real samples, the main macro-parameters that are representative of the mechanical behaviour of the rock type should be equivalent. These include the Young's modulus $(E)$, Poisson ratio $(v)$, tensile strength $(T)$, uniaxial compressive strength $\left(q_{u}\right)$ and triaxial compressive strength $(\hat{q})$. The rock sample and tests for material/mechanical properties adopted in this study is similar with those presented in Eshiet and Sheng (2017).

Two sets of tests were performed: biaxial tests consisting of unconfined and confined compression tests and shear tests to determine and calibrate joint properties. To determine the actual compressive strengths unconfined compression tests were conducted. Confined compression tests were necessary to establish the trend in compressive strength for varying confining pressures, which becomes useful (if the specimen is assumed to behave as a Mohr-Coulomb material) when defining the secant slope of strength envelopes to determine the corresponding friction angle and cohesion. During biaxial tests, values of the differential stress $\left(\sigma_{D}=\sigma_{y}-\sigma_{x}\right)$ are plotted against the axial strain, $e_{y}$. The compressive strength $(\hat{q})$ is taken as the peak value of this plot. Using results from the same test $E^{*}$ and $v^{*}$ are obtained assuming plane strain conditions, restated here as

$$
v^{*}=v /(1+v)
$$




$$
\begin{gathered}
v=-\Delta e_{x} / \Delta e_{y} \\
E^{*}=E /(1-v) \\
E=\Delta \sigma_{y} / \Delta e_{y}
\end{gathered}
$$

Where $v$ and $E$ are the plane stress Poisson's ratio and Young's modulus respectively. Simulations were carried out to replicate properties of generic rocks (e. g. Sandstone). The deciding stress-strain curve that established the match in unconfined compressive strength between the synthetic and real rock material is illustrated in Figure 2a. Standard numerical Brazilian tests were also carried out to determine the rock tensile strength (Figure $2 b$ ).

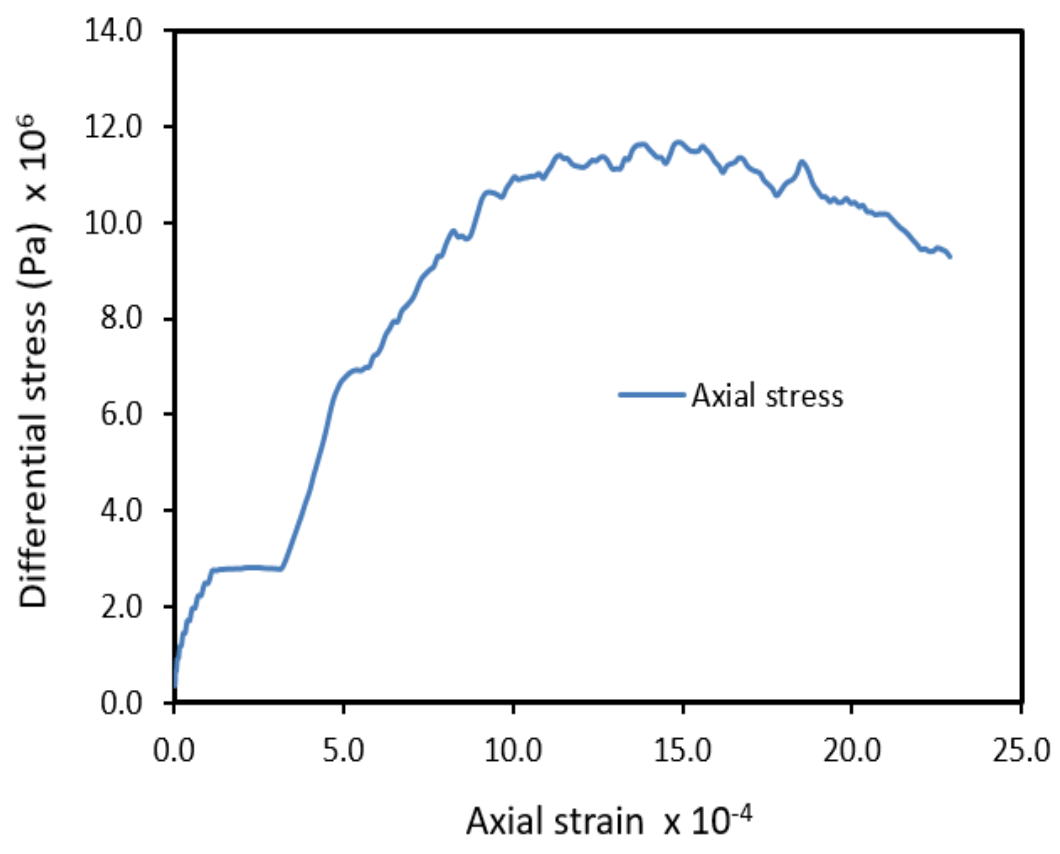

(a) Stress-Strain curve for rock in compression (Eshiet and Sheng, 2017) 


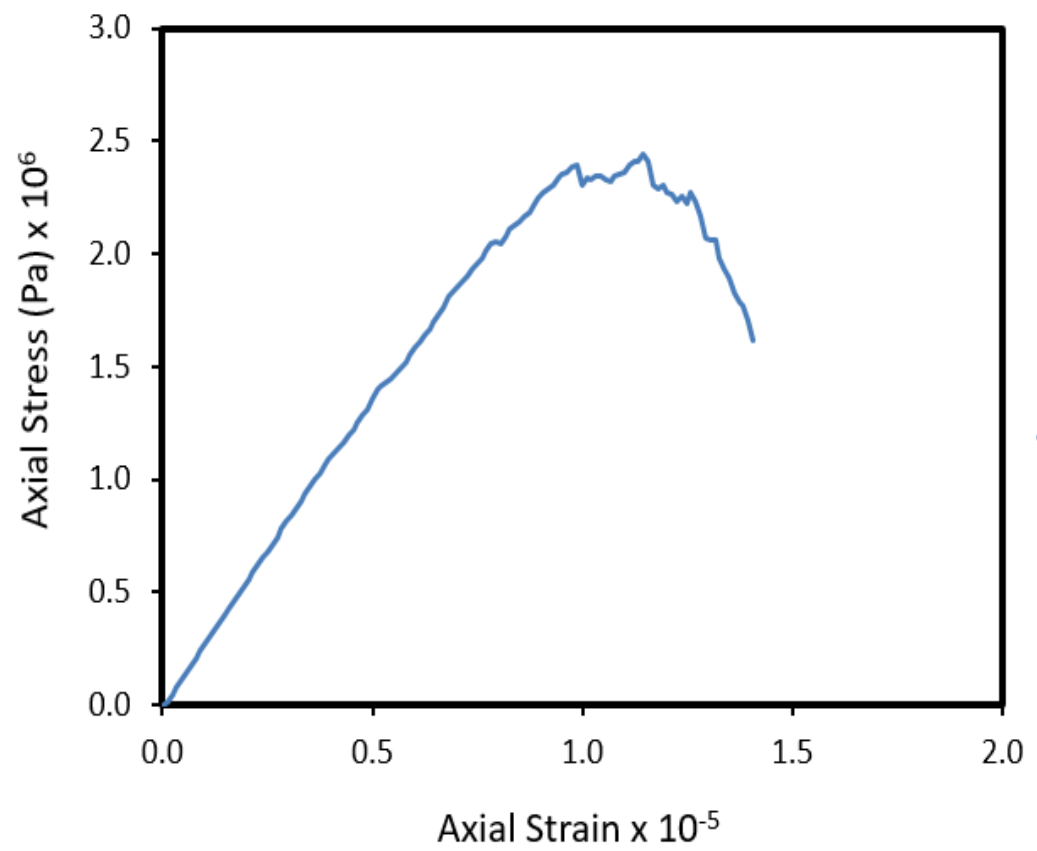

(b) Stress-Strain curve for rock in tension

Figure 2. Stress-Strain behaviour of synthetic rock

The calibration procedure for typical DEM synthetic samples are standard and usually entails mimicking the macro-properties and behavior of actual rocks using micro-properties. The set of micro-properties was calibrated based on the mechanical properties of typical sandstone including elastic modulus, Poisson's ratio, confined and unconfined compressive strength, and tensile strength. This was conducted using the 'trial and error' method where the micro-parameters are continually modified until the target macro-behaviour is achieved. It is a procedure commonly adopted and reported (e.g., Vallejos et al., 2016, Lee et al., 2016, Wen et al., 2016, Potyondy and Cundall, 2004). The calibration process implemented in this study was influenced by established relationships between micro-parameters and macro-properties (e.g., Huang et al., 2013, Yang et al., 2006, Chang and Misra, 1990). For instance, particle contact modulus $\left(E_{c}\right)$ affects elastic modulus $(E)$ but has a trivial impact on Poisson's ratio $(v)$; on the other hand, $k_{n} / k_{s}$ influences both elastic modulus and Poisson's ratio. Details of the micro-parameters and the rock key mechanical properties are given in Table 1 and 2 respectively. 


\subsection{Sensitivity to particle assembly}

Particle assembly is a function of particle size, and its distribution and arrangement. Particle size does not significantly affect crack initiation pressure, breakdown pressure and the spatial distribution of cracks or fracturing pattern (Shimizu et al., 2011). This is especially so for low viscosity fluids. Rather, these phenomena are greatly influenced by the macroscopic conditions of the rock (Shimizu et al., 2011). Both the rock sample and the joint were calibrated to derive macro-properties given in Table 2 and Table 3 respectively. The fracturing process and joint behaviour is, hence, predominantly dependent on the macroscopic characteristics of the rock mass. Generally, the effect of particle size on macro-properties diminishes when the particle size is sufficiently small in proportion to the dimension of the specimen.

Yang et al. (2006) determined a threshold of $H / R=80$; where, $H$ is the specimen height and $R$ is the average particle radius. Above this value, the impact of particle becomes considerably insignificant. Tests conducted by Huang (1999) using a series of specimens in the range of $H / R(120-$ 180) reveal very small differences in mean uniaxial strengths. Likewise, tests performed by Potyondy and Cundall (2004) with specimens in the range of $H / R$ (44-352) demonstrated the insensitivity of Poisson ration, elastic modulus and compressive strength with respect to particle size. Further investigations by Yang et al. (2006) considering specimens with $H / R$ ranging from 40 to 217 established that when $H / R \geq 80$ and $H / R \geq 100$, for elastic modulus and Poisson ratio respectively, they become independent of particle size. This is supported by Eshiet and Sheng (2014), where the collective sensitivity of mechanical properties (including elastic modulus, compressive strength and Poisson's ratio) to particle size is shown to be trivial for $H / R \geq 100$.

In essence, the effect on the macro-mechanical behaviour can be ignored within a determined range of $H / R$. The model material considered in this study was calibrated using specimens with the following dimensions: Height $=0.6 \mathrm{~m}$ and Width $=0.3 \mathrm{~m}$. For an average particle radius of $0.003 \mathrm{~m}$, the dimensionless parameter for particle size, $H / R$, is 200. This lies within the limits where the macro-mechanical characteristics of the rock material is not impinged by microscopic particle size and its distribution. Additional simulations using different particle assemblies within the prescribed range produces the same results.

\subsection{Joint calibration}

The procedure for the joint calibration is thoroughly illustrated in Eshiet and Sheng (2017) and the approach is merely reiterated here for completion. The Numerical simulation of direct shear box 
experiments were used to derive joint shear strength as well as other properties including joint cohesion, joint friction, joint roughness coefficient (JRC) and joint wall (compressive) strength (JCS). Joint properties pose a significant impact on the performance of jointed rock mass. Joint shear strength is a key property that influences its behaviour. On the other hand, joint cohesion, joint frictional resistance and stresses acting normal to the joint plane control the shear strength. The frictional resistance is influenced by dilatancy, which is in turn affected by its roughness. The Joint roughness coefficient (JRC) determines the extent of surface roughness and can be applied in the evaluation of non-planar joints (Barton 1976, Byerlee 1978). The relationship between these parameters is encompassed in the Mohr-Coulomb expression for shear strength, given as

$$
\tau_{p}=c+\sigma_{n} \tan \phi
$$

Where, $\tau_{p}$ is the peak shear strength, $c$ is the cohesive strength, $\sigma_{n}$ is the normal stress and $\phi$ is the angle of internal friction (friction angle). Where the shear strength is reduced to a residual value, $\tau_{r}$, the cohesive strength is removed and there is a decrease in the friction angle to a residual value, $\phi_{r}$. Equation 13 becomes

$$
\tau_{r}=\sigma_{n} \tan \phi_{r}
$$

The Mohr-Coulomb equation is, thus, suitable for defining the shear properties of rock joints. Direct shear tests were performed under different normal loading representing stresses from a minimum magnitude of $1 \mathrm{MPa}$ through a maximum magnitude of $5 \mathrm{MPa}$. While the joint cohesion was kept constant, sundry values of frictional resistance were used for each set of tests. These tests were necessary for determining the magnitude of the relevant joint properties and for calibration. Table 1-2 show values of the micro-properties for the synthetic rock and joint as well as the corresponding macro-properties for the rock. 
Table 1 Micro-Properties of rock sample

\begin{tabular}{ll}
\hline Parameter Description & \\
\hline Contact-bond normal strength (mean) & $5.0 \mathrm{MN} / \mathrm{m}^{2}$ \\
Contact-bond normal strength (std deviation) & $1.25 \mathrm{MN} / \mathrm{m}^{2}$ \\
Contact-bond shear strength & $5.0 \mathrm{MN} / \mathrm{m}^{2}$ \\
Contact-bond normal strength (std deviation) & $1.25 \mathrm{MN} / \mathrm{m}^{2}$ \\
Particle size (radius) & $0.002 \mathrm{~m}-0.004 \mathrm{~m}$ \\
Particle friction coefficient & 1.0 \\
Particle normal stiffness, $\boldsymbol{k}_{\boldsymbol{n}}$ & $29.0 \mathrm{MN} / \mathrm{m}^{2}$ \\
Particle shear stiffness, $\boldsymbol{k}_{\boldsymbol{s}}$ & $10.36 \mathrm{MN} / \mathrm{m}^{2}$ \\
Particle density & $2650 \mathrm{Kg} / \mathrm{m}^{3}$ \\
Porosity & 0.16 \\
Particle-particle contact modulus $\left(\boldsymbol{E}_{\boldsymbol{c}}\right.$ ) & $14.5 \mathrm{GN} / \mathrm{m}^{2}$ \\
Particle stiffness ratio & 2.8 \\
Joint Properties & \\
\hline Normal stiffness, $\boldsymbol{k}^{\boldsymbol{n}}$ & $1.583 \times 10^{12} \mathrm{~N} / \mathrm{m}^{3}$ \\
Shear stiffness, $\boldsymbol{k}^{\boldsymbol{s}}$ & $0.565 \times 10^{12} \mathrm{~N} / \mathrm{m}^{3}$ \\
Friction coefficient, $\boldsymbol{\phi}$ & Varied accordingly (between $0.0-1.0$ ) \\
Dilation angle, $\boldsymbol{\varphi}$ & Varied accordingly (between $0.0-40$ ) \\
Cohesive strength, $\boldsymbol{C}$ & 0.0 \\
\hline
\end{tabular}

Table 2 Mechanical properties (Eshiet and Sheng, 2017)

\begin{tabular}{ll}
\hline Parameter Description & \\
\hline Mechanical Properties & \\
Compressive strength, $\widehat{\boldsymbol{q}}$ & $11.7 \mathrm{MPa}$ \\
Elastic modulus, $\boldsymbol{E}$ & $9.7 \mathrm{GPa}$ \\
Poisson ratio, $\boldsymbol{v}$ & 0.19 \\
Tensile strength, $\boldsymbol{\sigma}_{\boldsymbol{t}}$ & $2.44 \mathrm{MPa}$ \\
\hline
\end{tabular}


A smooth planar longitudinal joint was created within a $0.3 \mathrm{~m} \times 0.6 \mathrm{~m} 2 \mathrm{D}$ rectangular sample (height $=0.3 \mathrm{~m}$, width $=0.6 \mathrm{~m}$ ) (Figure 3 ). This joint was made smooth by assigning a trivial value of roughness $(J R C \approx 0)$. Barton and Choubey (1977) developed a relationship between $J R C$ and joint roughness. AJRC between 0 and 2 for smooth planar joints is recommended. Also, the bond strength of the joint was altered by adjusting the smooth-joint contact properties of the adjoining particles that constitute the joint planar surfaces.

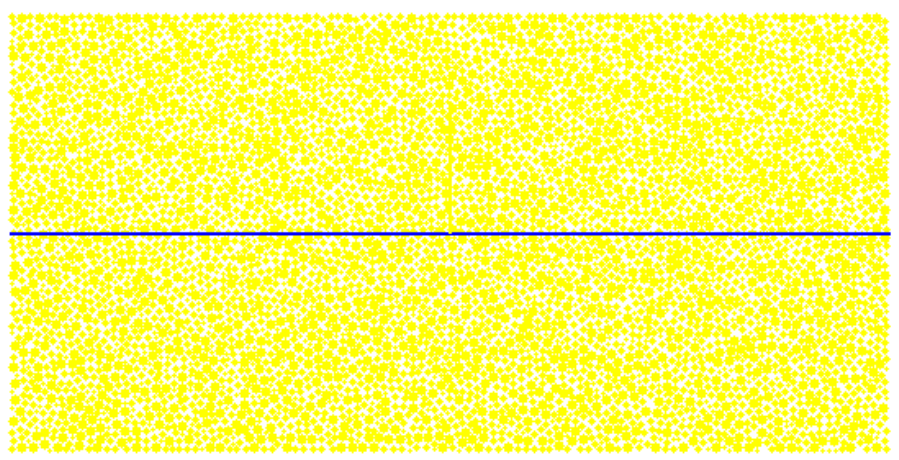

(a) Position and orientation of joint

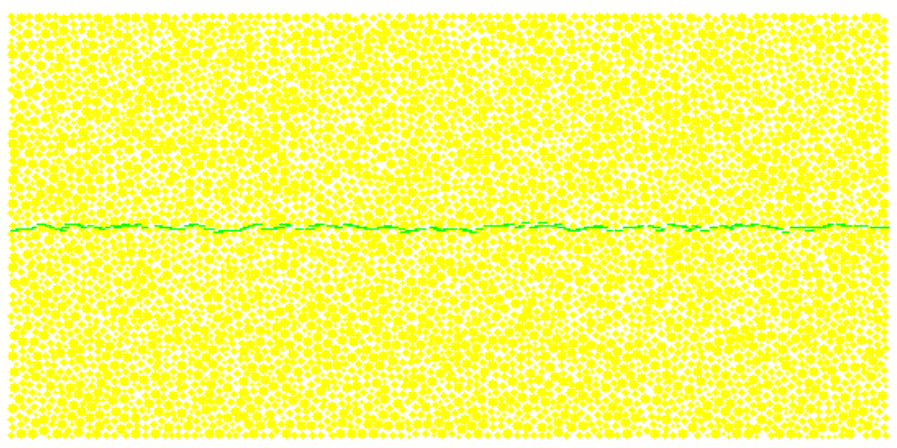

(b) Collection of smooth joint contacts that form the joint

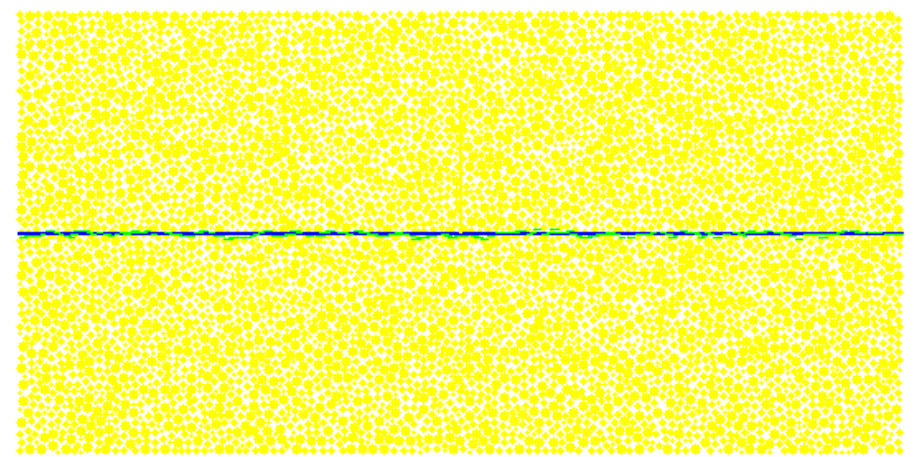

(c) Alignment of the smooth joint contacts with the joint geometry

Figure 3. Geometry of joint and contacts 
As shown from the configuration of the test (Figure 4), effective normal vertical stresses were exerted through horizontal walls placed at the top and bottom of the sample. Other closed boundaries of the specimen consist of a wall at the top left corner and another at the bottom right corner. The bottom left wall was fixed both vertically and horizontally; however, sliding movement of the particles in contact with the wall were not restricted vertically. Likewise, particles in contact with the top and bottom walls were permitted to slide horizontally. A constant load was applied on the top left wall, in the W-E direction, by moving the wall laterally in the same direction at a velocity of $0.003 \mathrm{~m} / \mathrm{s}$. The magnitude of the velocity was adjusted to this target value to prevent instabilities and ensure quasi-static equilibrium for the duration of the experiment.

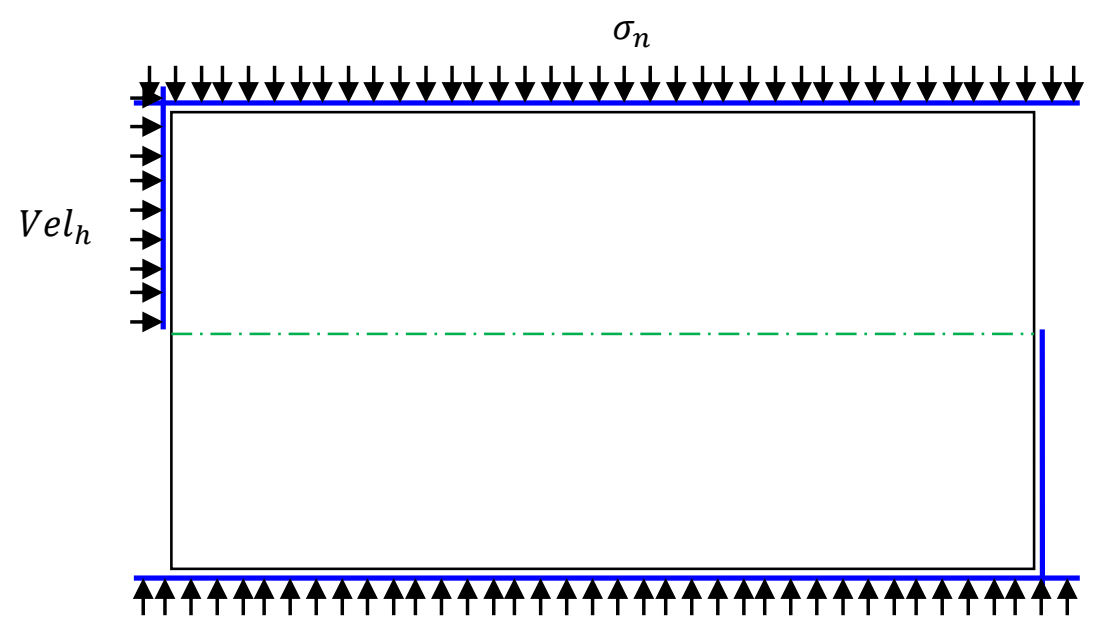

(a) Schematic of test configuration showing boundary conditions

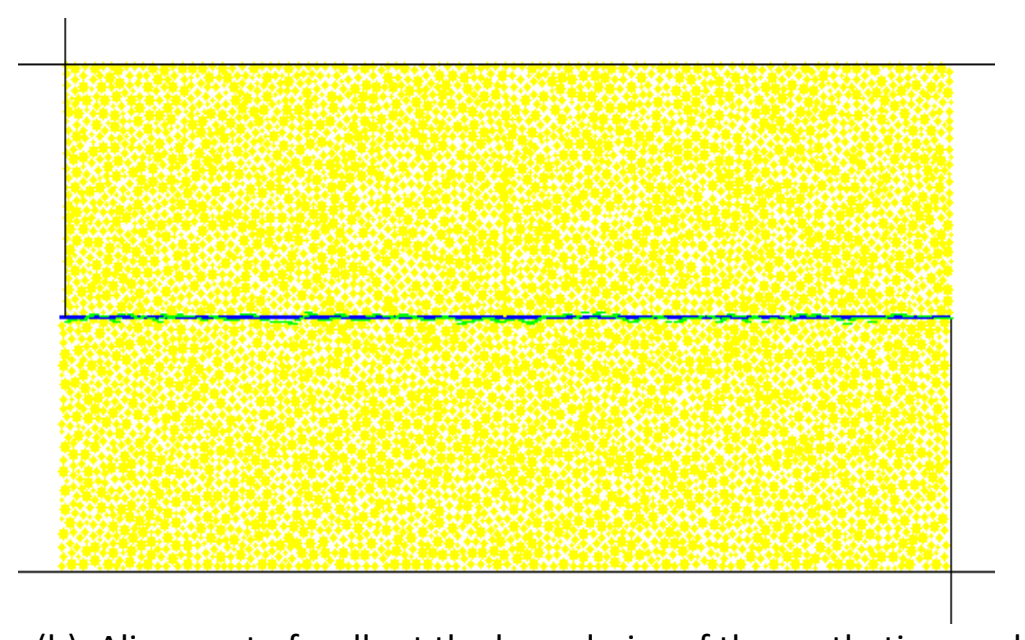

(b) Alignment of walls at the boundaries of the synthetic sample

Figure 4 Setup of the shear test showing the wall boundaries 
Periodic calculation and updates of the shear stress was carried out by dividing the average shear forces on the top left and bottom right vertical wall by the joint area. The normal stress was calculated by dividing the average of the vertical forces on the top and bottom wall by the joint area. Application of load on the top and bottom walls was achieved via a servo mechanism that ensures a consistent stress magnitude is maintained. For a specified value of joint friction coefficient, several tests were conducted and values of shear stresses and shear displacements recorded for each round. Each test was therefore carried out under set values of normal stress and joint friction coefficient. The response of dissimilar frictional rock joints subjected to varying overburden stresses is illustrated in Figure 5, where it is shown that for each state of vertical loading, the peak shear strength is attained prior to a steady decrease to a residual value.

A shear envelope based on peak strength rather than residual strength values was adopted, since it is a better reflection of the actual strength characteristics of a joint under the prevailing condition. The rate at which the joint reaches its peak strength is much higher than the reduction to its residual strength. This is observed from the steepness of the slope at the left hand side of the curves (Figure 5). It implies that it takes a much longer time for a joint to reach its residual strength after yielding. Shear strength increases with frictional resistance as well as effective stresses normal to the joint plane.

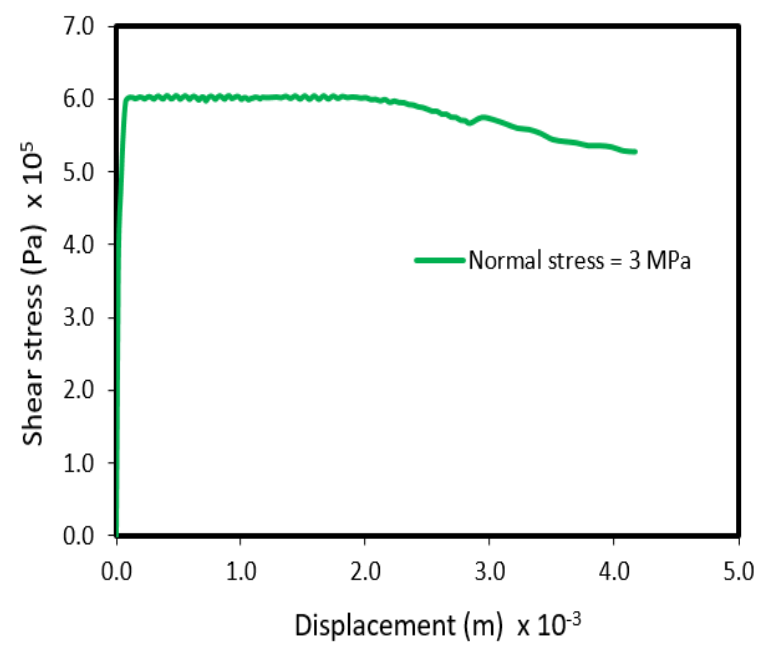

i) Shear behaviour of a joint with a friction coefficient of 0.2

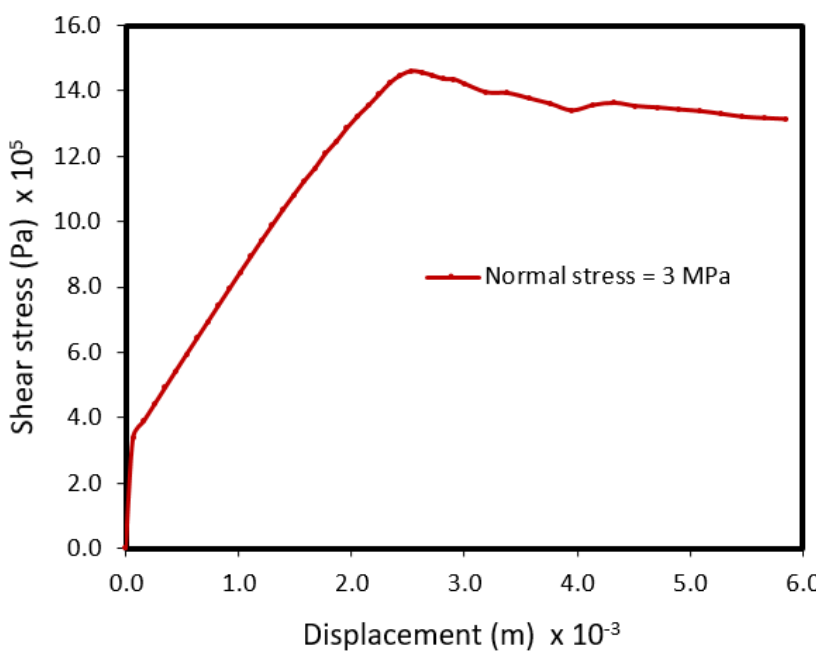

ii) Shear behaviour of a joint with a friction coefficient of 0.5

Figure 5. Trend of the joint shear stress development (Eshiet and Sheng, 2017) 
The calibration process for the joint friction was concluded by creating failure envelopes representing the different states of frictional resistance. These envelopes were drawn utilising the derived maximum shear strengths corresponding to the respective effective normal stress acting on the joint surface (Figure 6-7). The failure envelope for rock joints with different frictional resistances is indicated in Figure 6 and Figure 7 for a friction coefficient of 0.2 and 0.5 respectively; the mathematical expressions for these curves are given in Eshiet and Sheng (2017).

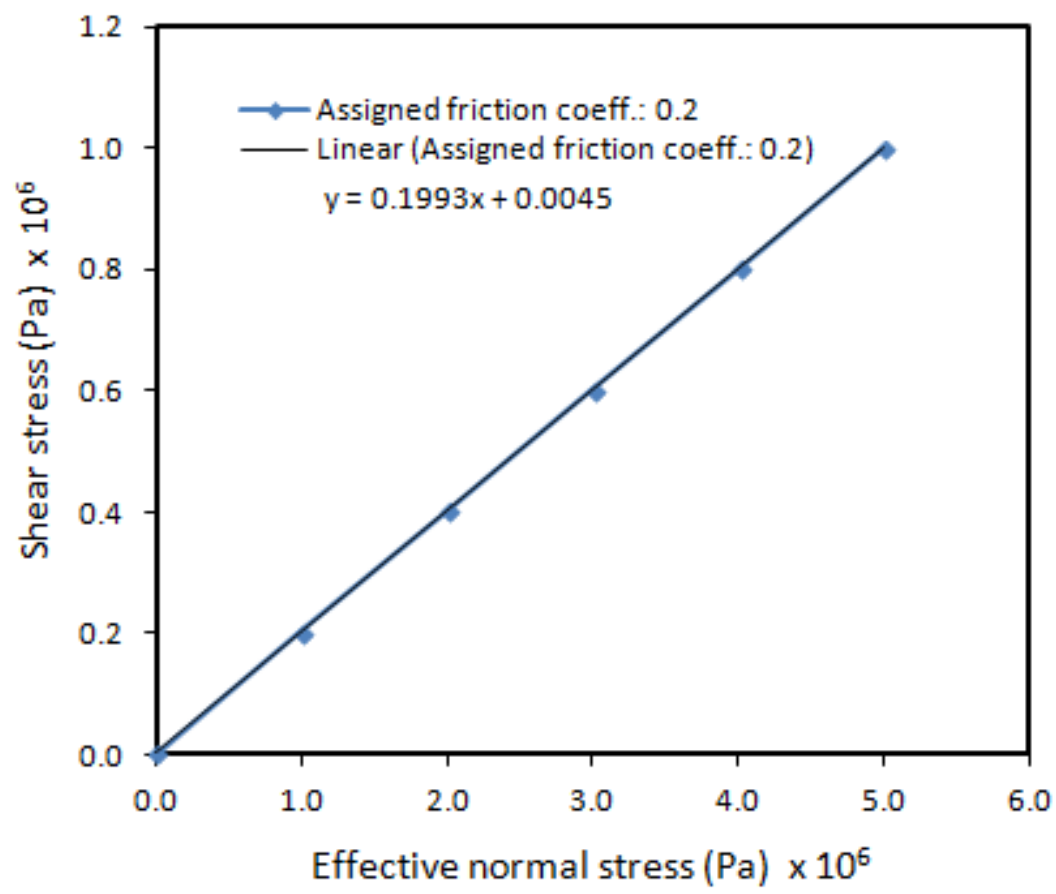

Figure 6. Failure envelope of the frictional joint (friction coefficient: 0.2) (Eshiet and Sheng, 2017) 


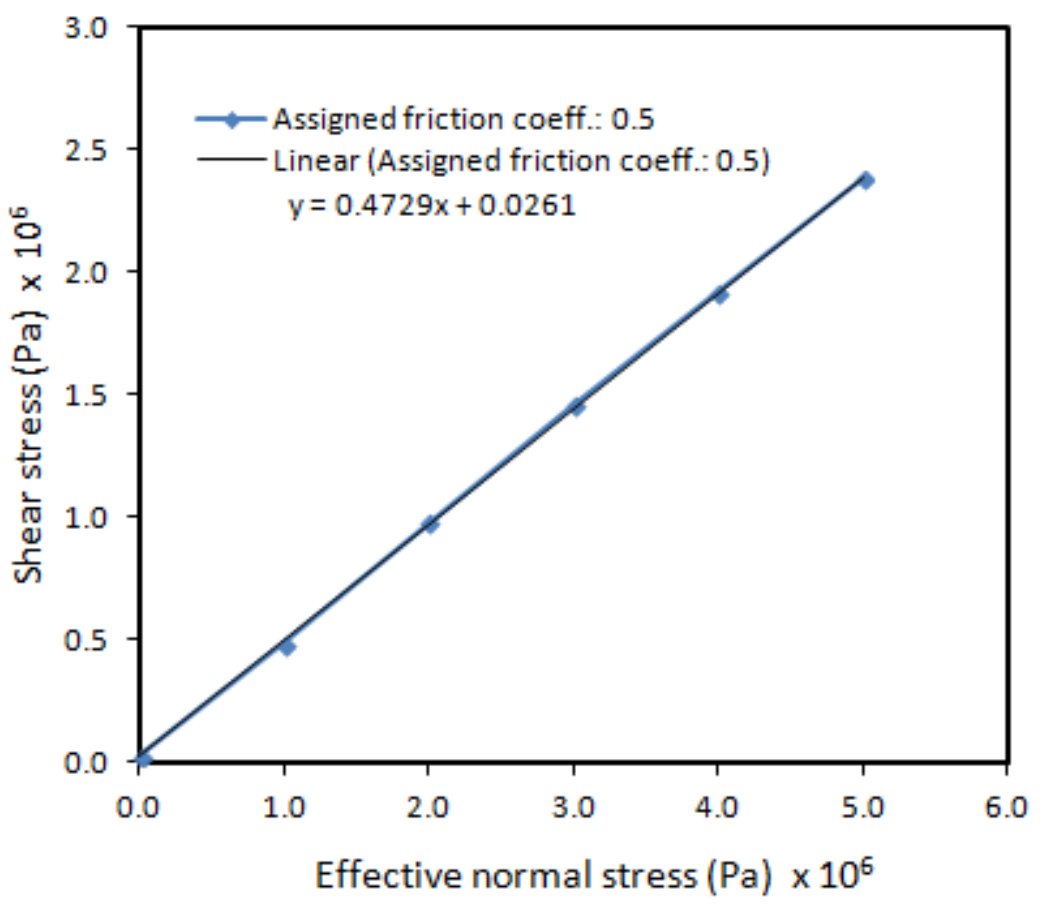

Figure 7. Failure envelope of the frictional joint (friction coefficient: 0.5) (Eshiet and Sheng, 2017)

Values of the micro-parameters employed as input for the joint frictional resistance and cohesion match those computed from the experiment. Other combinations of values for joint friction and cohesion used as input micro-properties produce analogous results. A comparison between microproperties and the derived macro-properties is given in Table 3.

Table 3 Comparison between inputted and derived joint properties (Eshiet and Sheng 2015, 2017)

\begin{tabular}{cccc|c|c}
\hline Parameters & Batch & \multicolumn{2}{c|}{ Micro-property value } & \multicolumn{2}{c}{ Derived value } \\
\hline \multirow{2}{*}{ Friction } & & Coefficient & Angle & Coefficient & Angle \\
\cline { 2 - 6 } & Test 1 & 0.20 & $11.3^{\circ}$ & 0.199 & $11.27^{\circ}$ \\
& Test 2 & 0.5 & $26.57^{\circ}$ & 0.473 & $25.3^{\circ}$ \\
\hline Cohesive strength & Test 1 & \multicolumn{2}{c}{0.0} & \multicolumn{2}{c}{0.0261} \\
(MPa) & Test 2 & \multicolumn{2}{c}{0.0} & \multicolumn{2}{c}{0.0045} \\
\hline
\end{tabular}

A full description of the distribution of contact forces within the jointed specimens for different frictional resistances and effective overburden stresses is given in Eshiet and Sheng $(2015,2017)$. The pressure between each pair of joint planes increases as the applied load normal to the joint surface becomes greater. The magnitude and spread of contact forces increases with the overburden load which also has a restraining effect on the degree of joint dilation. Normal stresses acting perpendicularly to joint planes have an attenuating effect on joint dilation. 
At higher normal stresses, there are greater concentrations of tensile contact forces at the bottom left and top right sections, indicating greater magnitude of tensile stresses in the same sections. This is more pronounced for joints with lower friction angles. Under the same conditions, compressive and shear contact forces are predominant at the bottom right and top left sections, although it is more evenly spread at the bottom half when the joint friction coefficient is lower. Compressive and shear contact forces are predominant along the joint planes due to sliding and the effect of the normal stress.

As the frictional resistance of the joint and the overburden stress increases, these have a corresponding impact on the severity of tensile and shear micro cracks Eshiet and Sheng (2015, 2017). The onset of these cracks usually originates at the vicinity of the joint plane.

\subsection{Dilatant behaviour of rock joints}

Plastic volumetric strain, which occurs due to plastic shearing, is controlled by the dilation angle. Cohesive soils are characterised by low dilation angles and can be assumed to be negligible, but the dilation angle for non-cohesive soils is dependent on the friction angle. The dilation angle remains consistent as plastic yielding takes place. Where the peak friction angle in non-cohesive soils is greater than $30^{\circ}$, its value in terms of the dilation angle $(\varphi)$ can be estimated as

$$
\phi_{p}=\varphi+30^{\circ}
$$

The peak friction angle $\left(\phi_{p}\right)$ and peak dilation angle $\left(\varphi_{p}\right)$ can be determined from the Mohr circle of stresses and strains respectively. Where $d \varepsilon_{v}, d \varepsilon_{1}, d \varepsilon_{3}$ and $d \gamma$ are the increments of the volumetric strain, major principal strain, minor principal strain and plastic shear strain, the volumetric strain is given as

$$
d \varepsilon_{v}=d \varepsilon_{1}+d \varepsilon_{3}
$$

The maximum plastic shear strain increment is

$$
d \gamma_{\max }=\frac{d \varepsilon_{1}-d \varepsilon_{3}}{2}
$$

The peak dilation angle is hence calculated from either of the following two expressions (Bolton, 1986, Salgado, 2006):

$$
\sin \varphi=-\frac{d \varepsilon_{v}}{\left|d \gamma_{\max }\right|}
$$




$$
\tan \varphi=-\frac{d \varepsilon_{v}}{|d \gamma|}
$$

Bolton (1986) describes the friction angle as consisting of two components: the critical friction angle $\left(\phi_{\text {crit }}\right)$ defined as its value when the soil attains a critical state and the dilation angle.

$$
\phi=\phi_{\text {crit }}+\varphi
$$

The strain-dilatancy relation for plane strain derived by Rowe (De Josselin de Jong, 1976, Rowe, 1969, Rowe, 1962) for densely packed granular materials in compression is expressed in form of the effective stress ratio given as

$$
R=D K
$$

Where

$$
\begin{gathered}
R=\frac{\sigma_{1}^{\prime}}{\sigma_{3}^{\prime}} \\
D=1-\frac{d \varepsilon_{v}}{d \varepsilon_{1}} \\
K=\left(\frac{\sigma_{1}^{\prime}}{\sigma_{3}^{\prime}}\right)_{\text {crit }}=\tan ^{2}\left(45+\phi_{f} / 2\right)
\end{gathered}
$$

Where $\phi_{f}$ is the interparticle friction angle corrected for work done or energy dissipated due to expansion; as such it is less than the residual friction angle $\left(\phi_{r}\right)$ (Rowe, 1962). The value of $\phi_{f}$ varies between the true angle of friction between the mineral surfaces of the particles $\left(\phi_{t}\right)$ and the angle of friction under constant volume $\left(\phi_{c v}\right)$ at the critical state (Rowe, 1969).

$$
\phi_{t} \leq \phi_{f} \leq \phi_{c v}
$$

At the critical state (when the material is in the loosest state) $\phi_{f}=\phi_{c v}$. From Equation 20, Rowe's strain-dilatancy relation is

$$
\frac{\sigma_{1}^{\prime}}{\sigma_{3}^{\prime}}=\left(\frac{\sigma_{1}^{\prime}}{\sigma_{3}^{\prime}}\right)_{c r i t}\left(1-\frac{d \varepsilon_{v}}{d \varepsilon_{1}}\right)
$$

Bolton (1986) found Equation 22 to be equivalent to

$$
\phi=\phi_{\text {crit }}+0.8 \varphi
$$


Equation 19 and Equation 22 show that dilation impacts on the angle of friction. Hence, any angle of friction greater than its value at the critical state $\left(\phi_{\text {crit }}\right)$ is attributed to the volumetric expansion of the material. The dilatancy angle is constant near and at peak strength. At the critical state the material is taken to be very loose, with zero dilation.

The shear resistance behaviour of non-planar joints can be determined based on the dilatants characteristics of granular (non-cohesive) materials.

According to Newland and Allely (1957), the maximum shear stress $\left(\tau_{\max }\right)$ is the aggregate of the shear stress necessary to overcome frictional forces - if the plane of sliding is in the same direction as the shear stress, $\tau_{r}-$ and the shear stress required to overcome additional resistance due to expansion, $\tau_{\theta}$. The extra resistance is caused by divergence in directions between the plane of sliding and the shear stress. $\tau_{r}$ is regarded as the residual shear stress

$$
\tau_{r}=\sigma_{n} \tan \phi_{b}
$$

Where $\phi_{b}$ is the basic friction angle of the surface assumed to be equivalent to the residual friction angle $\left(\phi_{r}\right)$ and in this context equal to $\phi_{c r i t}$. If $\theta$ is the average deviation of the displacement of particles from the direction of shear stress, the shear stress required to overcome the volumetric expansion is

$$
\tau_{\theta}=\sigma_{n} \tan \theta
$$

Equation 24 and Equation 25 are combined to obtain the maximum shear stress (Barton, 1976, Barton, 1973, Newland and Allely, 1957).

$$
\begin{gathered}
\tau_{\max }=\tau_{r}+\tau_{\theta} \\
\tau_{\max }=\sigma_{n} \tan \left(\phi_{b}+\theta_{d}\right)
\end{gathered}
$$

The increase in shearing resistance due to deviations from the direction of shear stress is also demonstrated in Patton (1966). At low normal stresses, Equation 26 can be used to determine the shear strength of non-intact rocks and non-planar joints that are rough and irregular. At high normal stresses, the effect of the second term in Equation 26 is negligible and the Mohr Coulomb expression given in Equation 13 becomes applicable because of the shearing off of the joint roughness. Asperities of joints or discontinuities contribute considerably to its shear strength. The average angle of deviation of the joint plane from the direction of applied shear stress $\left(\theta_{d}\right)$ is also denoted as the effective roughness (Barton, 1973, Barton, 1976) and the residual friction angle of natural joints fall within the range of $25^{\circ}$ to $35^{\circ}$, similar to the residual friction angles of the majority of rocks. 
In one dimension, the dilation of a joint or discontinuity $(\varphi)$ is the inclination of the shearing path (relative to the inclination of the joint plane). The dilation reaches its peak $\left(\varphi_{p}\right)$ at peak shear strength, defined as the instantaneous inclination of the shearing path at peak shear strength (Barton, 1976) and decreases with increasing normal stress (Barton, 1973). Barton (1976) derived a relationship involving the dilation angle, given as

$$
\tau=\sigma_{n} \tan \left(2 \varphi+30^{\circ}\right)
$$

Whereby, $30^{\circ}$ is taken as the average residual friction angle of flat non-dilatant joints and dilation is determined as

$$
\varphi=10 \log _{10}\left(\frac{q_{u}}{\sigma_{n}}\right)
$$

Equation 27 implies that dilation can be quantitatively related to the average angle of deviation of the joint plane (or the average deviation of the displacement of the joint surface particles) from the direction of applied shear stress $\left(\theta_{d}\right)$ or more generally the surface roughness. The relationship is stated as follows:

$$
\theta=2 \varphi=20 \log _{10}\left(\frac{q_{u}}{\sigma_{n}}\right)
$$

Equation 27a is thus rewritten as

$$
\tau=\sigma_{n} \tan \left(20 \log _{10}\left(\frac{q_{u}}{\sigma_{n}}\right)+30^{\circ}\right)
$$

This is valid for artificial faults, rough undulating interlocking joints and tension fractures. A more generalised form of Equation 29 is derived (Barton, 1976, Byerlee, 1978, Barton, 1973) by assuming that the unconfined compressive strength is equivalent to the joint wall compressive strength (JCS) especially for unweathered joints and that the coefficient of 20 denotes the upper limit of the scale of joint surface roughness, the lower limit being zero (Equation 30 ). The Joint roughness coefficient (JRC) defines the extent of surface roughness and the residual friction angle is represented by $\phi_{r}$.

$$
\tau=\sigma_{n} \tan \left(J R C \log _{10}\left(\frac{J C S}{\sigma_{n}}\right)+\phi_{r}\right)
$$

The generalisation of Equation 29 suggests it can be modified to fit smooth (planar) joints. For these form of joints the effect of asperities is considered insignificant, so $J R C \approx 0$ and Equation 30 reduces to an equation analogous to Equation 24. 


$$
\tau=\sigma_{n} \tan \left(\phi_{r}\right)
$$

For smooth non-dilatant rock joint surfaces, the dilation angle is equivalent to zero $(\varphi=0)$ due to the absence of asperities; but for rough, undulating and interlocking rock joint surfaces the dilation angle can be estimated from the following expression:

$$
\begin{gathered}
\phi=2 \varphi+\phi_{r} \\
\varphi=\left(\phi-\phi_{r}\right) / 2
\end{gathered}
$$

In this case $\phi$ is the joint friction angle and $\phi_{r}$ is the residual friction angle for non-dilatant rock joint surfaces. Equation 30 is applied in the model, where the absence of asperities, for instance, in smooth planar joints, is accounted for by assuming that the $J R C$ tends to zero (incorporated by assigning $J R C \approx 0$ ). The first term in the parenthesis of Equation 30 is a measure of the angle of deviation of the joint plane and defines the surface roughness. The dilation angle, $\varphi$, is related to the $J R C$ as per the following expression:

$$
2 \varphi=J R C \log _{10}\left(\frac{J C S}{\sigma_{n}}\right)
$$

\subsection{Numerical methodology}

\subsection{Configuration of domain}

The synthetic rock material was calibrated using numerical experiments including direct shear box and biaxial tests in order to attain matching properties similar to natural sandstone. Details of both micro properties (Table 1) and macro properties (Table 2) of the synthetic material describe its characteristics. Two parallel horizontal joints are placed at the centre of the model (Figure 8). The height and width of the model is given as $1 \mathrm{~m}$ and $2 \mathrm{~m}$ respectively and the joints located at $0.15 \mathrm{~m}$ above and below the central horizontal line. The significance of joint positions, orientation, density, population and interconnection is scheduled to be a subject of further investigations. The 2D representation comprises two joints traversing the left to right direction (i.e. in the XY plane). In addition, the joint planes are expected to project in the out-of-plane orientation ( $Z$ direction) for 3D considerations. 


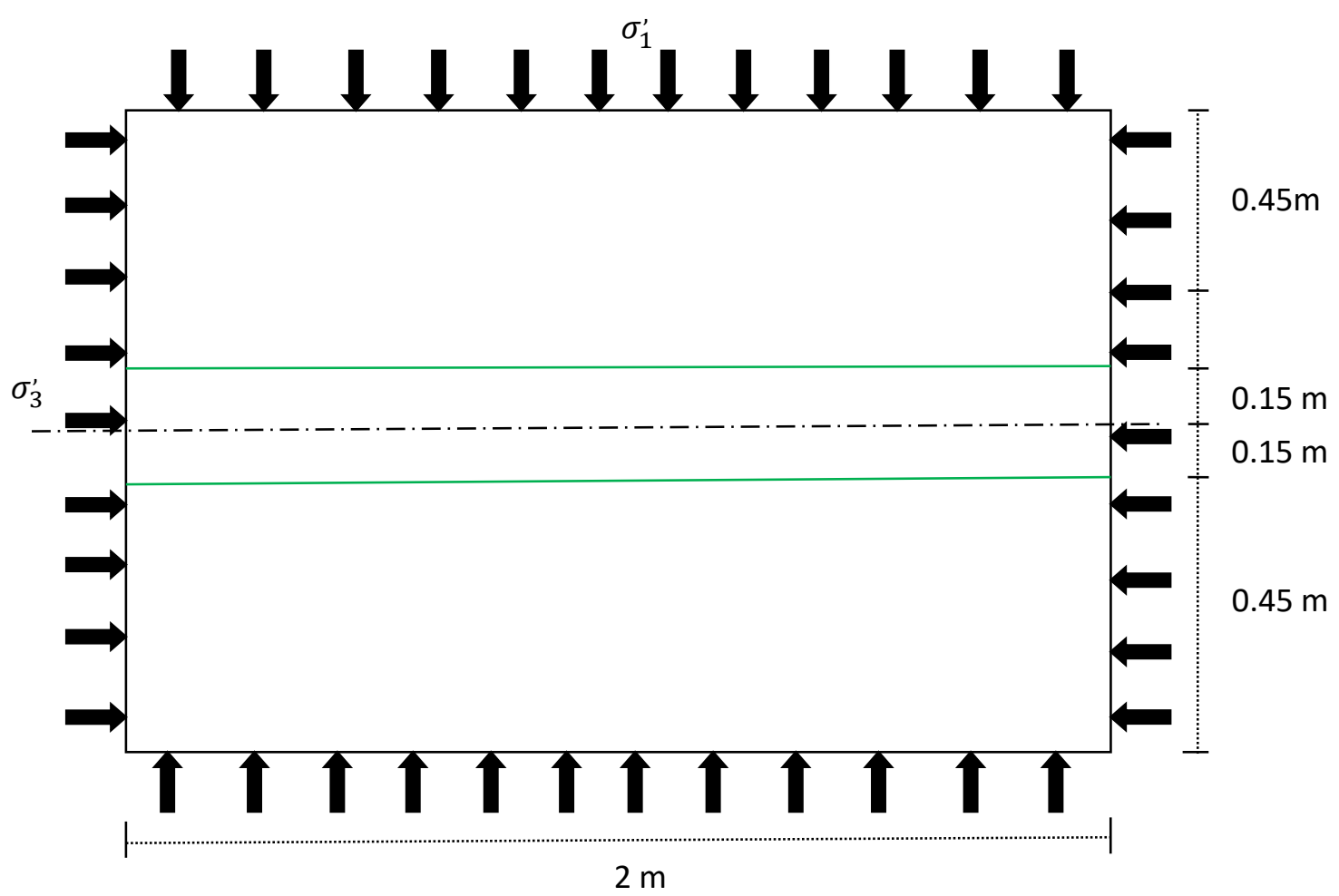

Figure 8. Model layout of rock mass consisting of twin parallel horizontal joints

\subsection{Fluid flow implementation}

Fluid flow within the rock is effectuated applying the algorithm described in Eshiet and Sheng (2014) and Eshiet et al. (2018). An abridged description of this procedure is given thus. The fluid flow region is delineated by domains which are representative of interparticle voids. These are interlinked together forming a network of voids directly associated with the particle assembly (Figure 9). Domains are enclosures formed by lines linking the centre of contacting particles. Flow between neighbouring domains are contingent upon pipes which signify interparticle contacts but are herein denoted as parallel-plate channels. Fluid passing through these channels is computed using a modified version of the Poiseuille equation (Equation 33a). These flow channels are interconnected through reservoirs which are representative of voids between particles (Eshiet et al. 2018, Eshiet and Sheng, 2014). Domains are enclosures formed by lines linking the centre of particles in contact (Figure 9). Fluid-solid interaction is modelled by hydro-mechanical coupling, where fluid pressure is continuously updated. Changes in fluid pressure is computed using Equation 33b. 


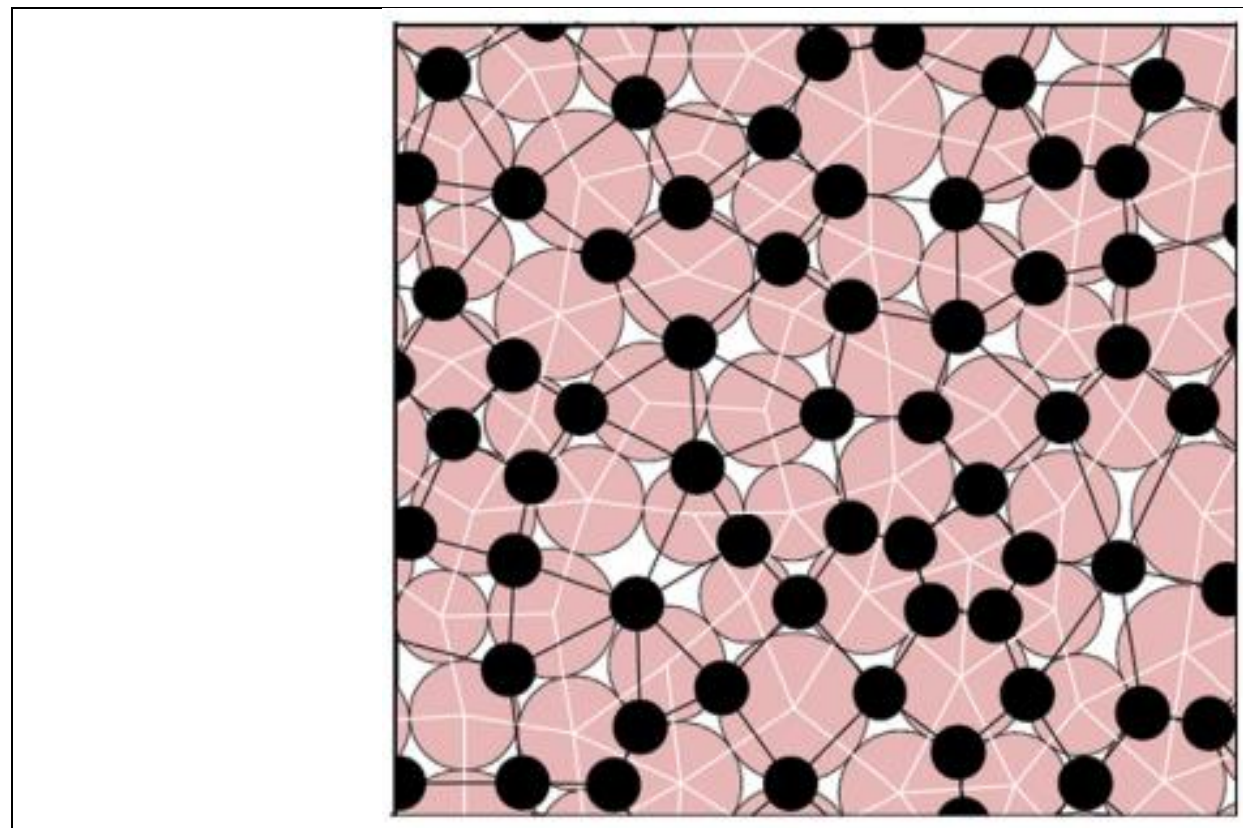

(a) Centre of reservoir domains (black dots), domain enclosed within polygons (white lines) and parallel-plate flow channels (black lines) (Itasca Consulting Group, 2014)

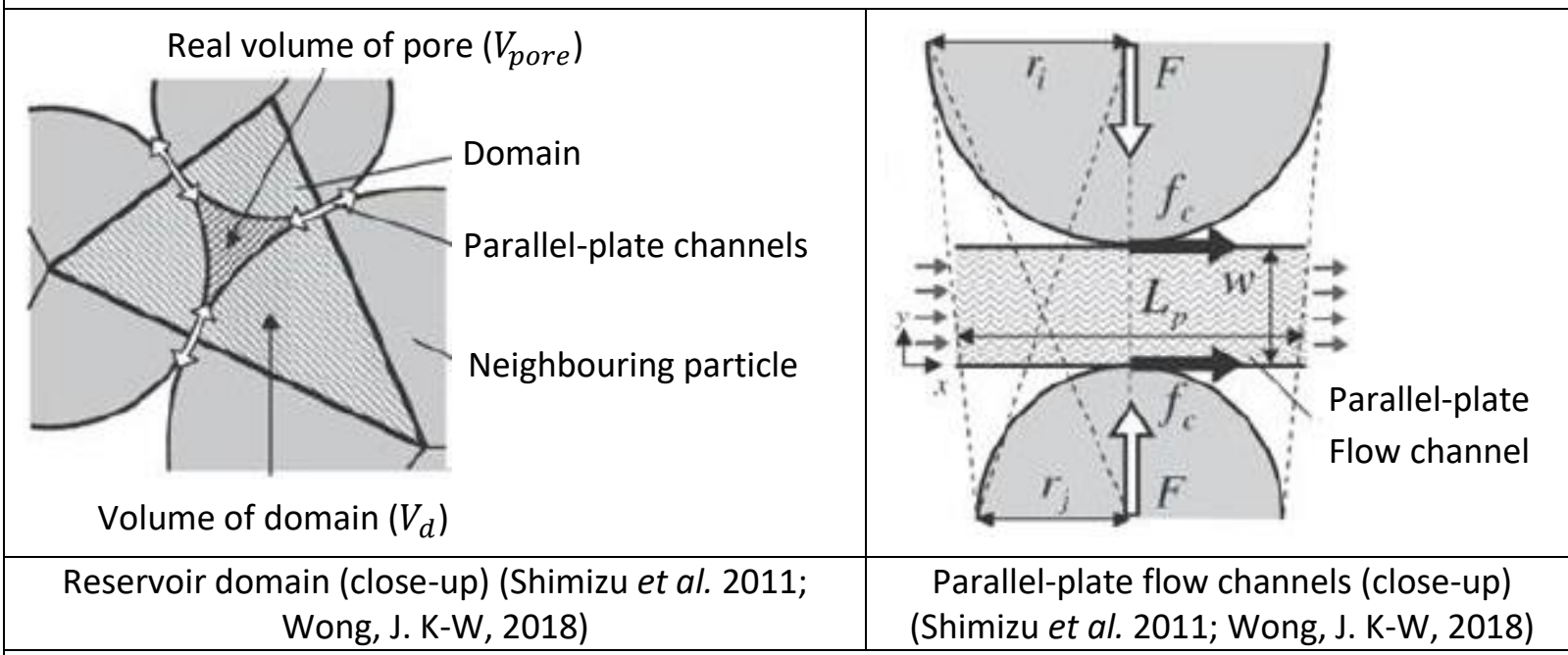

Figure 9. Embedded fluid flow model in particle assembly showing network of reservoir domains and flow channels.

$$
\begin{gathered}
Q_{p}=\frac{w a^{3}}{12 \mu} \frac{\Delta P}{L_{p}} \\
\Delta P=\frac{K_{f}}{V_{d}}\left(\sum Q \Delta t-\Delta V_{d}\right)
\end{gathered}
$$


$Q_{p}$ is the flow rate between domains, $w$ is the channel width, $a$ is the gap between a pair of contacting particles (also referred to as the aperture), $\Delta P$ is the difference in pressure between two interconnecting domains, $\mu$ is the dynamic viscosity of the fluid, $L_{p}$ is the length of the channel linking two domains, $K_{f}$ is the fluid bulk modulus, $V_{d}$ is the apparent domain volume, $Q_{p}$ and $Q$ is the flow rate between interconnecting voids (domains) within the particle assembly and the inflow rate of fluid into the domain from linking adjoining channels respectively, and $\Delta t$ is the timestep. The pathway between two voids is idealised as a channel with width, $w$, and length, $l_{p}$. The aperture influences the permeability of both the rock matrix and joint, whilst the fluid pressure in each domain has a mechanical effect on the surrounding particles. Detailed descriptions of formulations for fluid flow and mechanical fluid-solid coupling are presented in, e.g., Eshiet et al. (2018), Eshiet and Sheng (2014) and Shimizu et al. (2011).

\subsection{Loading and boundary conditions}

In-situ conditions are represented by overburden loading defined in terms of vertical stresses acting against the top and bottom servo-controlled walls as well as horizontal confining loads expressed as lateral stresses acting normal to the left and right boundary walls. These stresses are considered as principal stresses. The major principal stress $\left(\sigma_{1}^{\prime}\right)$ acts vertically with a magnitude of $2.5 \mathrm{MPa}$, while the minor principal stress $\left(\sigma_{3}^{\prime}\right)$ acts as a confining load in the lateral direction with a magnitude of 2.0 $\mathrm{MPa}$. There is a point injection of fluid at the centre of the rock domain between the two joints (Figure 10). The injection pressure is applied incrementally to a maximum pressure of $35 \mathrm{MPa}$ and then kept consistent at this magnitude. This perturbation of fluid pressure caused by this mode of injection is representative of a remote inflow of fluid from an isolated and singular point such as a wellbore. The key fluid properties are given in Table 4. 


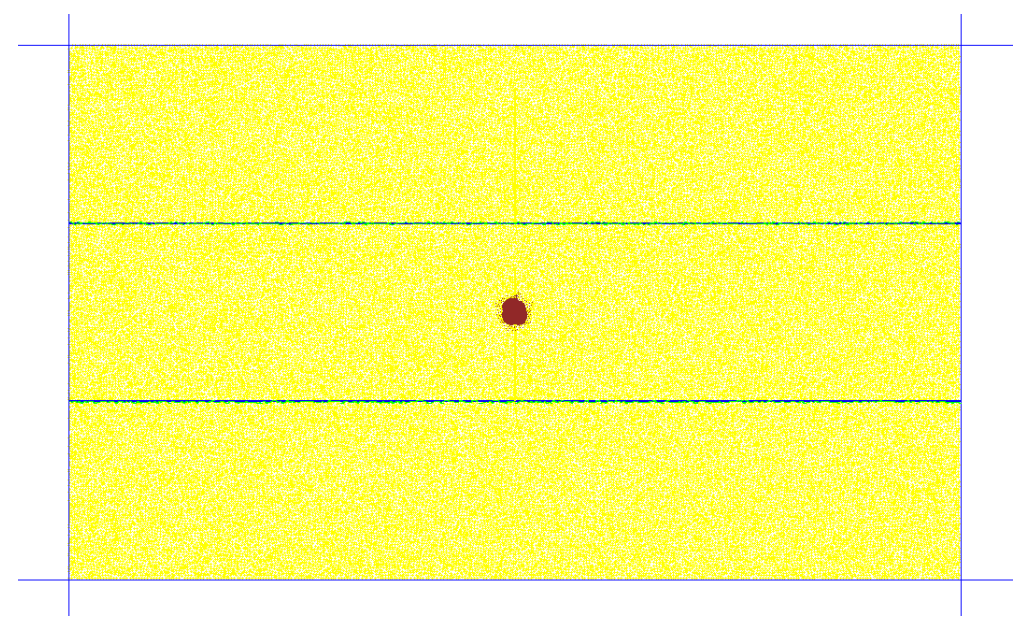

Figure 10. Injection of the fluid at the midpoint of the rock and between the pair of joints

Table 4. Fluid properties

\begin{tabular}{ll}
\hline Parameter Description & \\
\hline Viscosity, $\boldsymbol{\mu}$ & $3.95 \times 10^{-2} \mathrm{mPa}-\mathrm{s}$ \\
Density, $\boldsymbol{\rho}_{\boldsymbol{f}}$ & $479 \mathrm{Kg} / \mathrm{m}^{3}$ \\
Bulk modulus, $\boldsymbol{K}_{\boldsymbol{f}}$ & $0.035 \mathrm{GN} / \mathrm{m}^{2}$ \\
\hline
\end{tabular}

\subsection{Comparison with laboratory and field observations}

The validity of this numerical model is supported by previously reported laboratory and field observations (e.g., Cieslik, 2018; Kamonphet et al., 2015; Puntel, 2008; Barton and Choubey, 1977; Barton, 1973). This is expounded by examining the following: the strength envelope for smooth planar rock joints and the effects of dilation on fracturing.

\subsection{The strength envelope}

Barton and Choubey (Barton and Choubey, 1977) performed a comprehensive series of tests involving rock joints with varying asperities. Asperities are indicative of joint roughness and the joint roughness coefficient (JRC) is a measure of the degree at which these occur. Equation $30-$ an empirically derived relationship formulated in Barton (1973) - can be split into two terms. The first part of the equation accounts for joint asperities, with the JRC being a key determinant. The value of JRC ranges from 20 to 0 and the extent of roughness reduces with lower numbering. Hence, a JRC of 0 is representative of a smooth rock joint. The experimental study by Barton and Choubey (Barton and Choubey, 1977), involving 136 unfilled joints and representing eight types of rock, reveals values of total friction angles (peak $\arctan \tau / \sigma_{n}$ ) ranging between $26.6^{\circ}$ and $80.3^{\circ}$. The lower limit is 
indicative of smooth planar joints, whilst on the other hand, the upper limit is indicative of rough, undulating bedding joints. Total friction angle is shown to increase with joint roughness. The asperity element, $J R C \log _{10}\left(\frac{J C S}{\sigma_{n}}\right)$, constitutes a major proportion of the of the total friction angle. Its value can be as high as $55^{\circ}$ and is largely influenced by the JRC.

The Joint Wall Compressive Strength (JCS) is another important, albeit less dominant, parameter that contributes to joint asperity. The strength and deformation behavior of a jointed rock mass is dominated by the thin layers of rock adjoining the joint wall (Barton and Choubey, 1977). The significance of this parameter is more apparent if joints are weathered because the JCS then becomes considerably lower than the compressive strength of the rock mass as a whole. In some cases, there are inconsistencies in the extent of weathering between the joint wall and other interior regions of the rock mass. This attribute depends on the properties of the rock, especially its permeability (Barton and Choubey, 1977).

For impermeable rocks, the tendency is for the joint to be weathered while the rest of the rock remains unaffected; whereas, the weathering process in permeable rocks is homogeneous. In the absence of weathering - as may occur in intact rocks with joints - the JCS value is equivalent to the rock compressive strength. The JCS becomes progressively lesser than the compressive strength as the joint becomes more weathered in comparison to the rest of the rock (Barton and Choubey, 1977). Figure 11 describes the range of peak shear strengths derived from Barton and Choubey's (Barton and Choubey, 1977) experiments. From these experiments, three curves are depicted denoting the upper bound, mean and lower bound of the set of peak shear strength values. The upper and lower bound curves are attributed to rock joints with extremely high and low JRCS respectively. Very low JRCs are indicative of smooth planar joints.

Model joint calibration, in this study, is conducted on the basis that the joint is smooth and planar; therefore, results of the series of shear tests is directly compared against the lower bound curve (Curve 3) derived in Barton and Choubey (1977) (Figure 11). The two curves match, essentially illustrating the ability of the model to capture the features of rock joints devoid of asperities. 


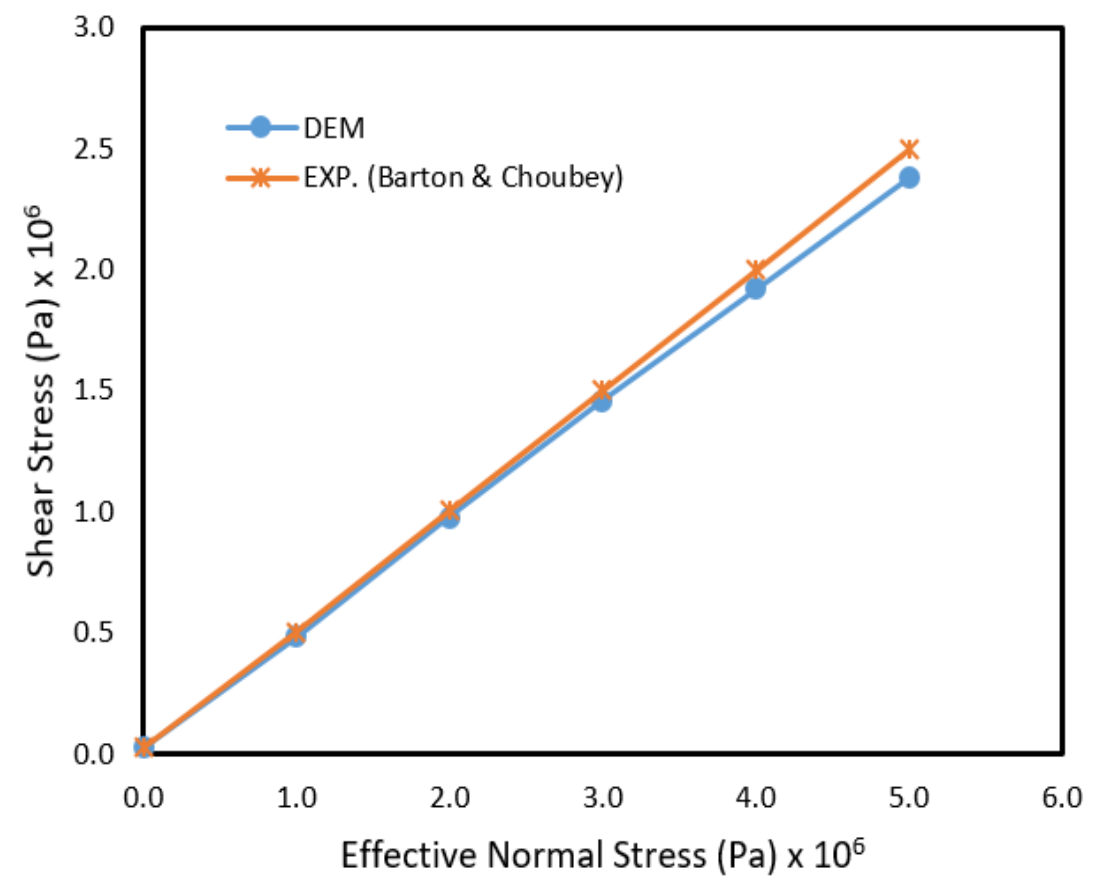

Figure 11 Experimental validation of DEM joint model based on data from Barton and Choubey (1977)

\subsection{Relationship between dilatancy and fracturing}

One of the phenomena observed from the numerical results is an increase in fracturing with joint dilatancy. The trend is qualitatively supported by the experimental work reported in Cieslik (2018), where a series of tests on sandstone was performed to assess the effect of dilatancy on the evolution of rock damage. The DEM model indicates a linear correlation between crack generation and ascent in dilatancy, which is reinforced in Cieslik (2008). A quantitative relationship between crack development and dilatancy is derived in Cieslik (2008), whereby the evolution of the damage variable $\left(D_{E}\right)$ of sandstone - determined on the basis of changes in axial stiffness - is linked with corresponding inelastic volume strains $\left(\varepsilon_{v o l}^{p l}\right)$. Transitions in axial stiffness described via the damage variable $\left(D_{E}\right)$ is used as measures of crack progression, whilst dilatancy is marked by inelastic volume strains.

The degradation of rock, foreshadowed by micro- and macro-crack proliferation as it weakens, occurs in concurrence with the dilatancy process. Both phenomena (crack development and dilatancy) are linearly related. This trend, as determined by the DEM simulation (Figure 12 and Figure 15), is underpinned by Cieslik's (Cieslik, 2008) experimental observation of sandstone under uniaxial and triaxial compression. 


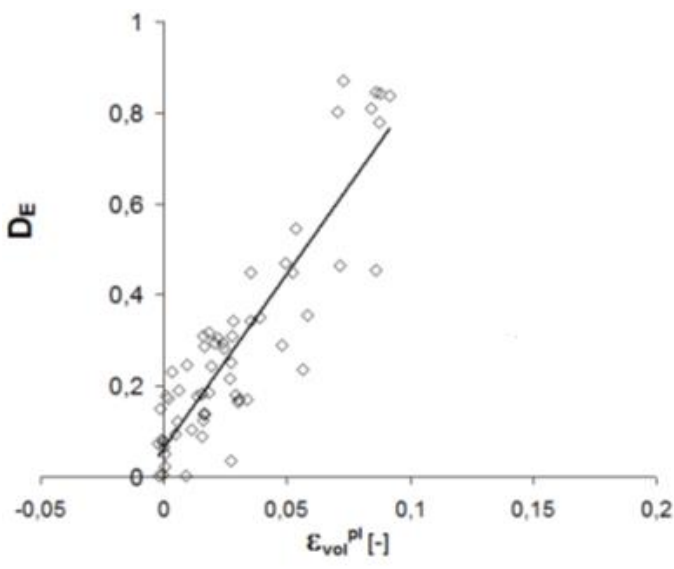

(a)

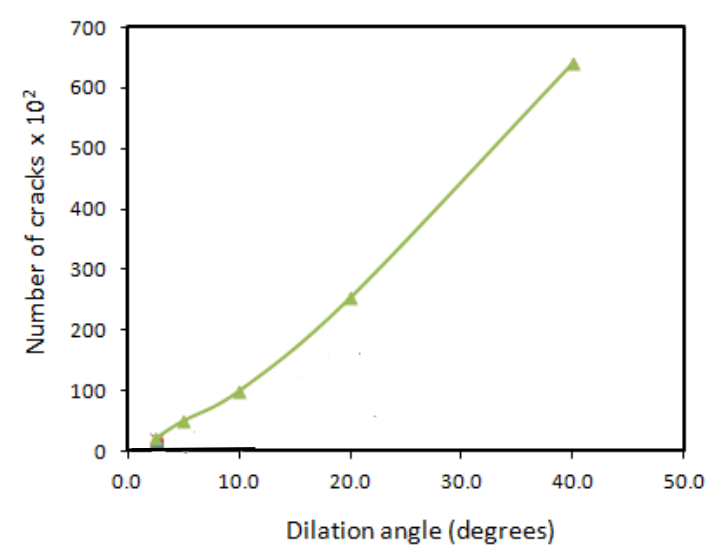

(b)

Figure 12 Linear relationship between dilatancy and crack proliferation: (a) trend shown in Cieslek (2008), where increase in crack demography is represented by changes in the damage variable $\left(D_{E}\right)$, and (b) DEM result.

\subsection{Results and discussion}

The performance of joints is governed by their characteristics. The major set of properties which influence the overall joint behaviour are the joint shearing resistance, frictional resistance, wall compressive strength and surface roughness. These properties, in varying ways, have an impact on joint behaviour which in turn influences their role as they interact with underground processes. Contributions from joints are relevant to the understanding of subsurface phenomena linked with jointed rock masses. The joint shearing resistance is a measure of its shear strength and is directly linked to the joint frictional resistance, especially instances where bonding or cohesion between the joint planes is insignificant. Changes in the joint frictional resistance will therefore affect its reaction in the presence of naturally occurring and anthropogenic processes in addition to transforming the manner in which the joint impacts on nearby events. The first set in the sequence of investigations involves an evaluation of the joint behaviour and its effect on surrounding underground events as the joint frictional resistance varies. A typical scenario of this case is illustrated in Eshiet and Sheng (2017) where both the responses and influences of joints due to the pressure intensity and perturbations of fluid injected from an isolated point source are appraised. Emphasis was given to the geomechanical response of the subsurface, measured with respect to the fracturing process. The pattern and intensity of fracturing were correlated with joint frictional resistance through procedures involving values of friction angles in the range of $0^{\circ}$ to $45^{\circ}$. 
The dilatancy of materials contributes to its frictional resistance. The relationship between the two properties has been established by researchers such as Rowe (1962) and Bolton (1986). Both residual frictional resistance and dilatancy constitute the actual frictional resistance of a material. The residual frictional resistance is a constituent of the total shear strength and is measured when the material is loose and in a critical condition. Equations 19 and 22, presented by Bolton (1986) and Rowe (1962), respectively describe this relationship. The frictional resistance of a material in its current state is hence reliant on its current dilatancy. Where the dilatancy is negligible, the actual friction angle is assumed to be equivalent to its residual value. Examples of such materials include loose non-cohesive granular materials, highly cohesive materials and materials that have sufficiently failed.

The dilatant behaviour of granular materials is based on concepts that are adopted in predictions of shearing characteristics of non-planar rock joints. The shear strength of rock joints is composed of two main components: the stress required to overcome the joint plane frictional resistance, referred to as the residual shear stress $\left(\tau_{r}\right)$, and the stress required to overcome the volumetric expansion due to the irregularity of the joint plane. Expressions describing these components are presented in Equations 24-26. The deviation of the displacement of particles from the direction of shear stress contributes to the joint shearing resistance and Equation 25 estimates the magnitude of this contribution. Equation 26 shows how the two components are combined to estimate the peak shearing resistance. The deviation of particle displacement is directly associated with the joint irregularity or surface roughness which controls its volumetric expansion during shearing. Joint dilatancy is hence characterised using Equation 25, which is also embodied in Equation 26. An index for the measurement of the volumetric expansion of rock joints is the dilation angle. Because the volumetric expansion is directly related to the joint surface roughness, the dilation angle can also be adopted as an index of the degree of roughness of the surface. The relationship between the joint dilation angle and its shearing resistance is presented in Equation 27a, which is further implied in Equation 30. In Equation 31 the dependence of the joint friction angle on its dilation angle is depicted. This link between the joint friction angle and dilation angle is applied in the formulation of Equations 29-30.

As previously mentioned, since the volumetric expansion of rock joints is controlled by the joint surface roughness, the dilatant behaviour can be used as an indicator of the surface roughness. The dilation angle is assumed somewhat proportional to the joint surface roughness with an increase in the joint dilation angle corresponding to an increase in the surface roughness. Quantification of the exact correlation is not within the scope of this work; nevertheless, this implied relationship is 
particularly useful for the evaluation of joint characteristics, especially where the roughness of nonplanar joints is to be adjusted. Through the modification of the dilatant behaviour, the surface roughness is automatically modified.

It is worthy to note that the emphasis of this work is not interfacial roughness; rather, it focuses on joint dilatancy, which is primarily considered an intrinsic property that controls volumetric expansion. Within the context of this investigation, joint dilatancy is, amongst other purposes, used as an indicator of the surface roughness because of their interrelationship. Joint asperity governs both interfacial dilation and frictional sliding, and the form of impart is associated with the size of asperities. Whereas, large asperities have dominant control over interfacial dilation, small asperities mainly contribute to the frictional sliding resistance (Maciejewski et al., 2020). Stated succinctly, the size and geometry of asperities control the normal and tangential displacement of joints, which directly define its dilatancy.

The ramification due to the impact of non-dilatant $(\varphi=0)$ frictional rock joints on fracture behaviour is demonstrated. This is further extended to dilatant rock joints where the contributions accrued from joint dilatancy are considered in tandem with its frictional resistance. To accomplish this, the two essential joint properties are considered concurrently: joint frictional resistance and joint dilatancy. The joint frictional resistance is directly denoted by its friction coefficient or friction angle. It is also partly influenced by the joint dilation angle, a parameter used as a measure of joint dilatancy. Correlations entailing the combined effect of these two parameters on fracture behaviour can then be established by a conjunctive application of the two properties. A systematic blending of the two properties is used to derive distinctive trends in the fracturing process that are linked to specific combinations of joint frictional resistance and dilatancy. The parametric values are given in Table 5.

Table 5. Combination of properties for dilatant rock joints

\begin{tabular}{|c|c|c|c|c|c|c|c|}
\hline \multicolumn{2}{|c|}{ Case 1} & \multicolumn{2}{|c|}{ Case 2} & \multicolumn{2}{|c|}{ Case 3} & \multicolumn{2}{|c|}{ Case 4} \\
\hline Friction & Dilatancy & Friction & Dilatancy & Friction & Dilatancy & Friction & Dilatancy \\
\hline \multirow{6}{*}{$0.2\left(11.3^{\circ}\right)$} & $2.5^{\circ}$ & \multirow{6}{*}{$0.5\left(26.6^{\circ}\right)$} & $2.5^{\circ}$ & \multirow{6}{*}{$0.7\left(35.0^{\circ}\right)$} & $2.5^{\circ}$ & \multirow{6}{*}{$1.0\left(45.0^{\circ}\right)$} & $2.5^{\circ}$ \\
\hline & $5.0^{\circ}$ & & $5.0^{\circ}$ & & $5.0^{\circ}$ & & $5.0^{\circ}$ \\
\hline & $10.0^{\circ}$ & & $10.0^{\circ}$ & & $10.0^{\circ}$ & & $10.0^{\circ}$ \\
\hline & $20.0^{\circ}$ & & $20.0^{\circ}$ & & $20.0^{\circ}$ & & $20.0^{\circ}$ \\
\hline & $30.0^{\circ}$ & & $30.0^{\circ}$ & & $30.0^{\circ}$ & & $30.0^{\circ}$ \\
\hline & $40.0^{\circ}$ & & $40.0^{\circ}$ & & $40.0^{\circ}$ & & $40.0^{\circ}$ \\
\hline
\end{tabular}

A range of friction coefficients between 0.2 and 1.0 and a range of dilation angles between $2.5^{\circ}-40^{\circ}$ are used. The combination of these two parameters is shown in Table 5. A conservative estimate 
will be to assume that the residual friction angle can be mobilised to as high as $30^{\circ}$ (Barton, 2013). The peak friction angle will therefore depend on how much both residual friction and dilation angles have been mobilised. Depending on underlying stress conditions, it is possible for rock dilation angles to evolve in some cases to values exceeding $40^{\circ}$ (e.g., Zhao and Cai, 2010), which is especially applicable at low confining stress conditions since the peak dilation angle drops as confining stress increases. Nonetheless, a dilation angle of $40^{\circ}$ falls-to large extent-within the upper range; thus, there are no imperatives to evaluate higher values since it will be redundant.

When magnitudes of the friction coefficient and dilation angle are both low; for instance, 0.2 and $2.5^{\circ}$ respectively, the resulting fractures are constrained and do not grow beyond the bounds of the upper and lower joints (Figure 13a). Only a few isolated spots of mostly shear cracks are observed at the upper and lower outer regions. The severity of fracturing events can be likened to those involving non-dilatant frictionless joints or non-dilatant low-frictional joints, under analogous conditions (Eshiet and Sheng 2017); however, the distribution of fracturing differ as non-dilatant joints tend to cause the generation of more dispersed fractures that tend to grow slightly further laterally. As exemplified, the incidence of even a small amount of dilation influences fracturing. Where even a small rise in dilation (e.g., $\varphi=5.0^{\circ}$ ) is imposed on frictionless or low-frictional joints, the fractures grow upwards and downwards towards the upper joint and lower joint respectively (Figure 13b). Some of these fractures propagate perpendicularly to the joints while others approach the joints at inclined orientations (Figure 13b). In addition, the onset of new cracks occurs at several lone locations along the upper and lower joint planes. Once the propagating fractures cross the bounding joints, their rate of advancement becomes more rapid as they are no longer within the restrictive zone. Non-frictional and low-frictional joints are more susceptible due to the relative ease at which the joint planes can slide against each other in response to induced loads. The effect of dilation is hence more prominent as it instigates joint separation and shearing. This implies a higher possibility of lateral displacements and crack initiation than would otherwise occur if the joint frictional resistance was greater.

Shear cracks are predominantly instigated along the joint planes as a result of the horizontal motion of the joint planes as the slide against each other (Figure 13b). A greater proportion of all other fracturing events are induced following the failure of the rock in tension. This phenomenon is further evidenced in Figure $13 \mathrm{c}$ where the dilation angle is increased to $10^{\circ}$. Figure $13 \mathrm{c}$ mirrors a more extensive version of Figure 20c, depicting additional pockets of crack initiation across both joints. It also shows an advanced growth of some fractures that were earlier created along the joint plane. As the joint dilatancy increases it enables the onset of more cracks as well as exacerbates the outward 
proliferation of fractures away from the joints. A corresponding increase in fracturing occurs with an additional increment in joint dilatancy $\left(\varphi=20.0^{\circ}\right)$. The fractures that are formed the joint surfaces propagate outwards and in directions parallel and at the vicinity of the joints. Fractures are more likely to grow along the joint plane than in outward directions. The singular points of crack events along the joint planes tend to grow to interconnect with other before propagating away from the joint into other areas. At a high state of joint dilatancy $\left(\varphi=40.0^{\circ}\right)$, a more aggravated condition ensues depicted by a more widely distributed pattern of fracturing occurring both along the joint planes and in other zones within and outside the twin joints (Figure 13e).

Cavitation at the span of joint planes is an additional phenomenon that can be caused by joint dilatancy. This feature becomes more pronounced in joints with medium to high magnitudes of dilatancy, and the population and size of cavities rise with dilatancy. Comparisons between joints with dilation angles of $20^{\circ}$ (Figure 13d) and $40^{\circ}$ (Figure 13e) indicate a larger number and size of cavities when the joint dilation angle is $40^{\circ}$. As the fractures cross the joint, an initial cavity is created at the upper joint at a location almost directly above the fluid injection point (Figure 13). The size and rate of enlargement of this cavity is influenced and increases with joint dilatancy. Whereas, the initial cavity created at the position approximately above the injection point is consistent for joints with different values of dilatancy, the point of initiation and number of cavities created in other regions vary with joint dilatancy (Figure 13).

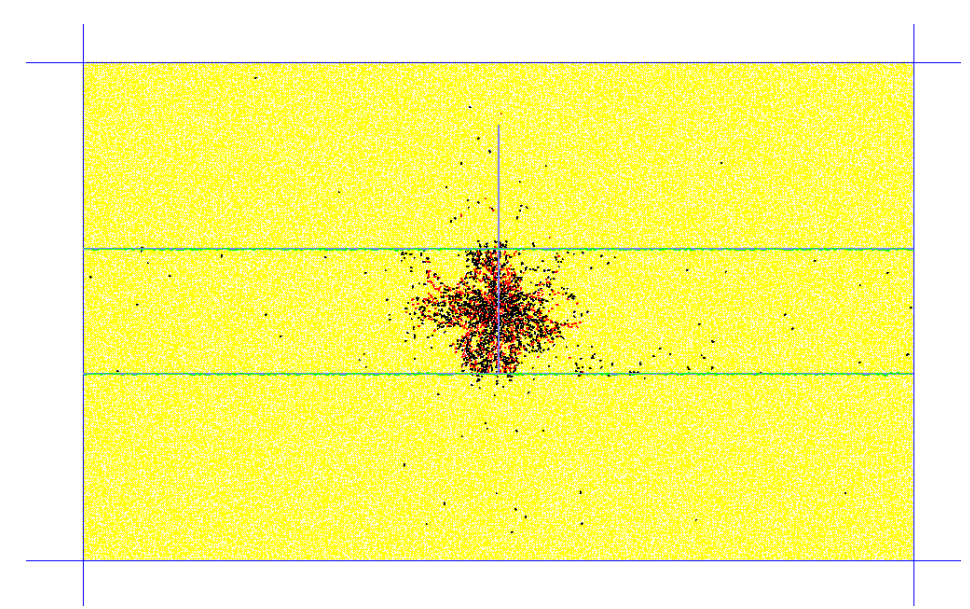

a. Fracture development (dilation angle: 2.5 ) 


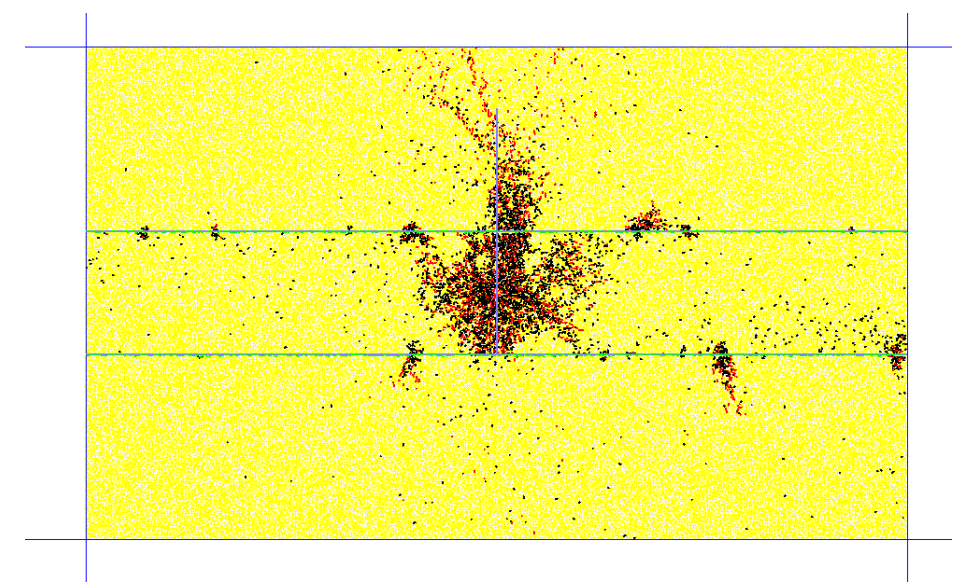

b. Fracture development (dilation angle: 5.0 )

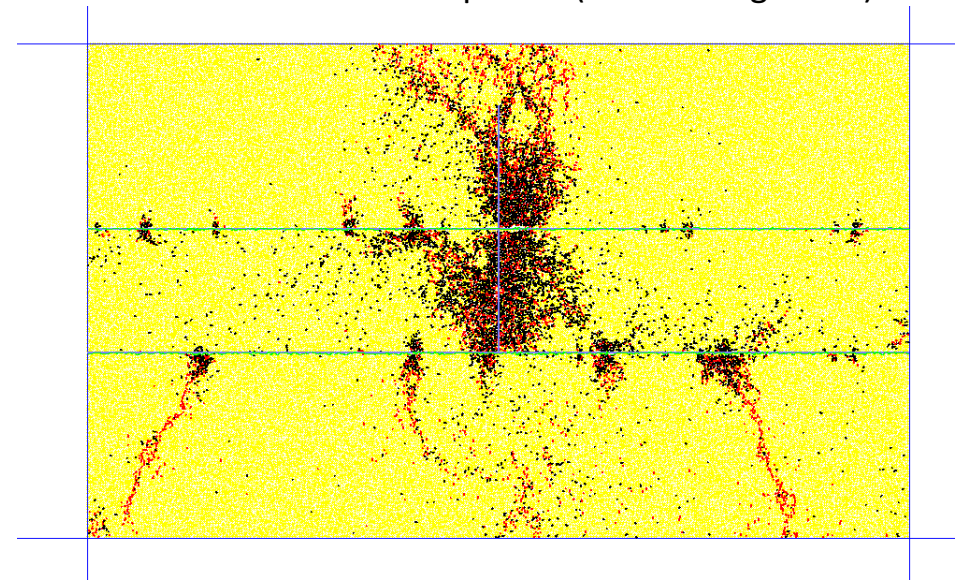

c. Fracture development (dilation angle: 10.0)

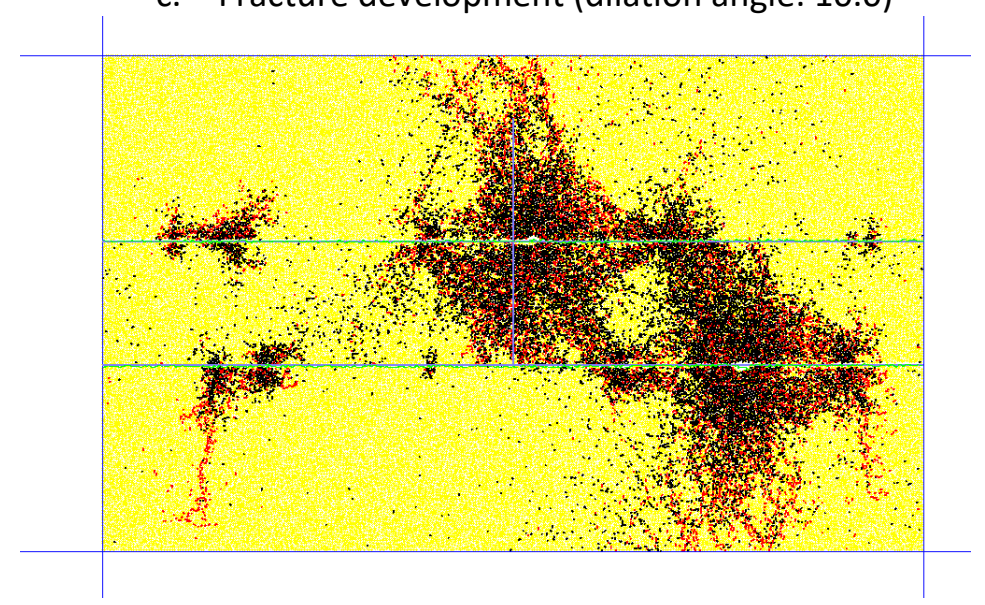

d. Fracture development (dilation angle: 20.0) 


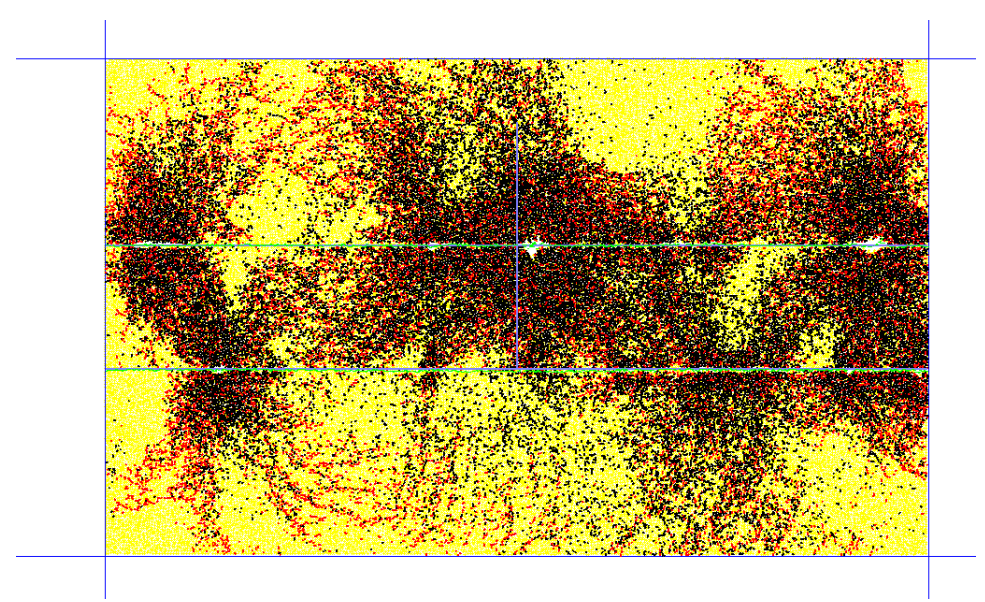

e. Fracture development (dilation angle: 40.0 )

Figure 13. Impact of dilatancy on fracture development (friction coefficient: 0.2)

The number and rate of proliferation of shear induced cracks are considerably greater than tensile induced cracks. The discrepancy accrues over time and after protracted periods there is an overwhelming presence of shear cracks. This predominance is primarily caused by the shearing characteristics of the joint, which is manifested through the sliding motion of the joint planes, as they remain subjected under pressure from the fluid flow and subsurface stress conditions. The restriction in the shearing of a joint increases with its frictional resistance. Joints with low friction are prone to larger lateral displacements since the planes slide more easily. This shearing action is more likely to instigate shear cracks. On the other hand, joints with high friction initiate lesser shear cracks.

A juxtaposition of the effect of various values of joint dilatancy indicates a similar trend in the impact on fracturing which become more severe as the joint dilation angle increases (Figure 14-16). At the medium to high range of dilation angles $\left(>10^{\circ}\right)$, the corresponding development in the extent of fracturing is not proportional to increases in joint dilatancies (Figure 16). This observation becomes more obvious with time lapse and is valid for tensile and shear induced fracturing events. As time elapses, there is a tendency towards a proportional relationship between dilatancy and total crack development (Figure 13). The trend is immediately apparent at medium to high range dilation angles $\left(>10^{\circ}\right)$ and is valid for both types of fracturing event (i.e., fracturing induced by shear and tensile stress) when considered separately. 


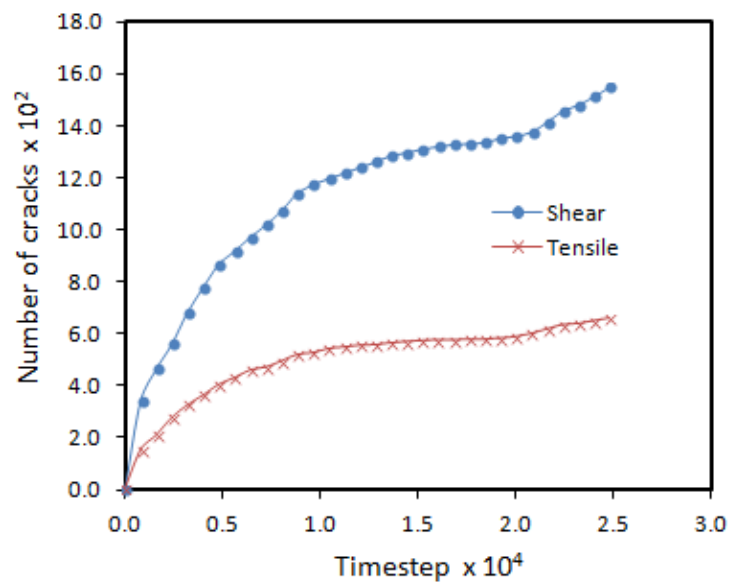

a. Fracture development (dilation angle: 2.5 )

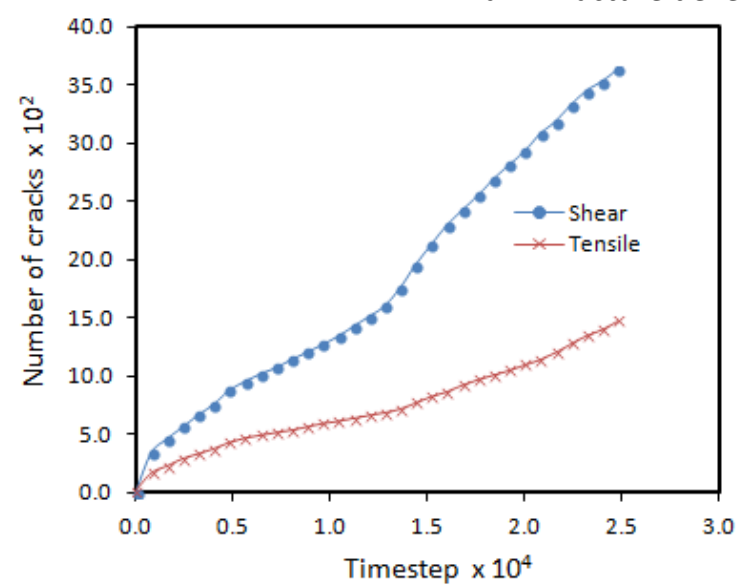

b. Fracture development (dilation angle: 5.0 )

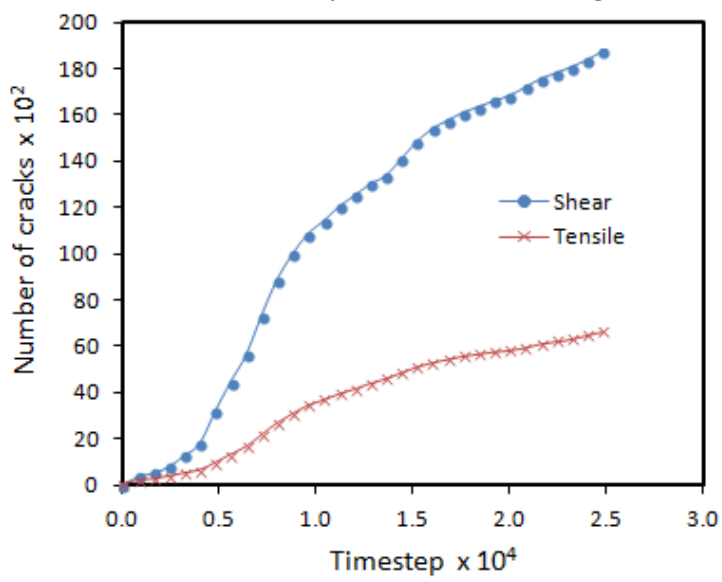

d. Fracture development (dilation angle: 20.0)

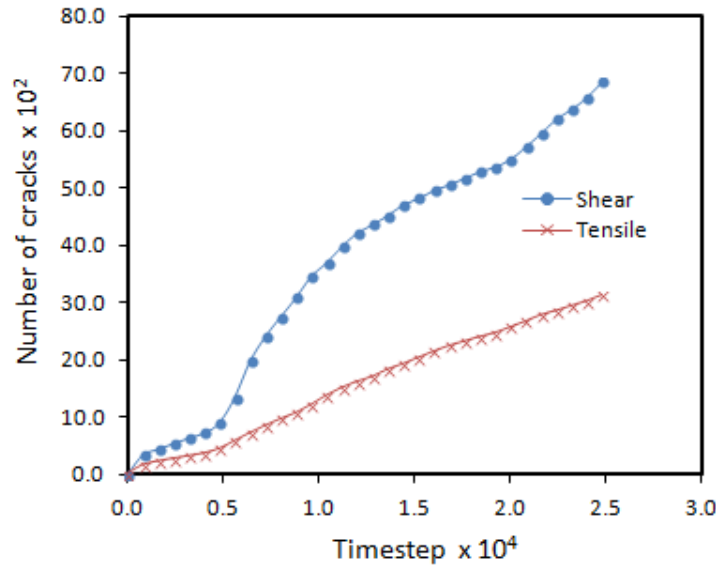

c. Fracture development (dilation angle: 10.0)

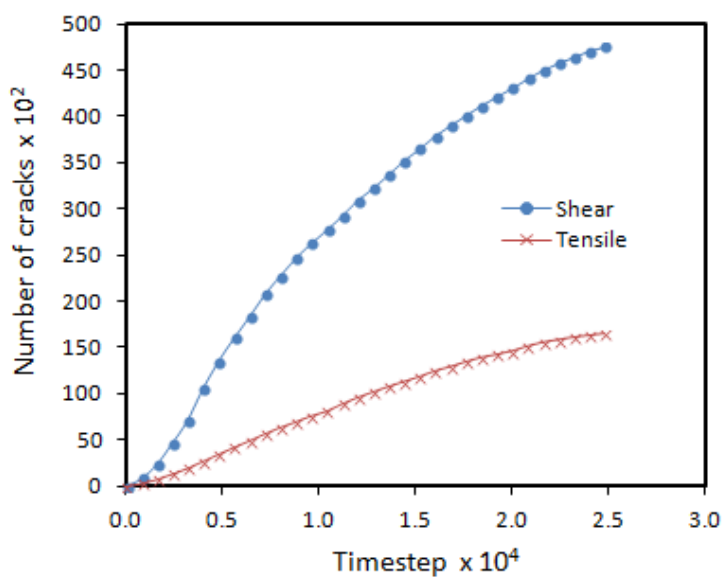

e. Fracture development (dilation angle: 40.0)

Figure 14. Evolution of tensile and shear fractures at different joint dilatancies (Friction coefficient: 0.2 ) 


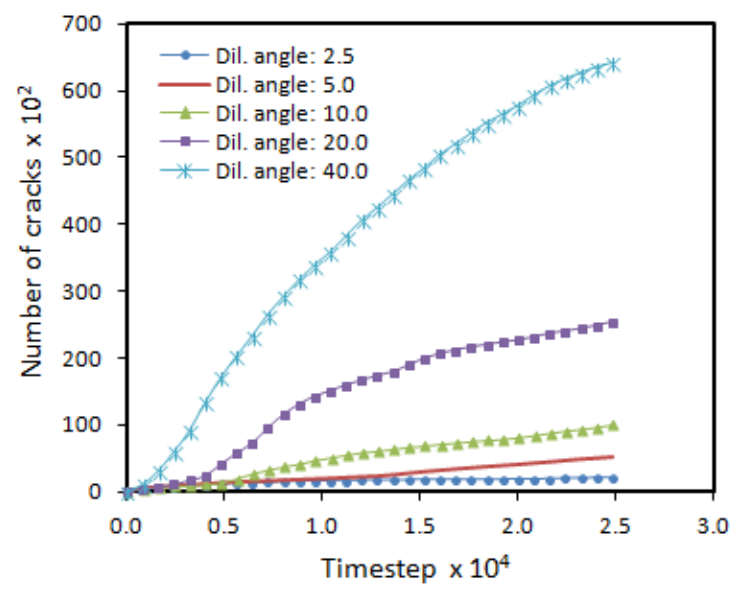

a. Total fracture development

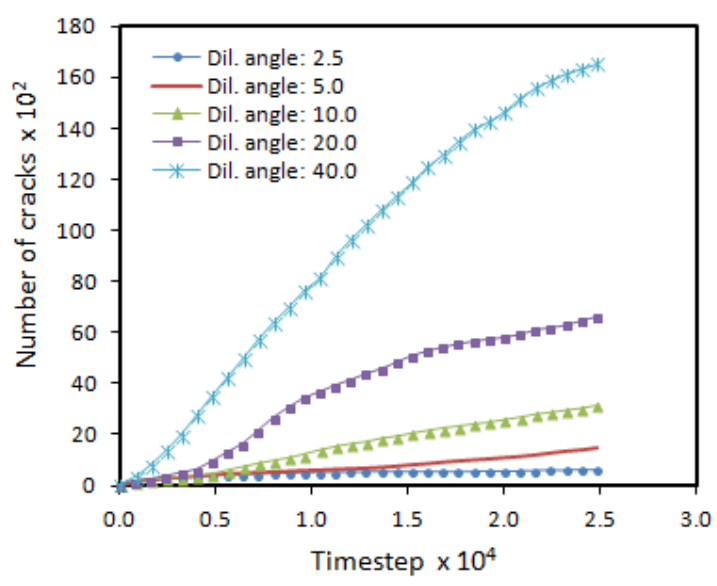

b. Tensile fracture development

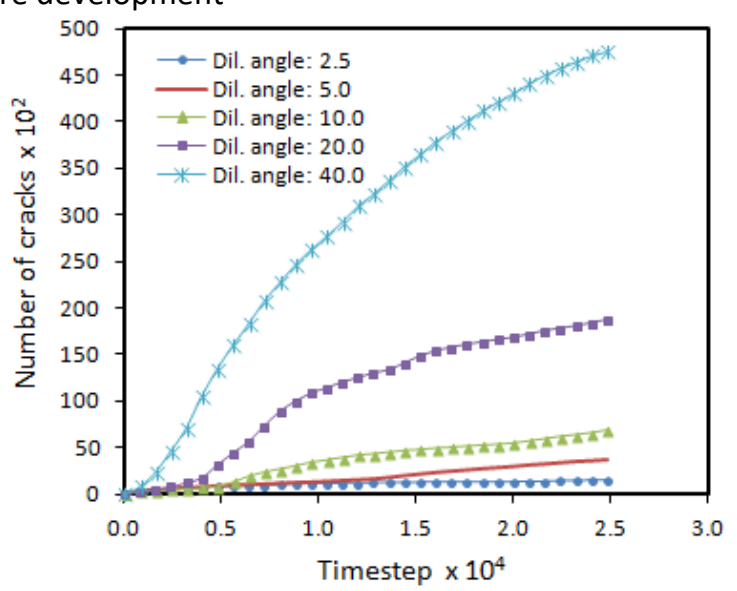

c. Shear fracture development

Figure 15. Influence of dilatancy on the generation of fractures (Friction coefficient: 0.2 )

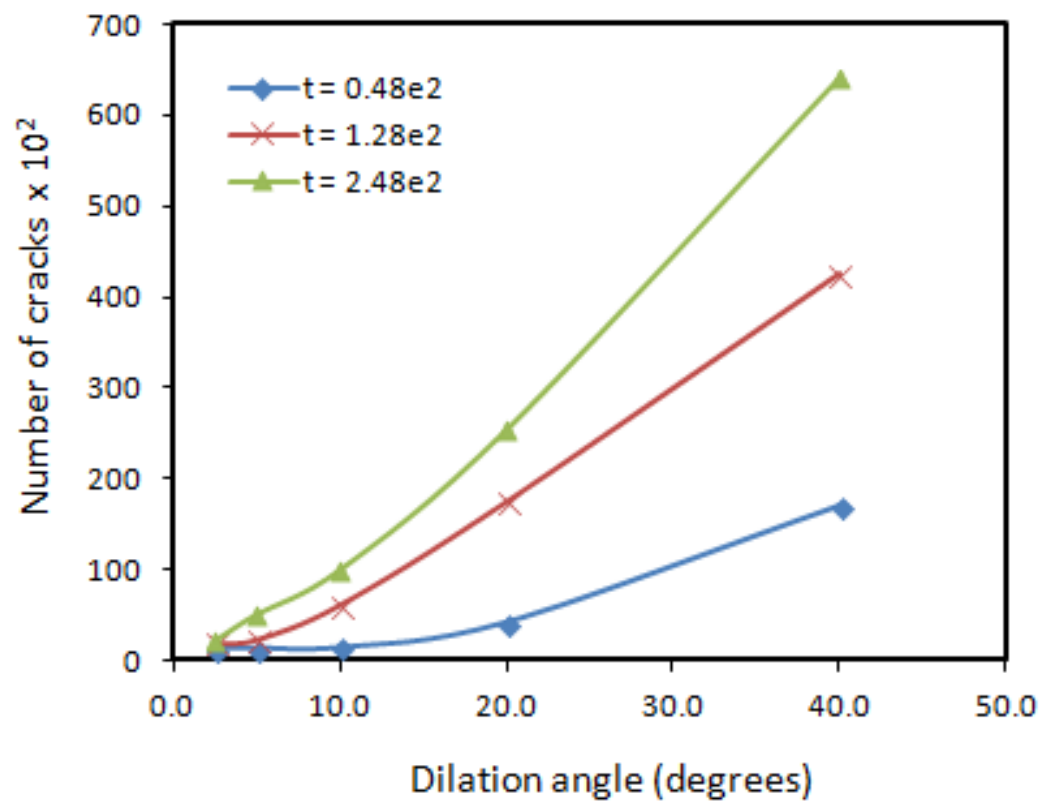

Figure 16. Effect of rock joint dilatancies on the build-up of total fractures (Friction coefficient: 0.2 ) 
With a small increment in joint friction coefficient (from 0.2 to 0.5 ) the intensity of fracturing is considerably less. When the dilation angle is maintained at $5.0^{\circ}$, the fracture front crosses the upper and lower joints with a small margin at locations almost aligned with the point of fluid injection (Figure 17a). Fracture initiation at detached locations along the upper and lower joint surfaces only begin to occur when the joint dilation angle is increased to $10^{\circ}$ (Figure 17b). A further increase in the dilation angle to $15^{\circ}$ facilitates the initiation of additional fractures at other points along the joint surfaces and an extension of the fractures earlier created thereby permitting interconnectivity between individual fractures (Figure 17c). A better-defined coalescence of fractures exists with a joint dilation angle of $20.0^{\circ}$. This is remarkably different from the outcome when the joint friction coefficient is 0.2 , where even for a dilation angle of $5.0^{\circ}$ an extensive fracture growth across the joint and a patchy incidence of fracture initiations ensues and at a dilation angle of $20.0^{\circ}$ noticeable cavities are created by the length of the joint surfaces.

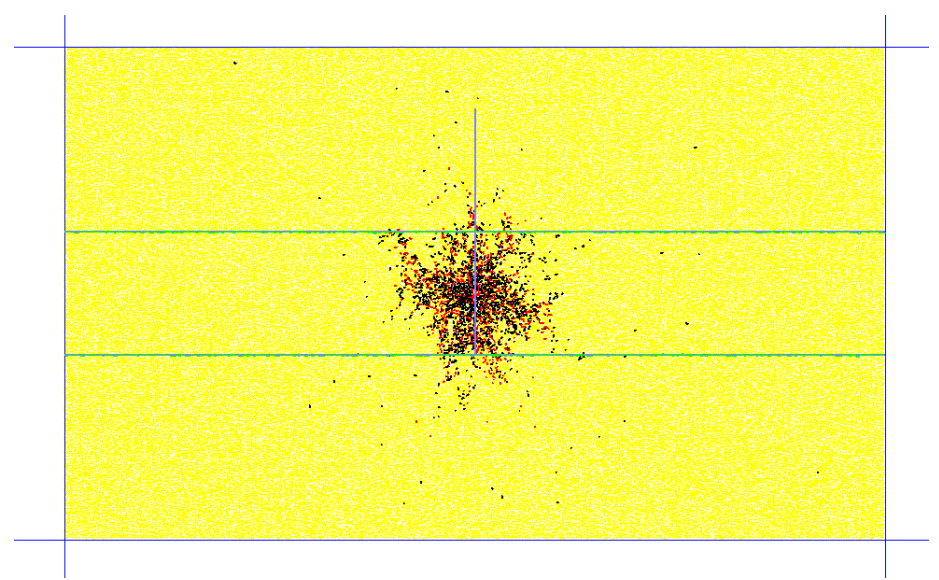

a. Fracture development (dilation angle: 5)

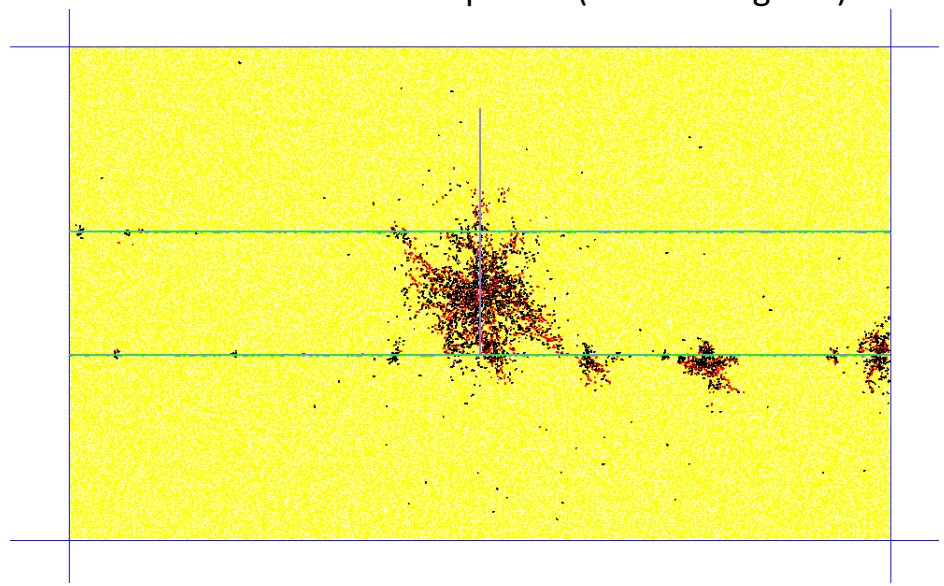

b. Fracture development (dilation angle: 10.0) 


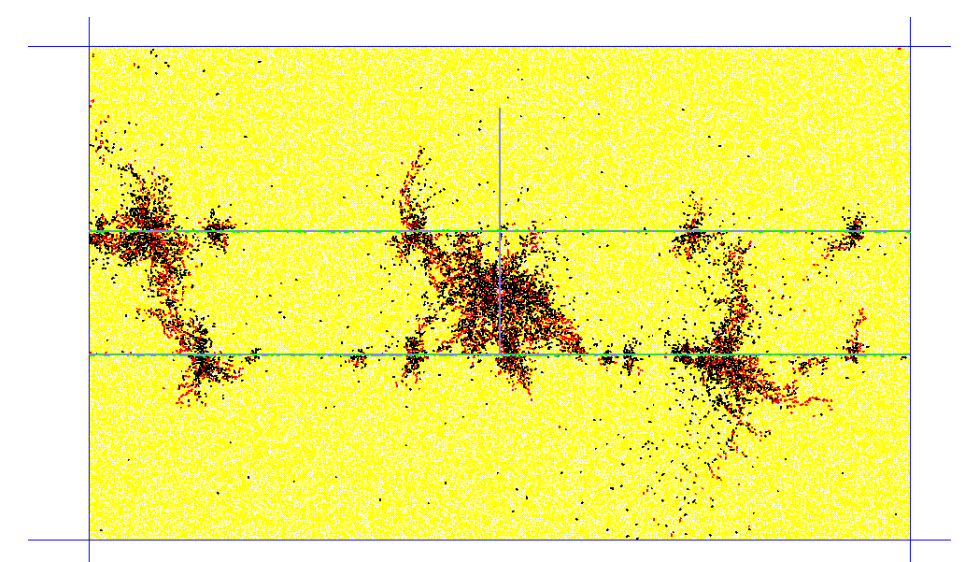

c. Fracture development (dilation angle: 15.0)

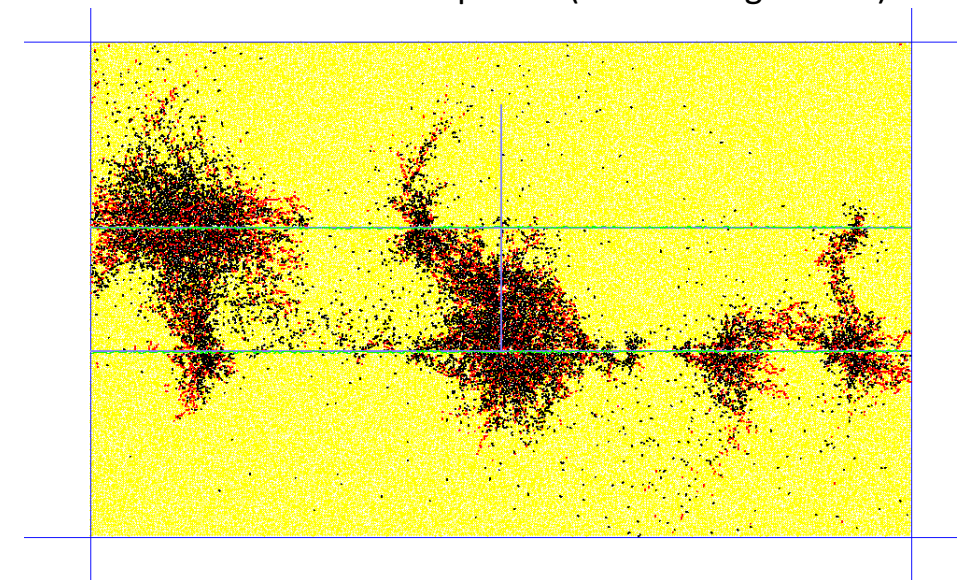

d. Fracture development (dilation angle: 20.0)

Figure 17. Impact of dilatancy on fracture development (friction coefficient: 0.5 )

As would be expected, the occurrence of crack events increases over the elapse period of fluid injection and the population of shear-induced cracks surpasses those that are tensile-induced (Figure 18). In addition, the gradient representing the rate of increase in number of cracks is consistently greater for shear cracks. However, the trend of rise in population of cracks is less smooth as indicated by the sharp changes in the slope of the lines and is easily noticeable with the tensile cracks. The rate of creation of tensile cracks is almost linear for a joint with a friction coefficient of 0.2 and a dilation angle $>5.0^{\circ}$. Under the same conditions the rate of creation of tensile cracks for a joint with a friction coefficient of 0.5 and a dilation angle $>5.0^{\circ}$ does not follow a steady gradient; rather the gradient becomes steeper with time.

A comparison of the different rock dilation angles with a constant frictional coefficient $(\phi=0.5)$ indicates an increase in the rate and magnitude of shear and tensile fracturing with dilatancy (Figure 19). When the dilation angle is $\geq 15.0^{\circ}$ the rate of increase ceases to be regular, consisting of periodic sharp upward deviations. Also, the increase in intensity of fracturing is disproportionate to 
the increase in dilatancy; as the joint dilatancy is increased, the severity of fracturing is not proportional to the regular increments in dilation angle.

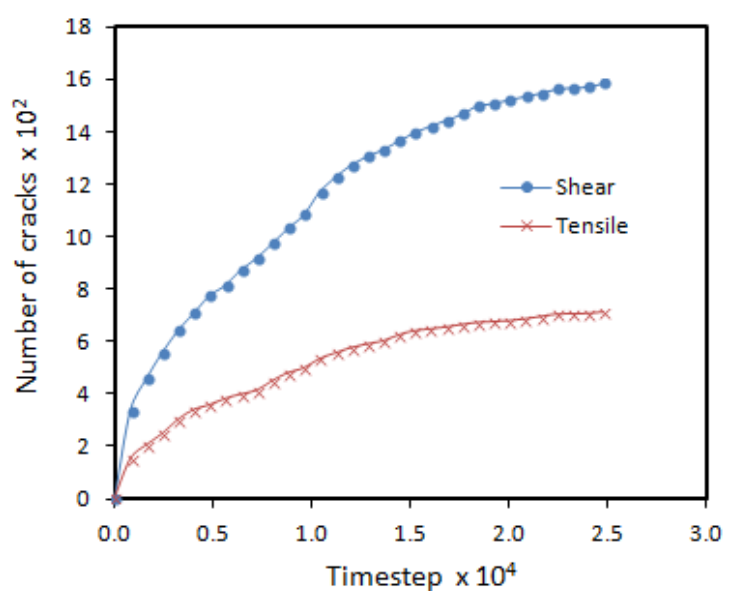

a. Fracture development (dilation angle: 5.0)

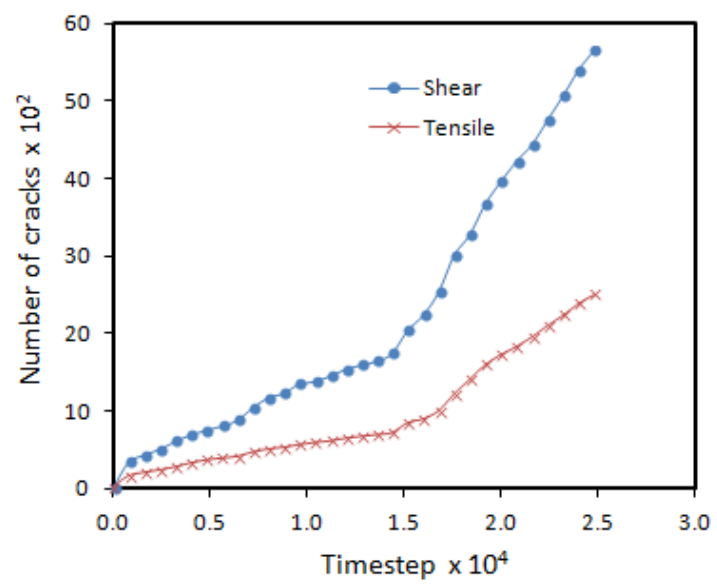

c. Fracture development (dilation angle: 15.0)

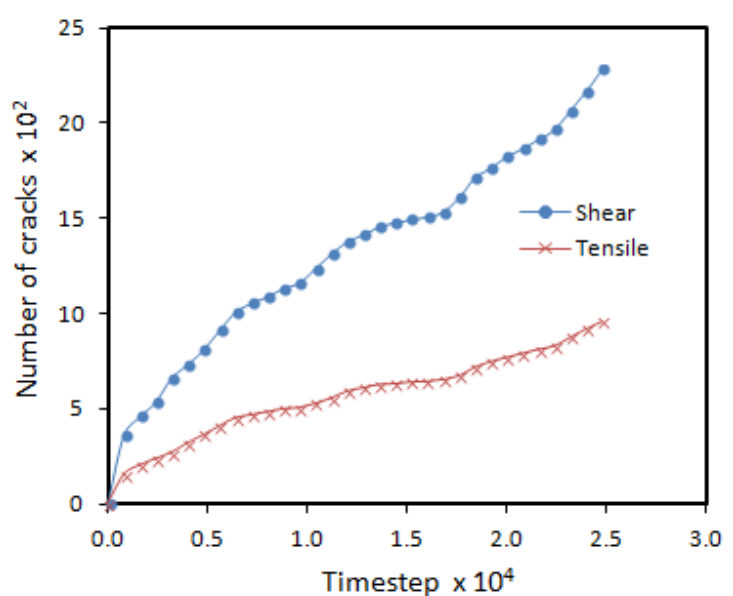

b. Fracture development (dilation angle: 10.0)

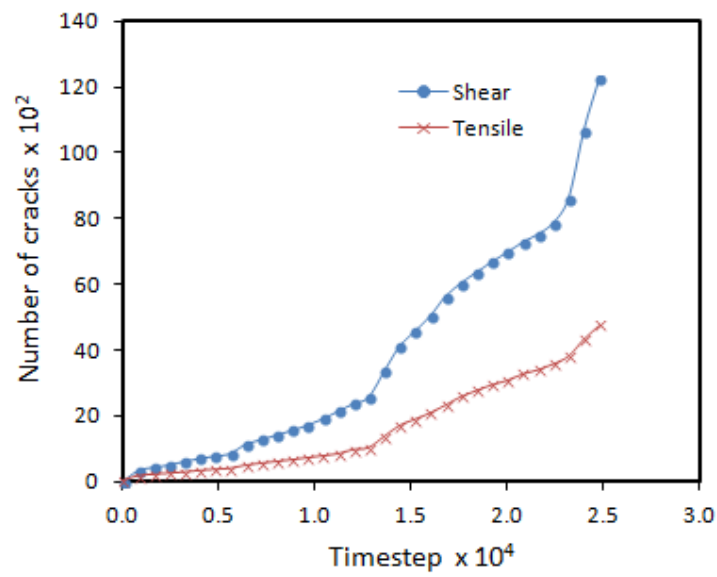

d. Fracture development (dilation angle: 20.0)

Figure 18. Evolution of tensile and shear fractures at different joint dilatancies (Friction coefficient: 0.5 ) 


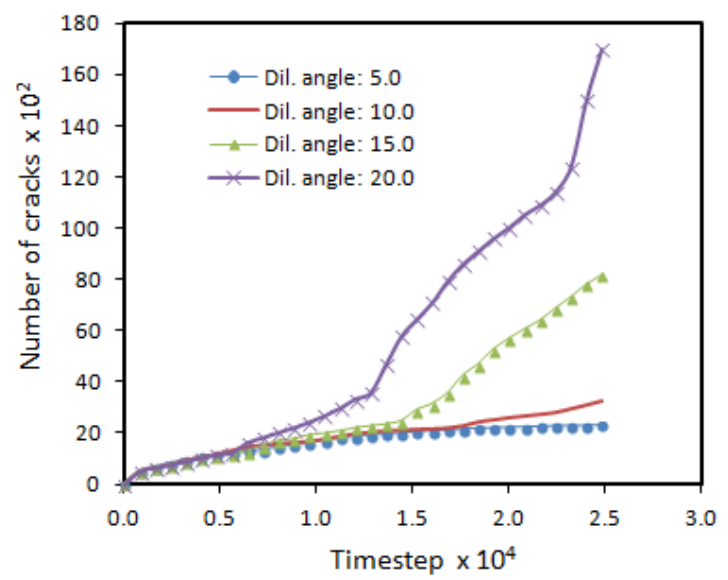

a. Total fracture development

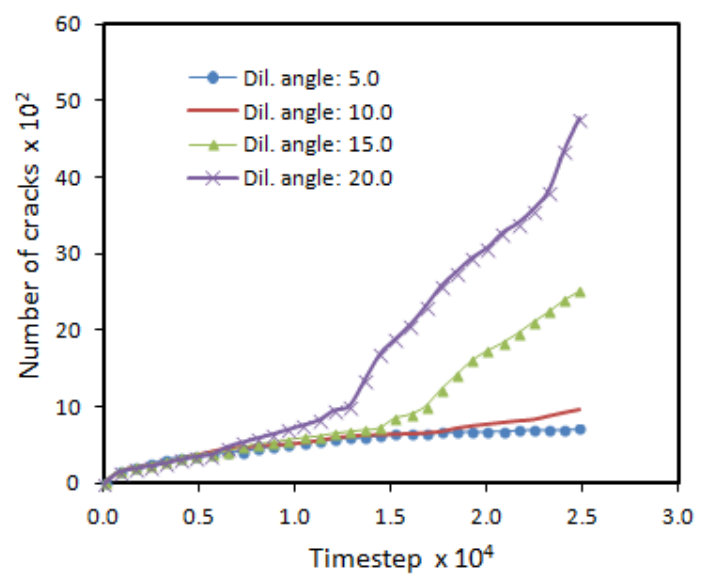

b. Tensile fracture development

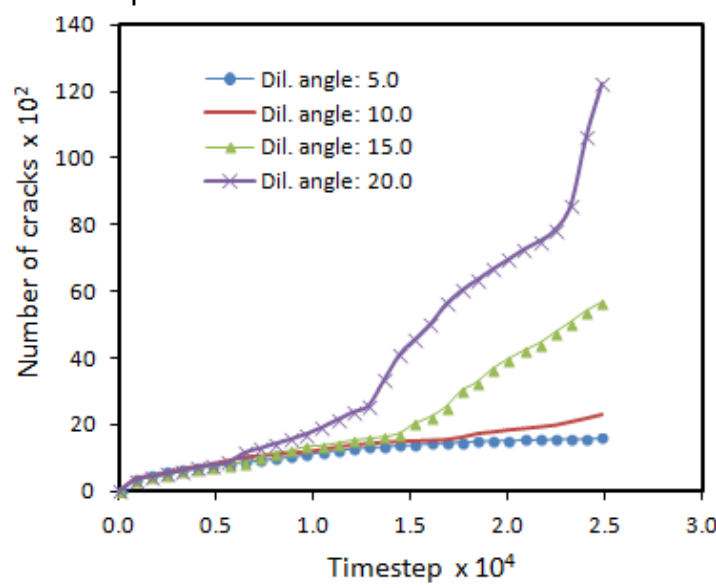

c. Shear fracture development

Figure 19. Influence of dilatancy on the generation of fractures (Friction coefficient: 0.5 )

An additional increase in the frictional resistance $((\phi=0.7)$ leads to a further reduction in the enormity of fracturing events. Although, when the dilation angle is $10.0^{\circ}$, there is a spot of fracture initiations along each joint surface located diagonally from each other, proliferation of fracture initiation at the joint surface does not commence until the dilation angle is increased to $20.0^{\circ}$ (Figure 20). At a joint dilation angle of $30.0^{\circ}$, the state of fracture growth is well developed and widely spread (Figure 20e). The trend indicating the rate of increase in magnitude of fracturing is similar when compared to joints of friction coefficient 0.5 (Figure 21). The effect of dilatancy becomes significant at a dilation angle $\geq 20.0^{\circ}$ (Figure 22). As the magnitude of frictional resistance increases towards the high range, it becomes more dominant and smaller values of dilation angles cease to have much impact on the fracturing process. Changes in the value of the dilation angles $\leq 5.0^{\circ}$ have negligible impacts and produce similar effects. Below this limit, the contribution due to dilatancy is trivial and is analogous to conditions involving non-dilatant rock joints. For a joint friction coefficient of 0.7 , the fracturing processes when the dilation angle is $0.0^{\circ}, 2.5^{\circ}$ and $5.0^{\circ}$ are nearly identical (Figure 20a-b). 
In Figure 22, the effect of a joint dilation angle of $10.0^{\circ}$ seems similar to that when the dilation angle is between $0.0^{\circ}$ and $5.0^{\circ}$. Nonetheless, a closer view of the same result (Figure 23) indicates a greater population of cracks for a dilation angle of $10.0^{\circ}$. Even though the magnitudes of total and shear fracturing for both dilation angles of $2.5^{\circ}$ and $5.0^{\circ}$ are alike, the magnitude of tensile fracturing for a dilation angle of $2.5^{\circ}$ is slightly higher, highlighting subtle differences on a more detailed scrutiny. The modification in steepness of the gradient representing a rise in the rate of increase in number of cracks is sharper as the joint friction coefficient is augmented to 0.7 , illustrated by comparing Figure 19 and Figure 22.

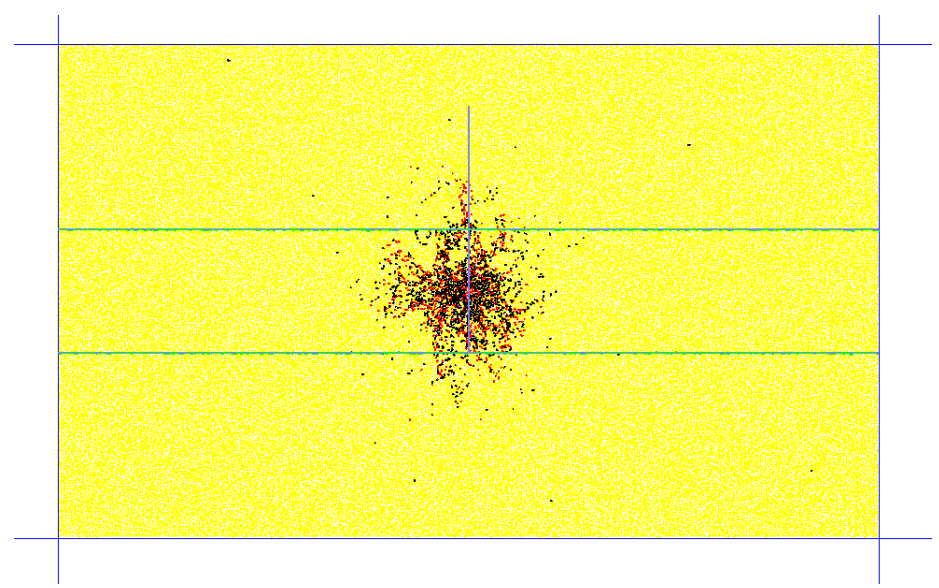

a. Fracture development (dilation angle: 2.5 )

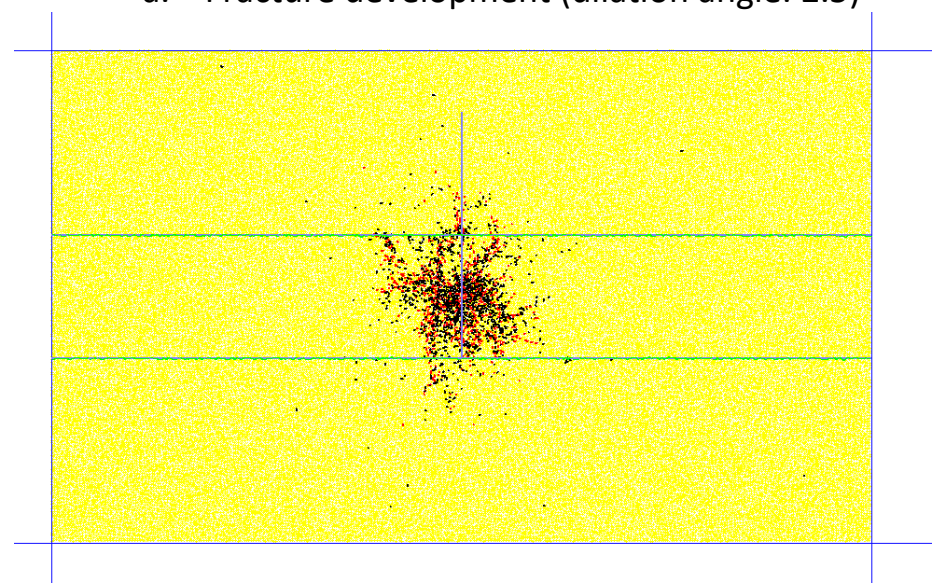

b. Fracture development (dilation angle: 5.0) 


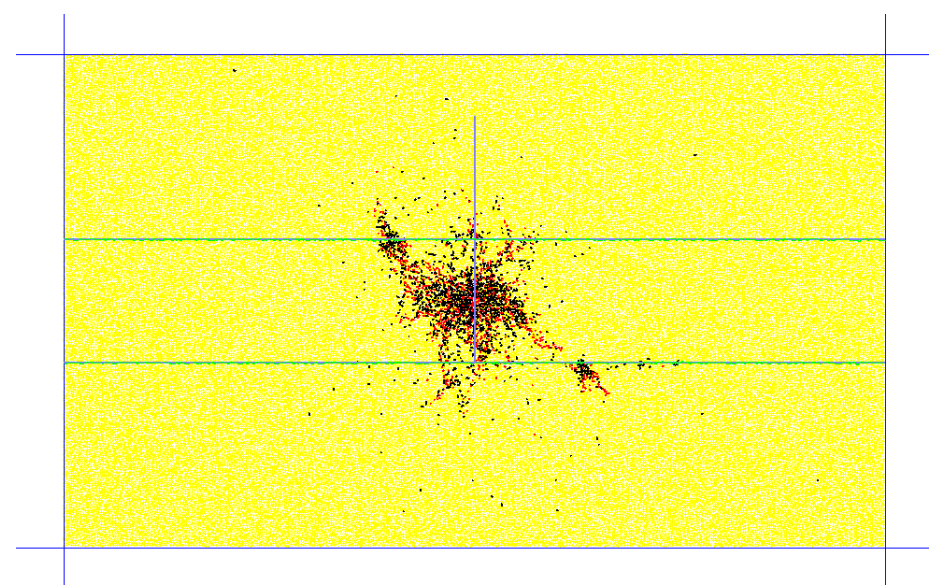

c. Fracture development (dilation angle: 10.0)

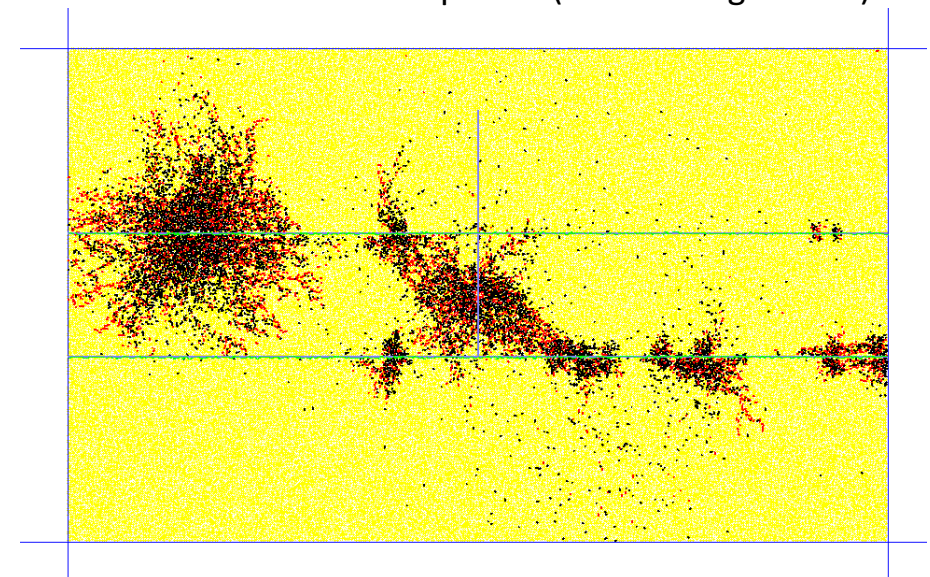

d. Fracture development (dilation angle: 20.0)

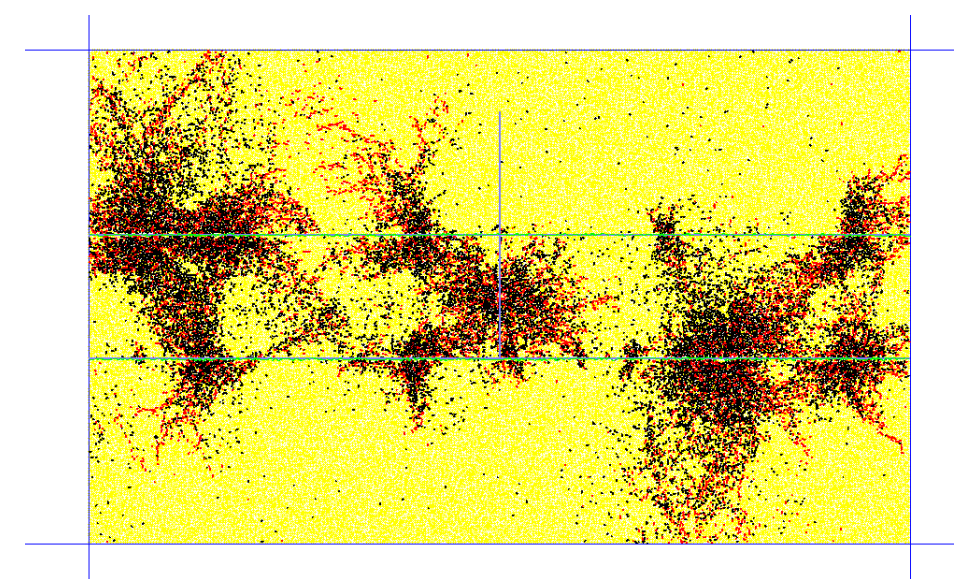

e. Fracture development (dilation angle: 30.0 )

Figure 20. Impact of dilatancy on fracture development (friction coefficient: 0.7) 


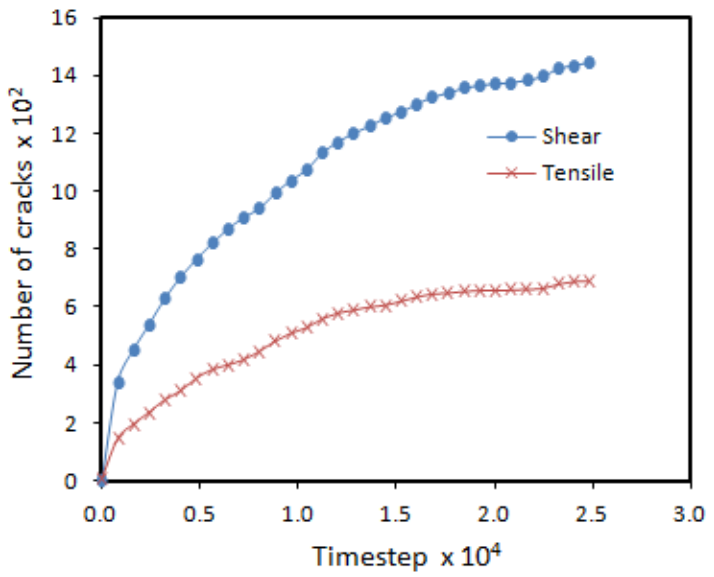

a. Fracture development (dilation angle: 2.5 )
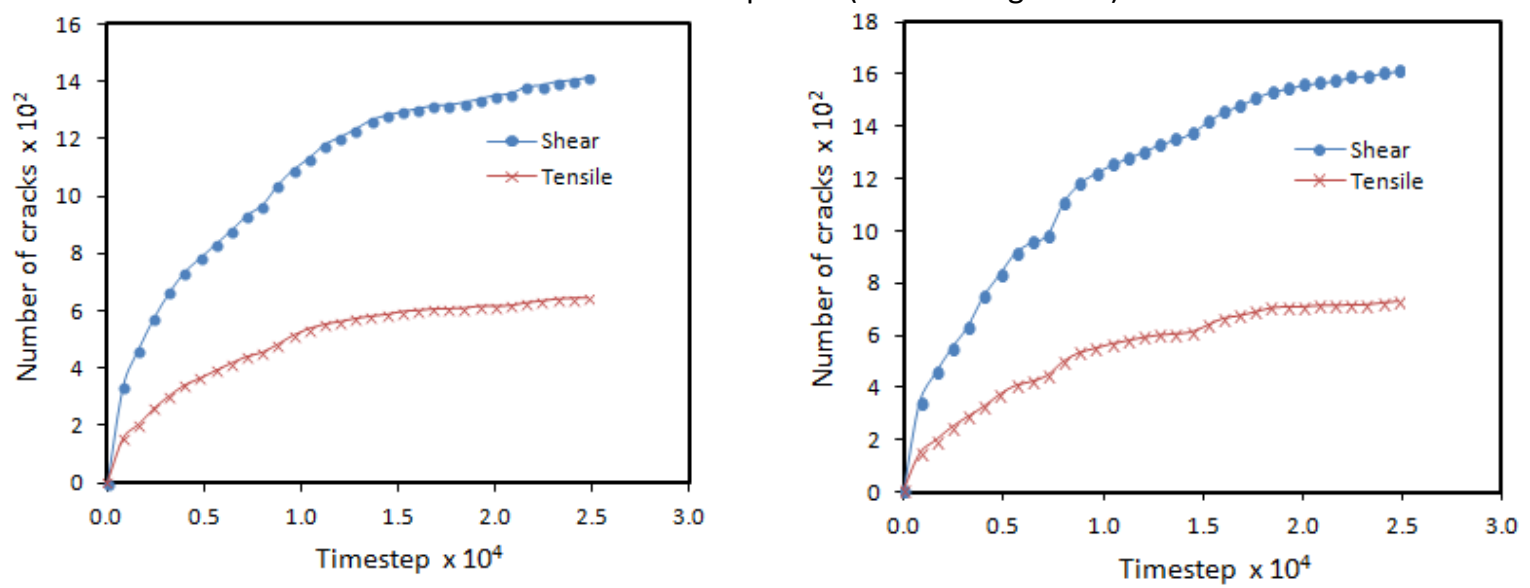

b. Fracture development (dilation angle: 5.0)

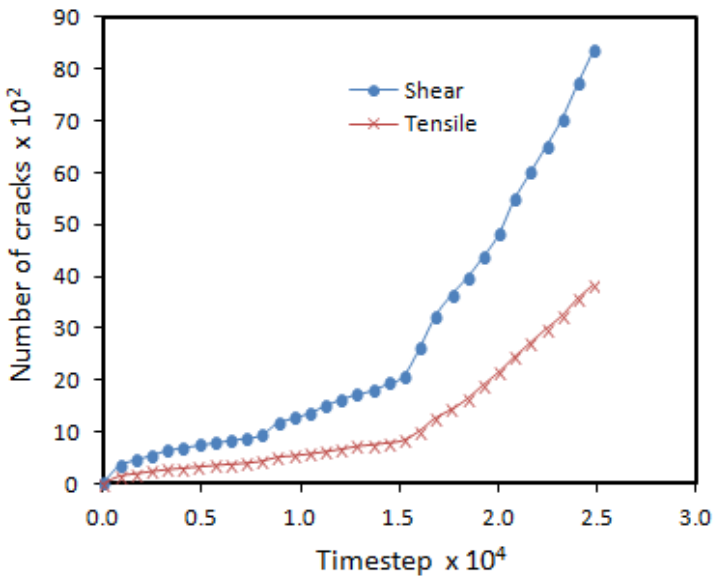

d. Fracture development (dilation angle: 20.0)

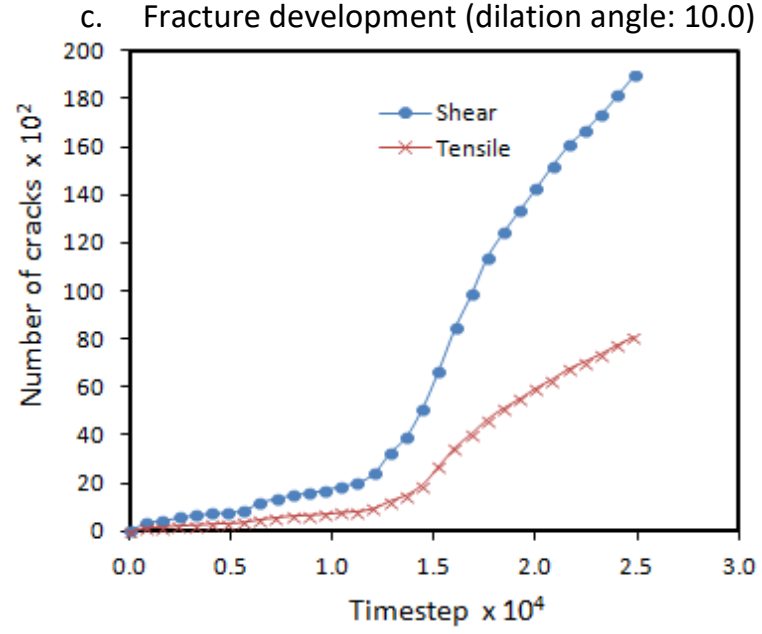

e. Fracture development (dilation angle: 30.0 )

Figure 21 Evolution of tensile and shear fractures at different joint dilatancies (Friction coefficient: 0.7 ) 


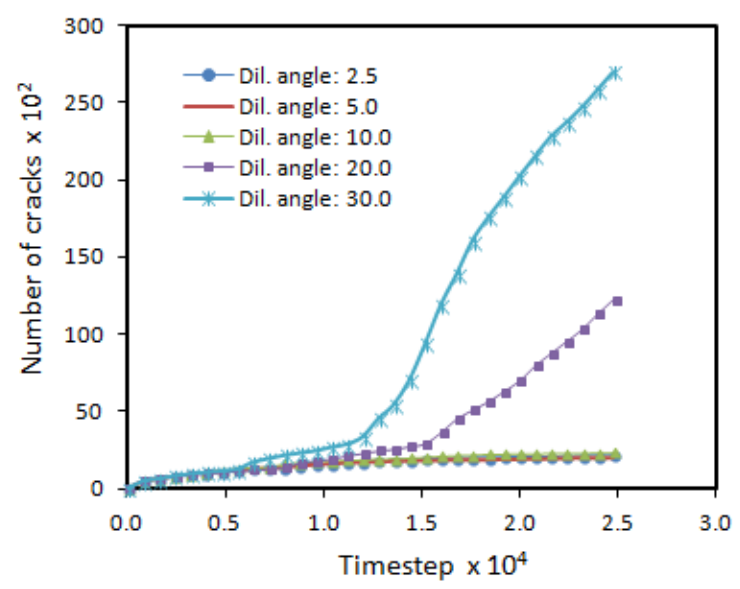

a. Total fracture development

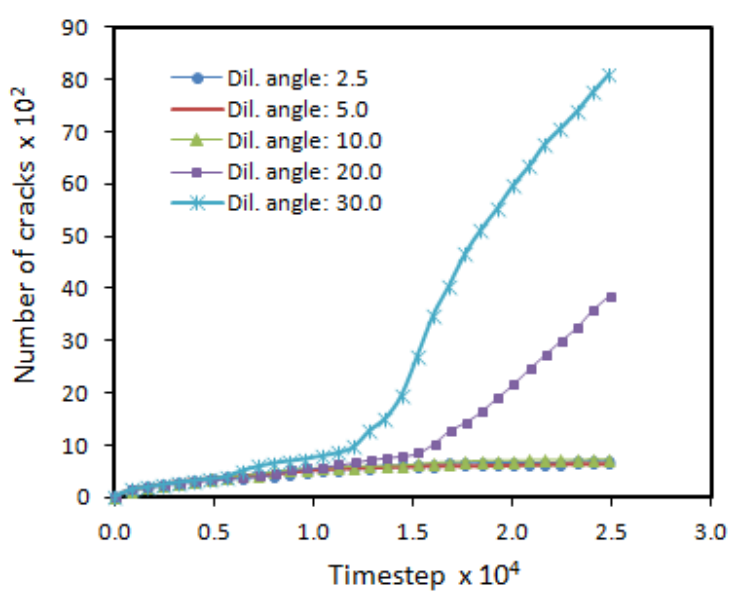

b. Tensile fracture development

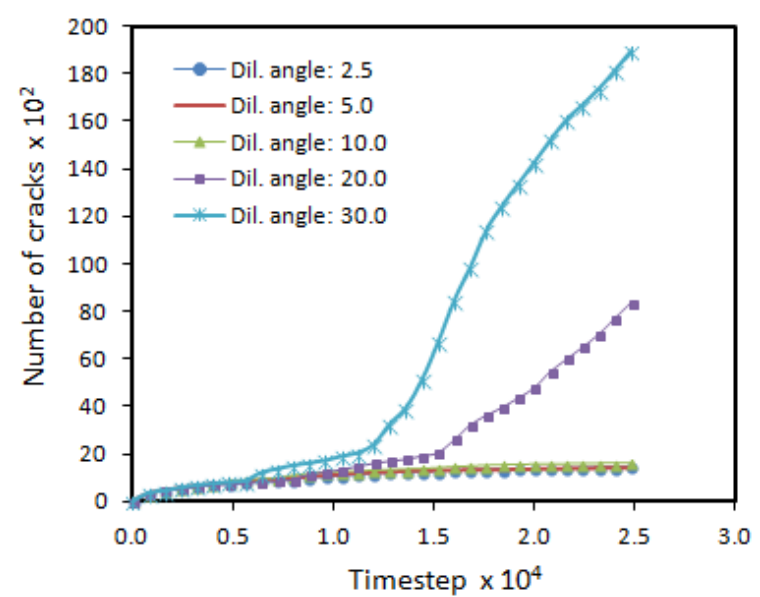

c. Shear fracture development

Figure 22. Influence of dilatancy on the generation of fractures (Friction coefficient: 0.7)

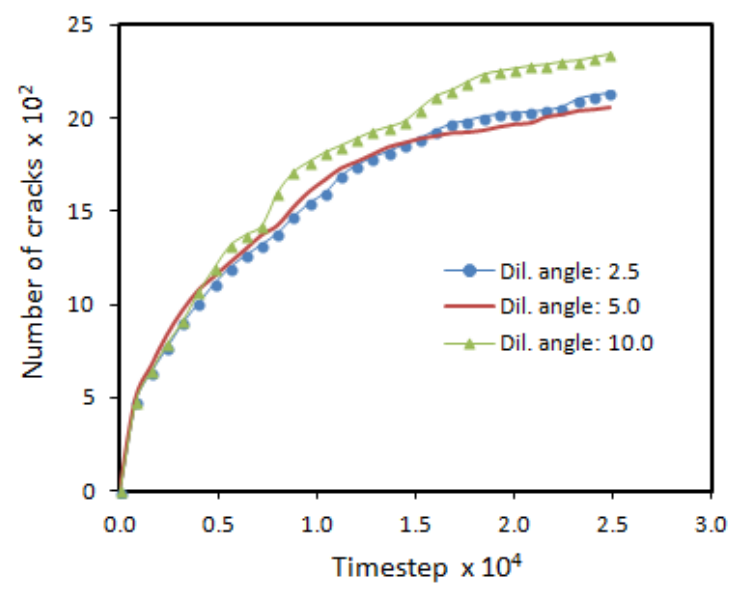

a. Total fracture development 


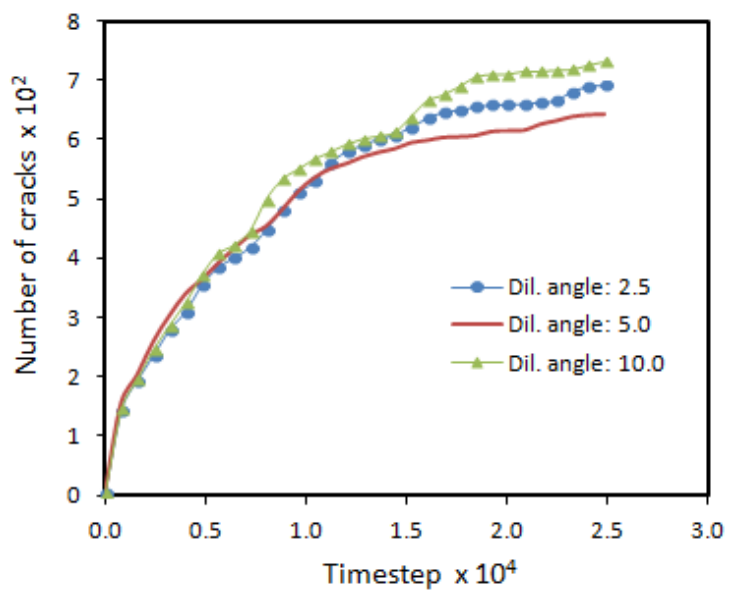

b. Tensile fracture development

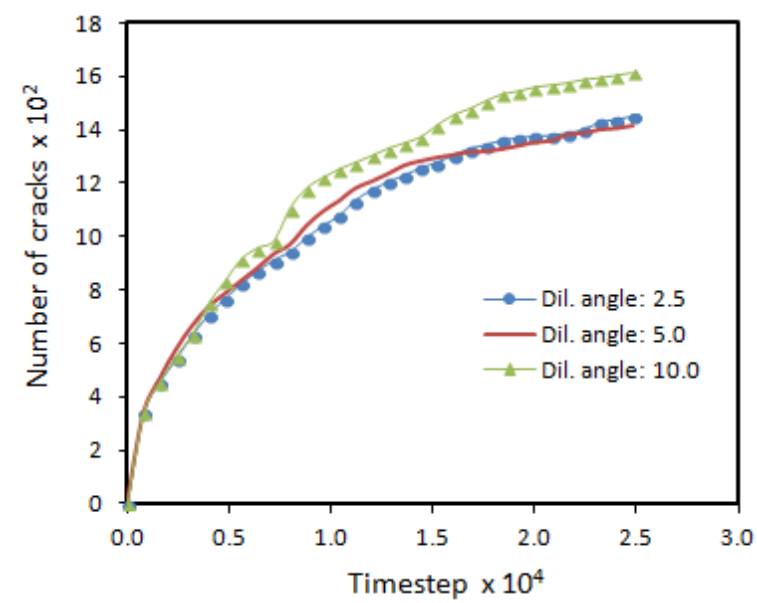

c. Shear fracture development

Figure 23. Influence of dilatancy on the generation of fractures (Friction coefficient: 0.7)(close-up)

Initiation and progression of fractures are constrained even further when the friction coefficient reaches a value of 1.0 (Figure 24). At a dilation angle of $20.0^{\circ}$, fracture growth is normal and is uninfluenced by the high dilatant condition. Sporadic occurrences of fracture initiation on the joint surface is only noticed when the dilation angle is increased to $30.0^{\circ}$ (Figure $24 \mathrm{~d}$ ) and even at $40.0^{\circ}$ there is no advancement in the complexity of fracturing, albeit they are different. A comparison of the state of fracturing between rock joint frictional coefficients of 0.2 and 1.0 indicates a remarkable difference (Figure 24e and Figure 13e). For the same amount of time lapse and a dilation angle of $40.0^{\circ}$, the fracturing involving a rock joint frictional coefficient of 0.2 is considerably immense.

The sharp inclination of the fracture development curves as shown in Figure $25 \mathrm{~d}$-e indicate a rapid proliferation of fractures at a threshold dilation angle of $30.0^{\circ}$ after a certain period. The degree of steepness of the gradient of this section of the curve for a joint with a friction coefficient of 1.0 is greater than the gradient for a joint with a friction coefficient of 0.7 , which in turn is greater than the gradient for a joint with a friction coefficient of 0.5 . In other words, an increase in the joint frictional resistance increases the steepness of the gradient. Likewise, the steepness of the slope increases with joint dilatancy (Figure 15, Figure 19, Figure 22, Figure 26), although its influence is suppressed as the frictional resistance becomes progressively dominant (Figure 22 and Figure 26). This behaviour becomes apparent when the friction coefficient reaches 0.7 . At this value, a joint dilation angle below $10.0^{\circ}$ would not significantly affect fracturing in comparison to dilation angles $\geq 20.0^{\circ}$ (Figure 22). 
In like manner, for a joint friction coefficient of 1.0 the influence of dilatancy only becomes significant at a dilation angle $\geq 30.0^{\circ}$ (Figure 26); values of $25.0^{\circ}$ and below have similar and considerably lower impacts. Within the range of dilation angle $0.0^{\circ}-25.0^{\circ}$, the difference in number of crack events is small. Notwithstanding, a closer inspection shows that a rock dilation angle of $7.5^{\circ}$ permits the occurrence of more cracks when compared to dilation angles exceeding $7.5^{\circ}$ but in the limits $7.5^{\circ}<\varphi \leq 25^{\circ}$ (Figure 27). At the vicinity of joints of high frictional resistance $(\phi=1.0)$, fracture development at low joint dilatancy (e.g. $7.5^{\circ}$ ) is greater than fracture development at medium joint dilatancy (e.g. $20^{\circ}-2^{\circ}$ ) (Figure 27). This is observed in both tensile and shear fracturing and the phenomenon is well defined if the friction coefficient is sufficiently high. A lower dilation angle does not necessarily imply lesser magnitudes of fracturing.

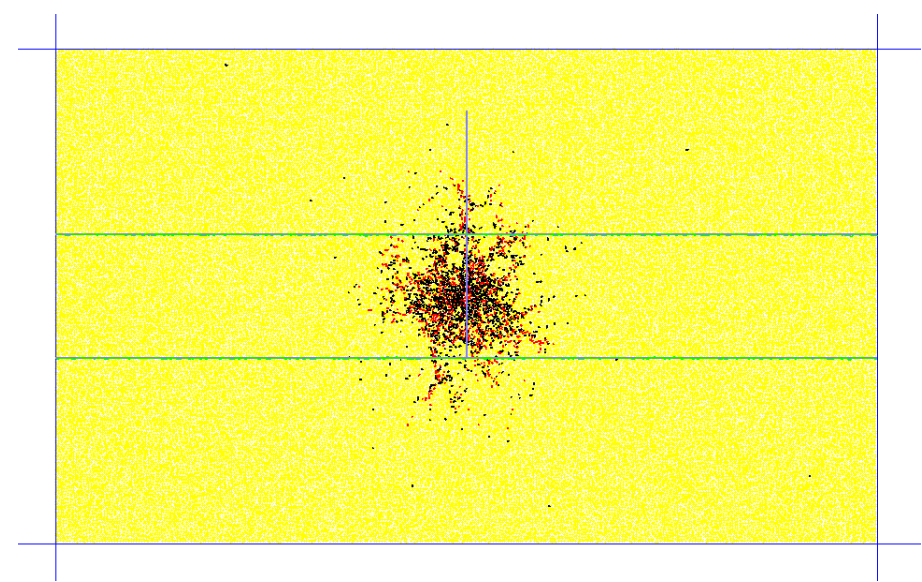

a. Fracture development (dilation angle: 7.5 )

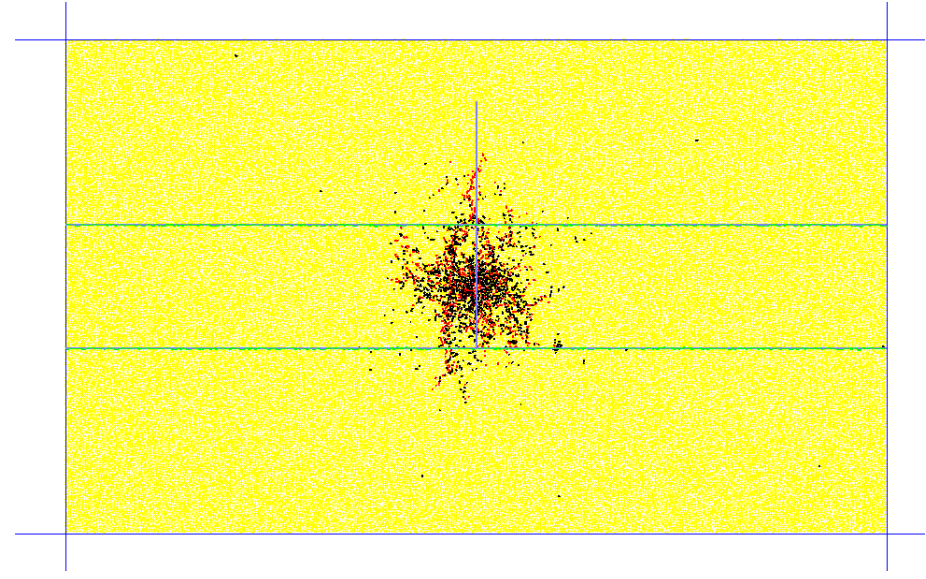

b. Fracture development (dilation angle: 20.0) 


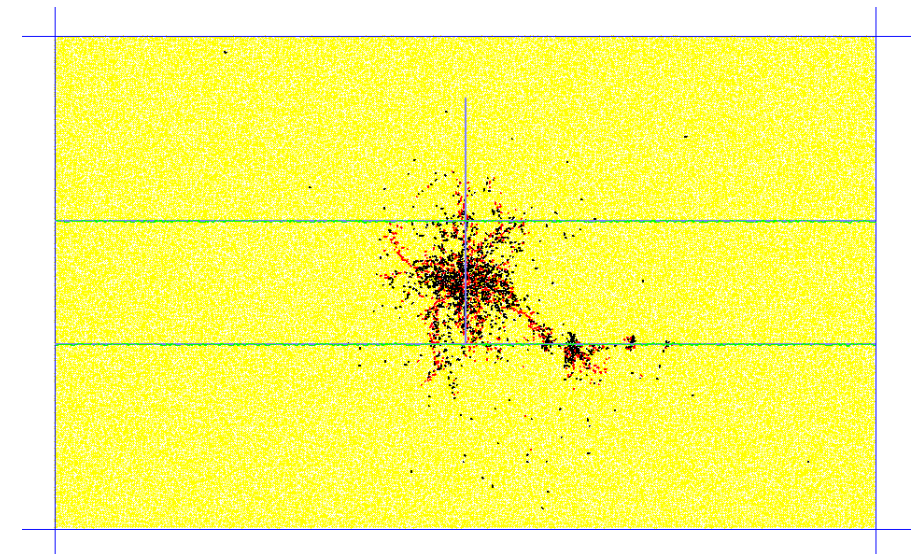

c. Fracture development (dilation angle: 25.0)

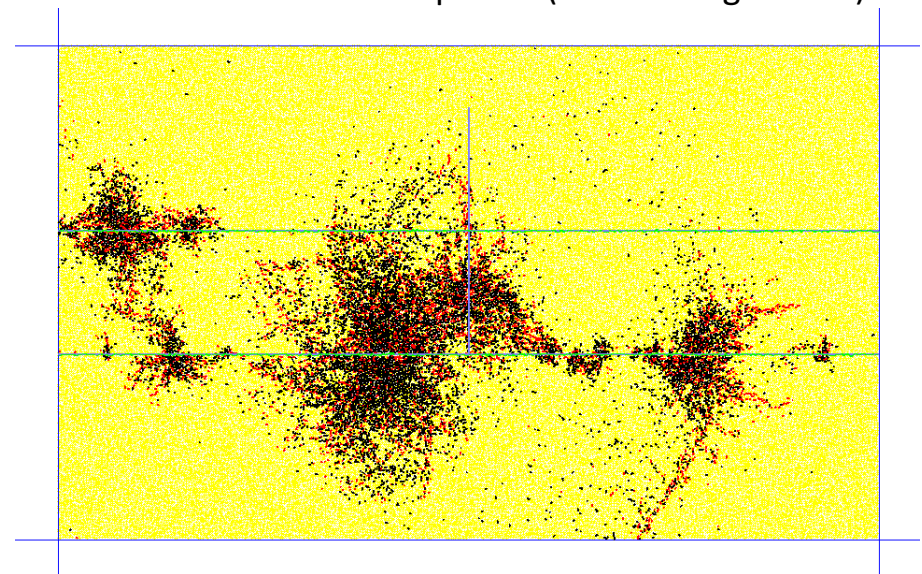

d. Fracture development (dilation angle: 30.0 )

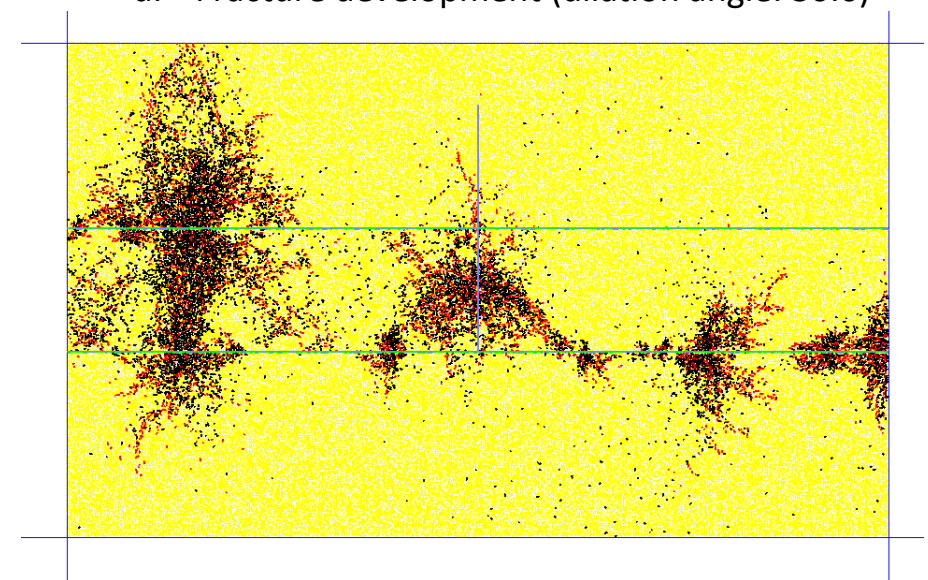

e. Fracture development (dilation angle: 40.0)

Figure 24. Impact of dilatancy on fracture development (friction coefficient: 1.0) 


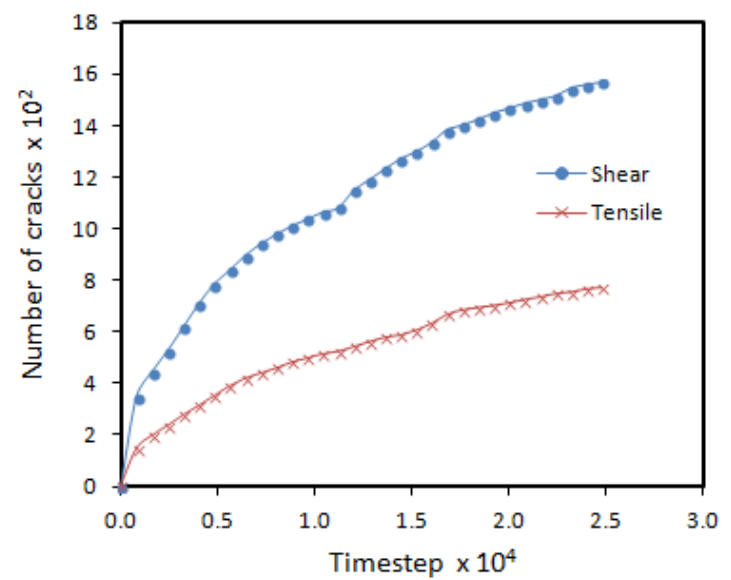

a. Fracture development (dilation angle: 7.5)
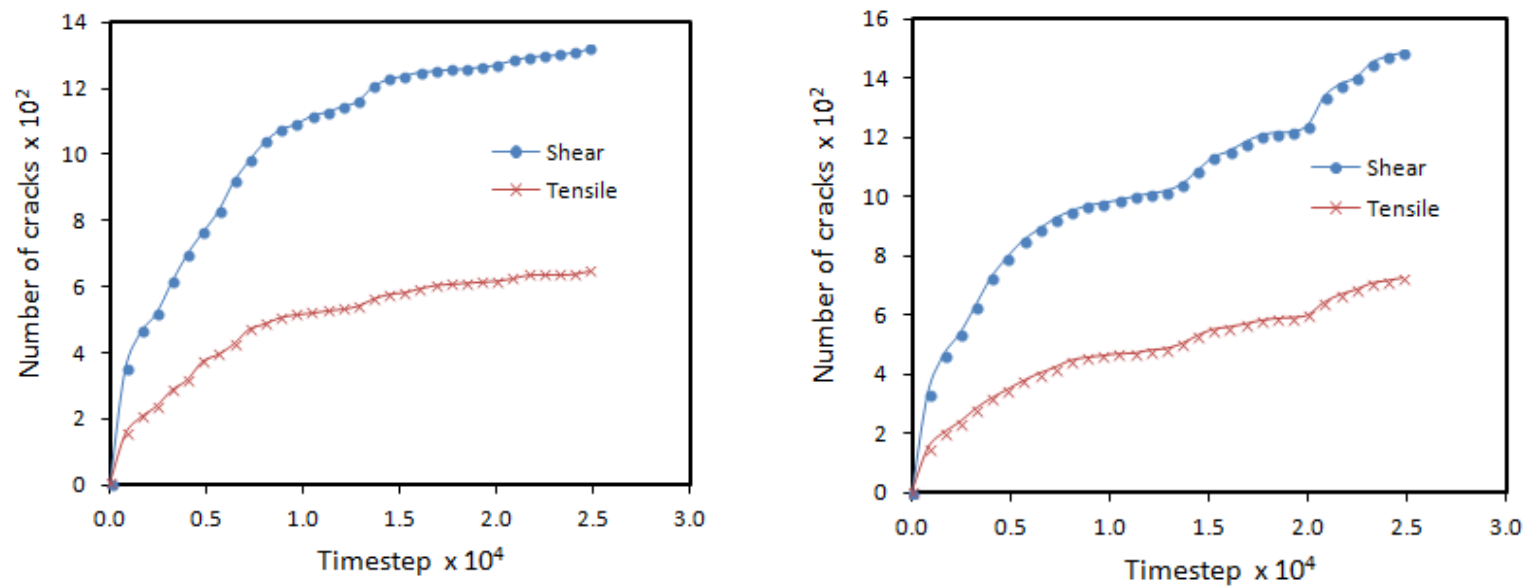

b. Fracture development (dilation angle: 20.0)

c. Fracture development (dilation angle: 25.0)
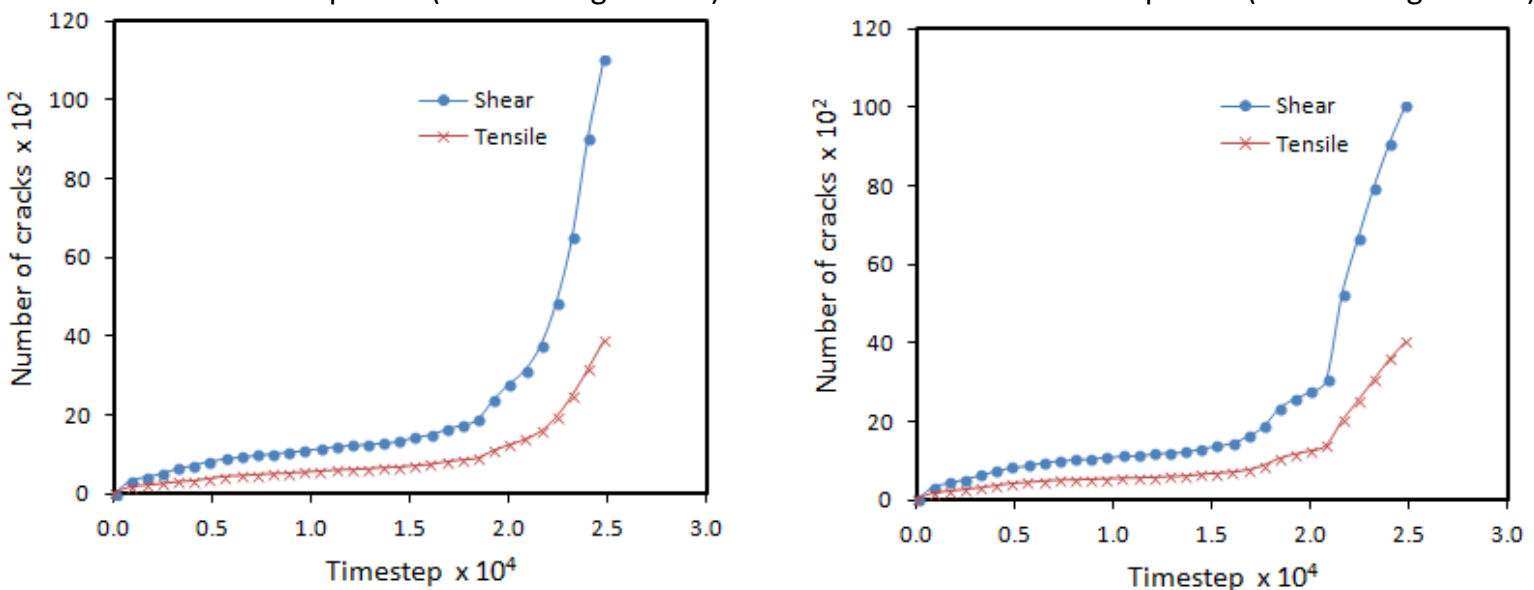

d. Fracture development (dilation angle: 30.0 )

e. Fracture development (dilation angle: 40.0)

Figure 25. Evolution of tensile and shear fractures at different joint dilatancies

(Friction coefficient: 1.0) 


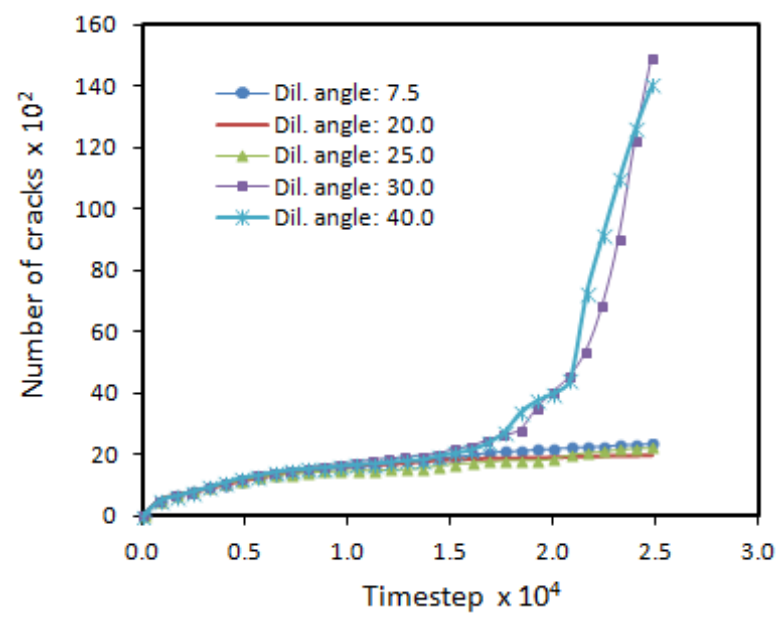

a. Total fracture development

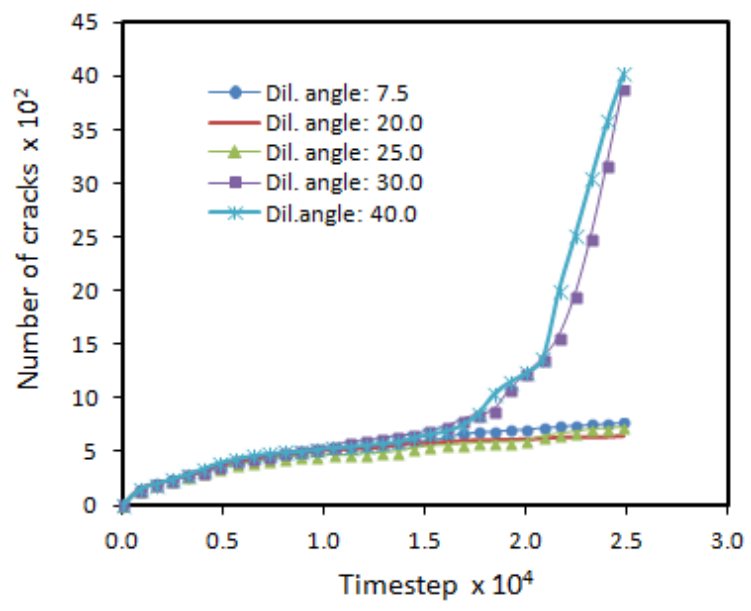

b. Tensile fracture development

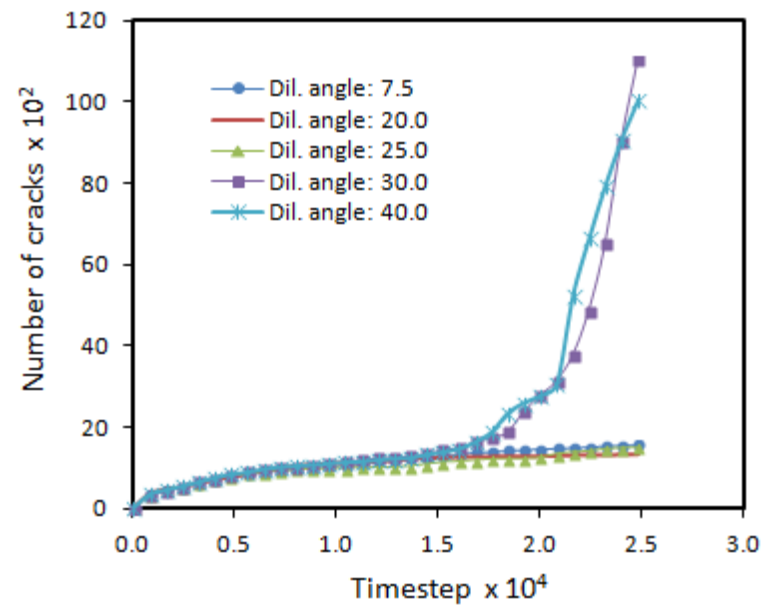

c. Shear fracture development

Figure 26. Influence of dilatancy on the generation of fractures (Friction coefficient: 1.0)

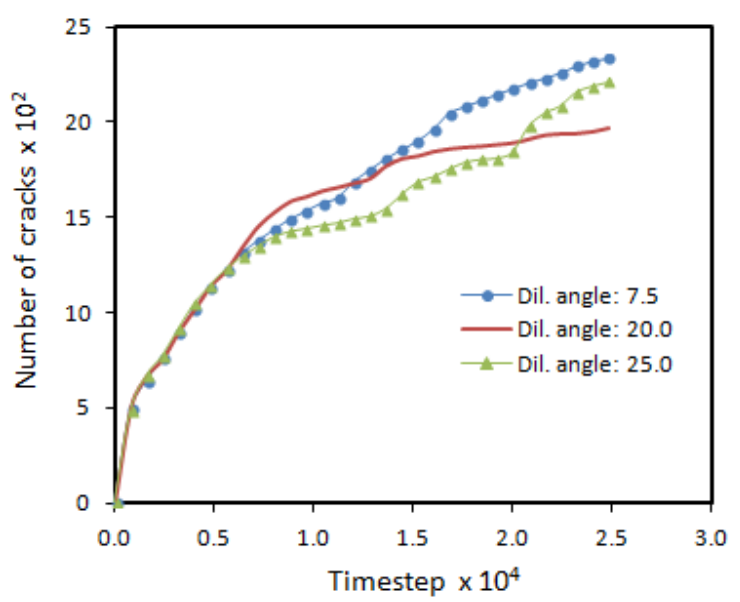

a. Total fracture development 


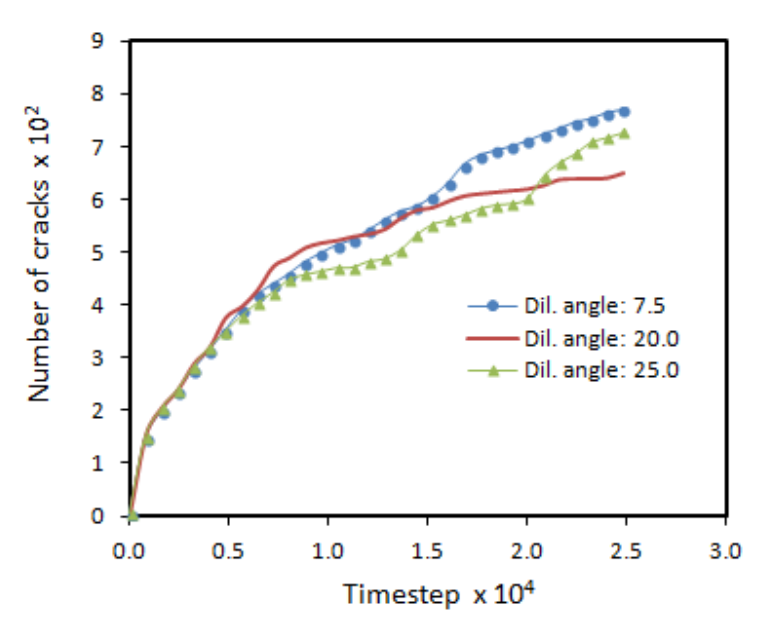

b. Tensile fracture development

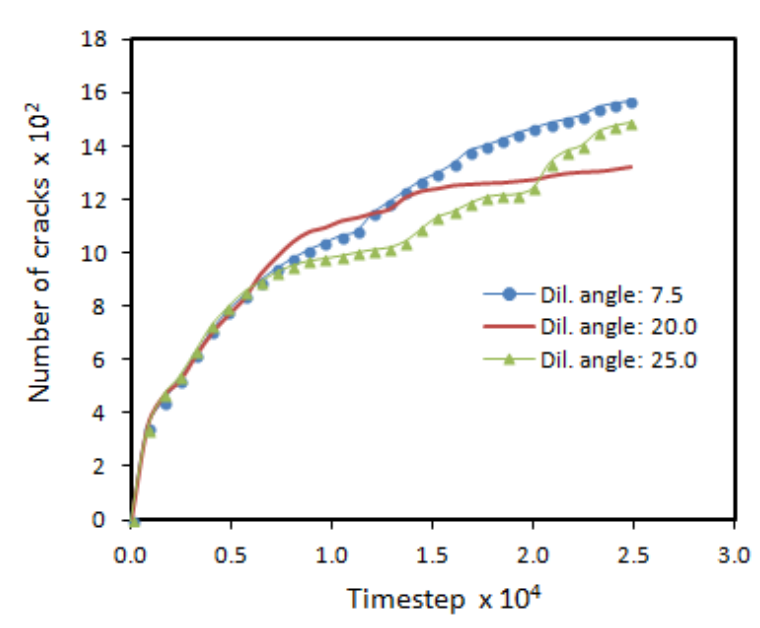

c. Shear fracture development

Figure 27. Influence of dilatancy on the generation of fractures (Friction coefficient: 1.0)(close-up)

A supplementary illustration of the effect of joint frictional resistance on fracturing under different dilatancies is presented in Figure 28-33. At a joint dilation angle of $2.5^{\circ}$ (Figure 28), differences in frictional resistance do not lead to a significant change in the fracturing behaviour. The impact of the frictional resistance becomes noticeable when the joint dilation angle is increased to $5.0^{\circ}$, with the number of cracks and frictional resistance having an inverse relationship that is consistent for a range of joint dilation angles spanning up to $40^{\circ}\left(5.0^{\circ}<\varphi \leq 40.0^{\circ}\right)$ (Figure 29-33). The same trend in fracturing behaviour can be assumed for joint dilation angles above $40.0^{\circ}$. Generally, an increase in joint frictional resistance decreases the rate and magnitude of fracturing if the joint dilation angle is at least equal to $5.0^{\circ}$.

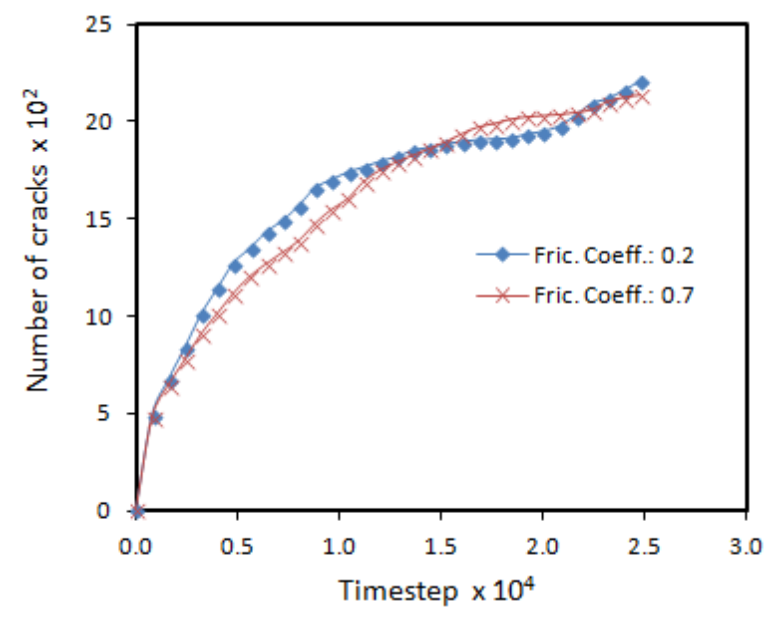

a. Total fracture development 


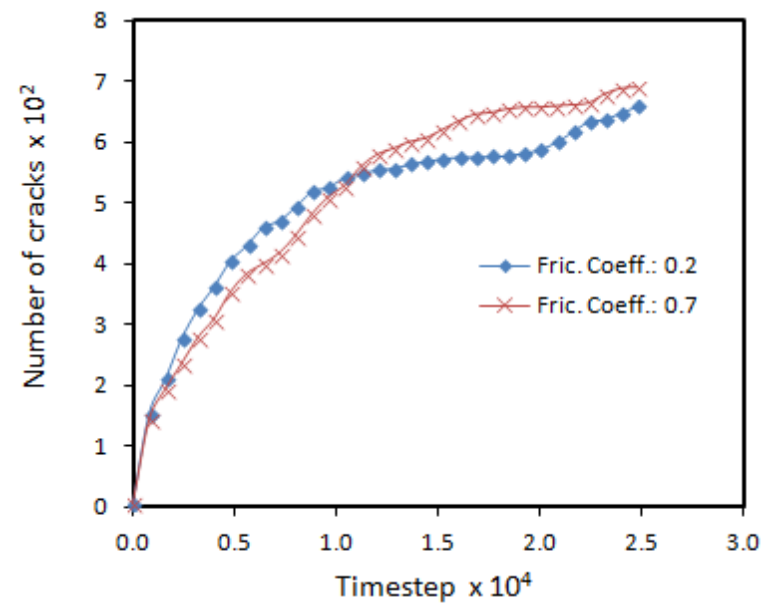

b. Tensile fracture development

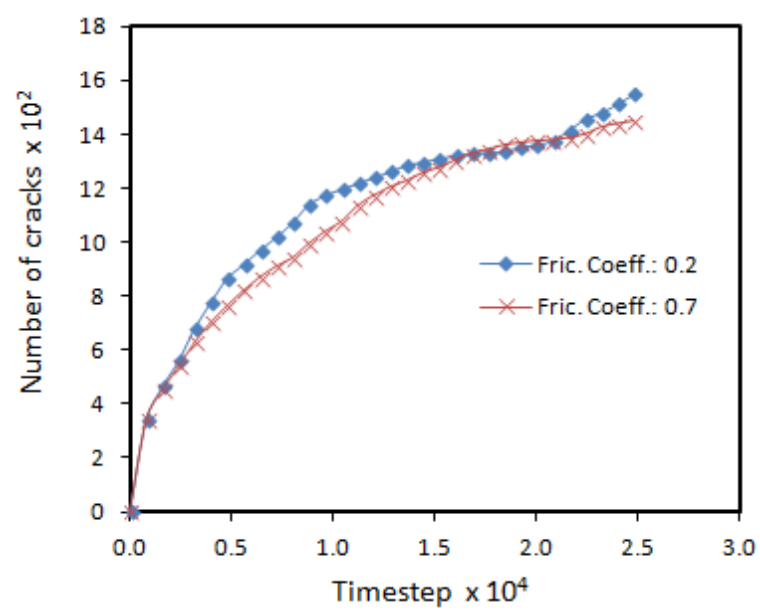

c. Shear fracture development

Figure 28. Alterations in fracturing due to the implications of joint friction (dilation angle: 2.5)

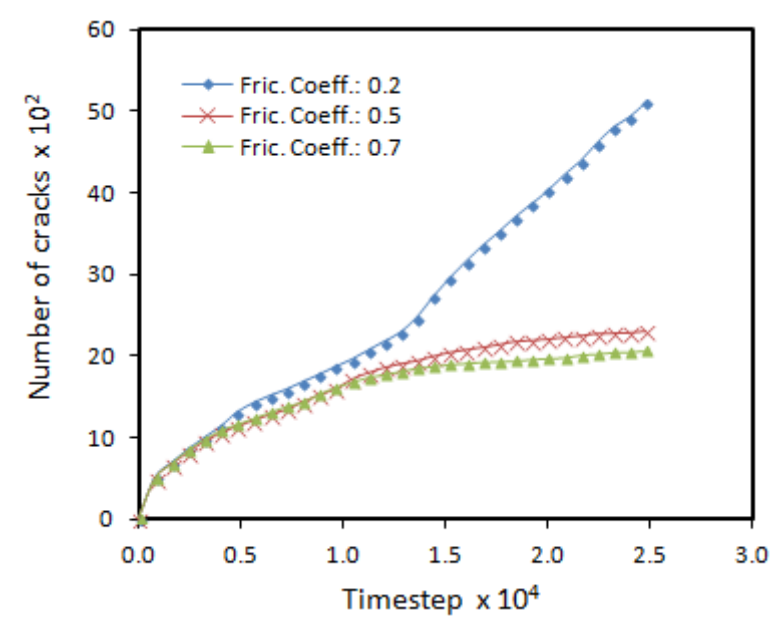

a. Total fracture development

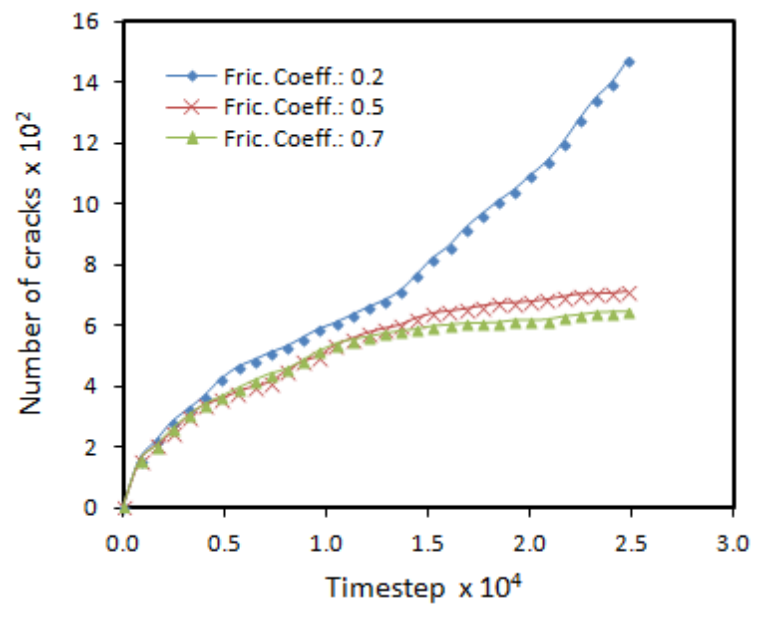

b. Tensile fracture development

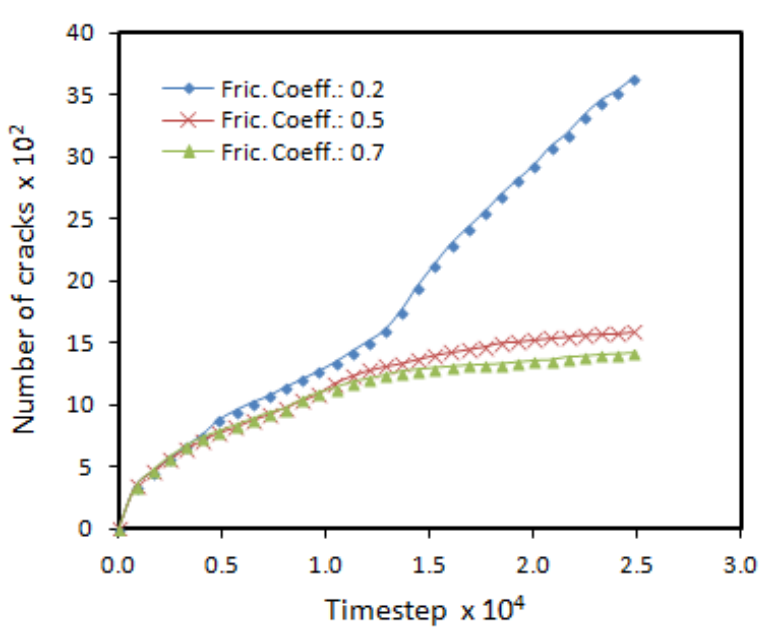

c. Shear fracture development

Figure 29. Alterations in fracturing due to the implications of joint friction (dilation angle: 5.0) 


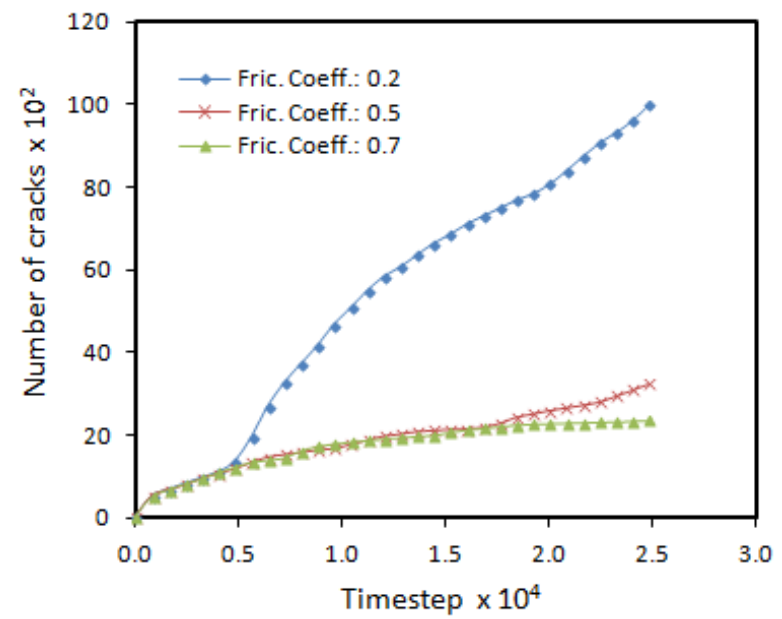

a. Total fracture development

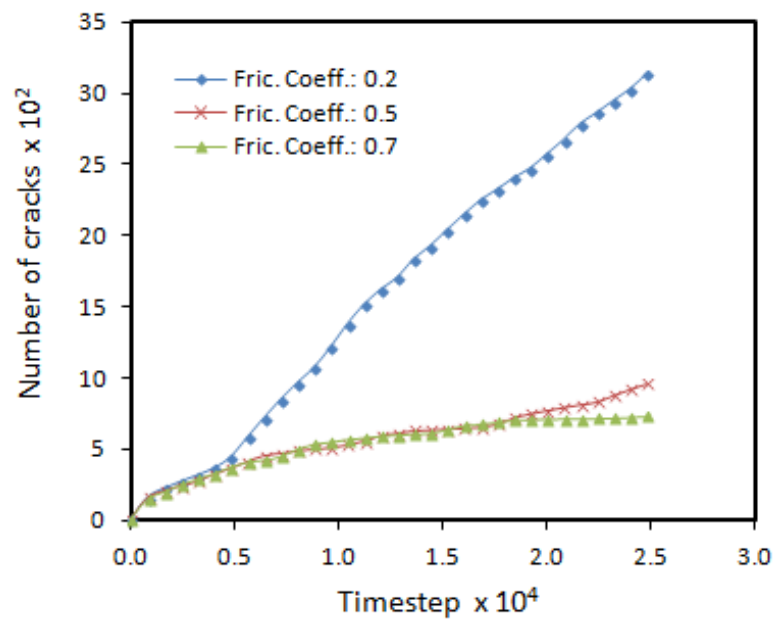

b. Tensile fracture development

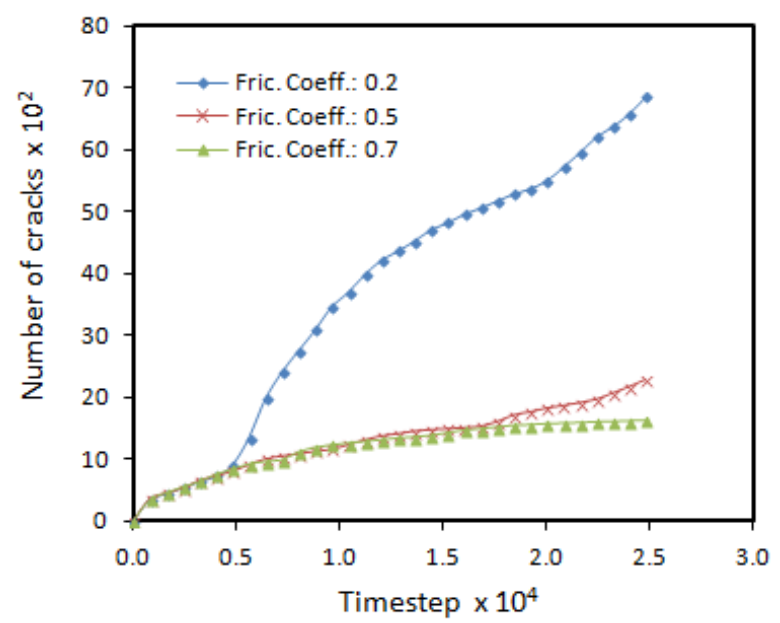

c. Shear fracture development

Figure 30. Alterations in fracturing due to the implications of joint friction (dilation angle: 10.0)

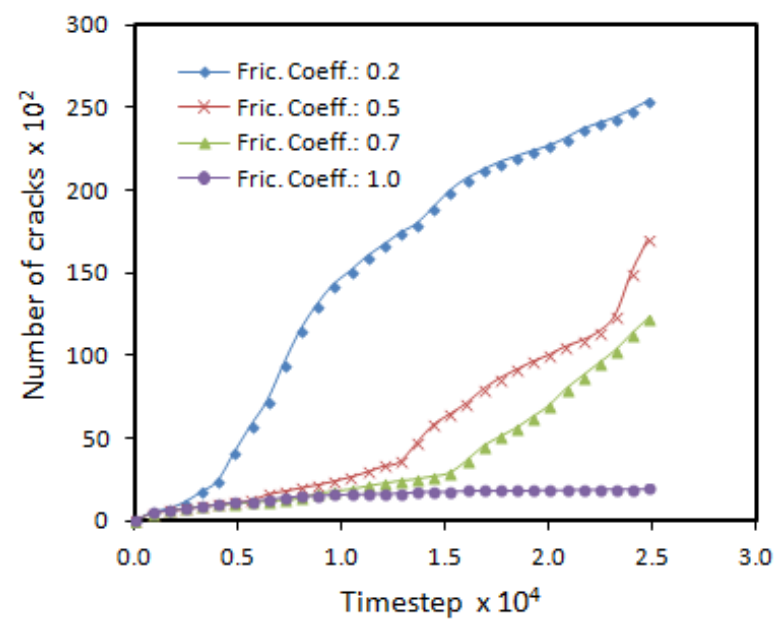

a. Total fracture development 


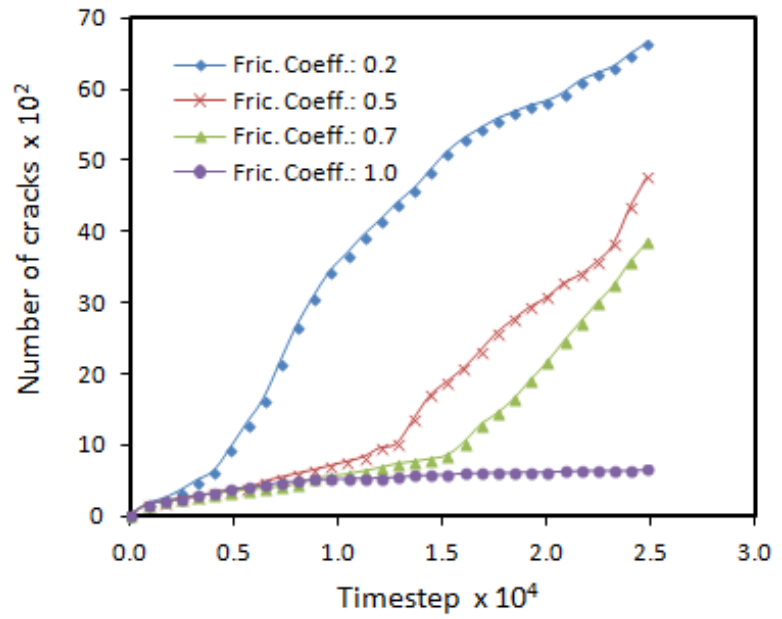

b. Tensile fracture development

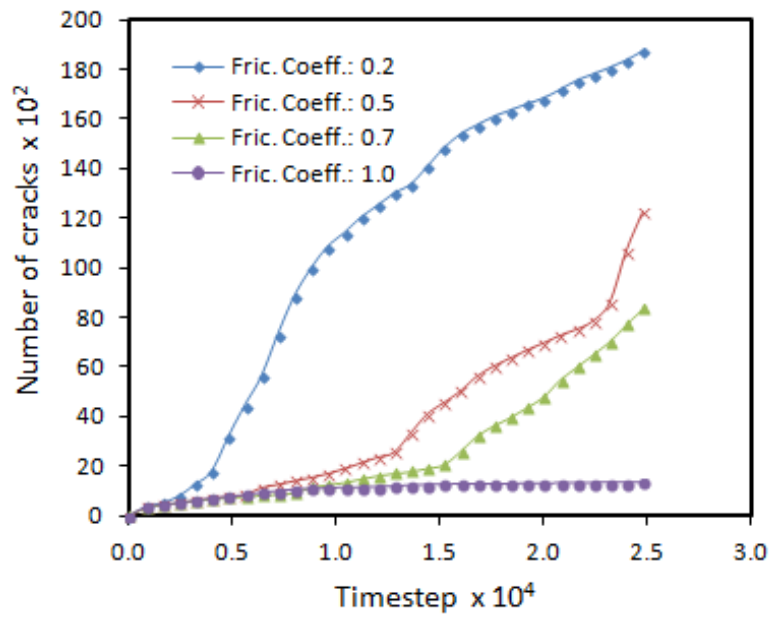

c. Shear fracture development

Figure 31. Alterations in fracturing due to the implications of joint friction (dilation angle: 20.0)

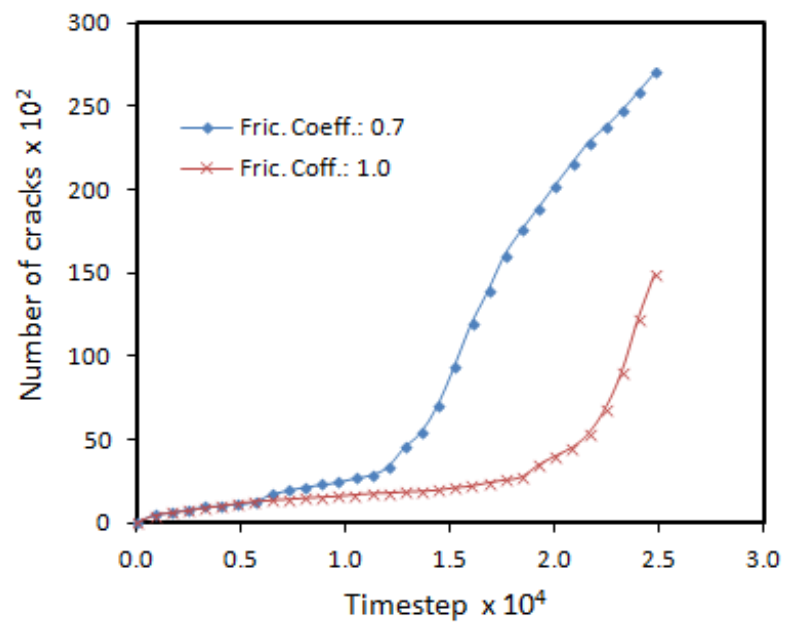

a. Total fracture development

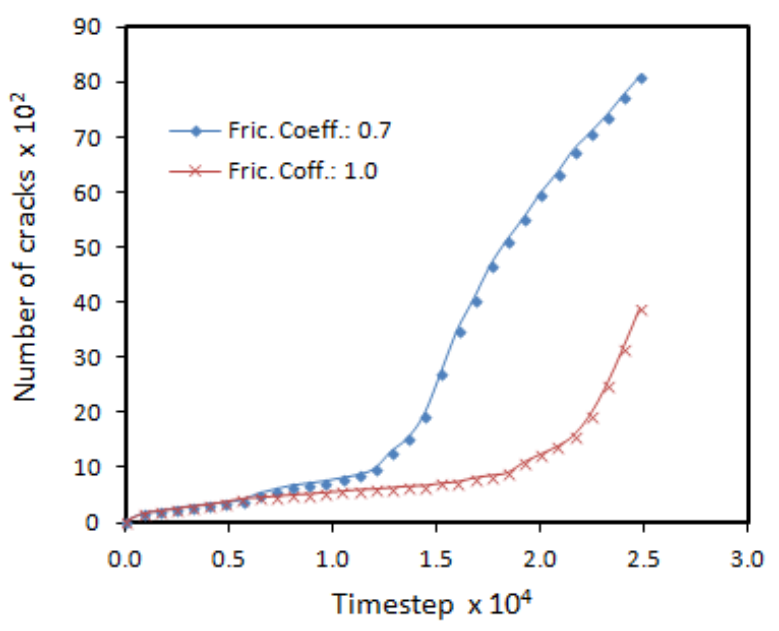

b. Tensile fracture development

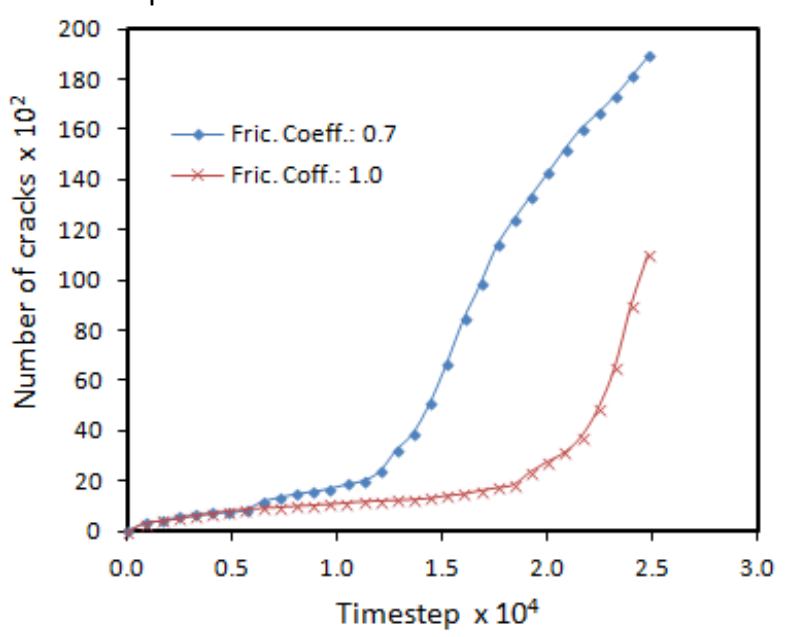

c. Shear fracture development

Figure 32. Alterations in fracturing due to the implications of joint friction (dilation angle: 30.0 ) 


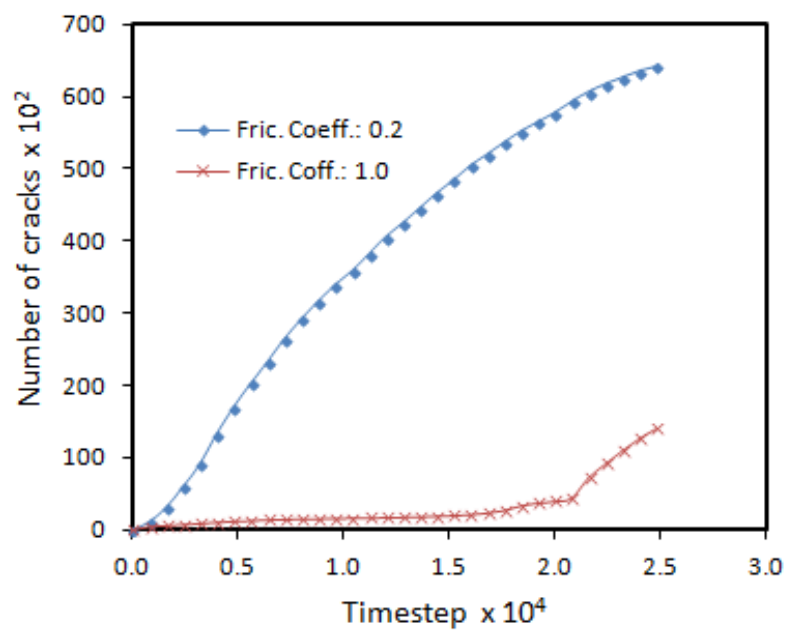

a. Total fracture development

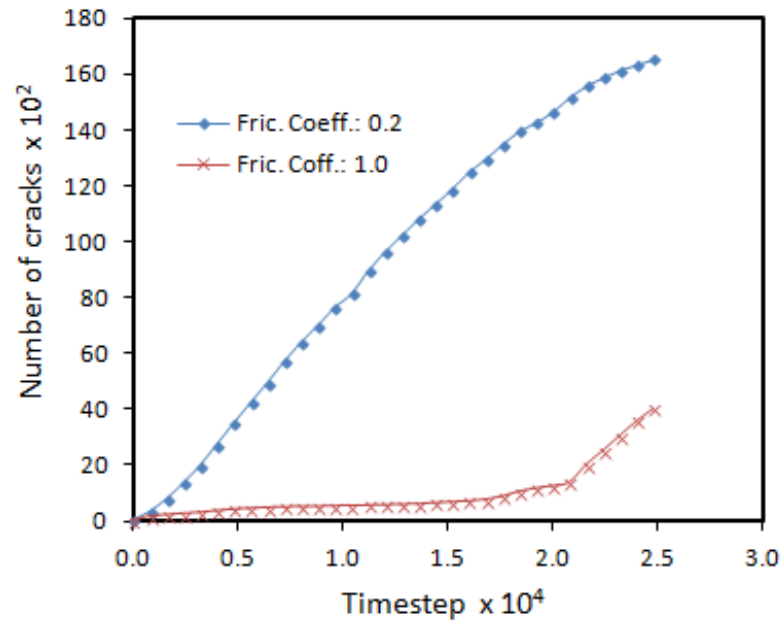

b. Tensile fracture development

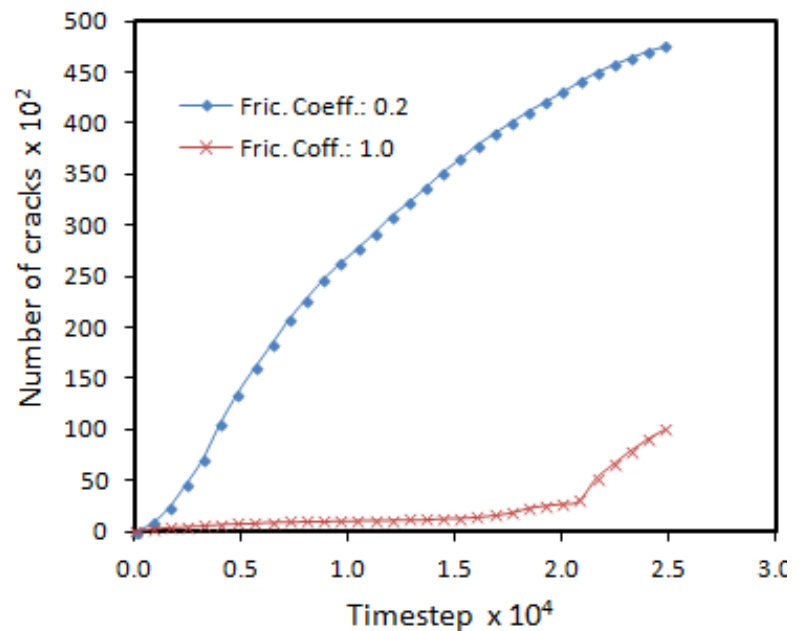

c. Shear fracture development

Figure 33. Alterations in fracturing due to the implications of joint friction (dilation angle: 40.0 )

\subsection{Conclusion}

Discontinuities such as joints are integral components of rock masses and contribute to their structural integrity. They apparently influence the general behaviour of the rock and in particular its response to external loading conditions arising from fluid flow and stress inducements. The behaviour of joints is mostly determined by the characteristics of its interface, which is in turn governed by its chemical and mechanical properties. Moreover, these two set of properties are interconnected, since the chemical constituents of the fills and host rocks duly influence the mechanical properties. The mechanical and physical properties of fills have a direct impact on the structural behaviour of the interface, and their presence or absence determines, to a large extent, the status of joints. How the joint responds to changes within the host rock is chiefly regulated by its 
properties. The most dominate mechanical properties comprise joint shear strength, joint compressive strength (JCS), joint frictional resistance, joint cohesion, joint dilatancy and joint surface roughness, which can be designated by the joint roughness coefficient (JRC). Some of these properties are interrelated. For a non-bonded joint (assumed to have negligible cohesion), the fundamental properties that control its mechanism include its frictional resistance, dilatancy and compressive strength.

Joint dilation angle and friction angle have an interactive relationship; its dilatancy influences the frictional resistance. When the joint friction angle is within the low range, the response of the joint becomes highly sensitive to its dilation such that small magnitudes in its dilation angle are capable of significantly escalating the intensity of fracturing. As the joint dilatancy rises, it promotes the propensity for the following to occur: i) additional points of fracture onset along the joint plane, 2) augmentation in the proliferation and growth of fractures at the length of the joint and in outward directions, 3) amplification in the affinity for cavity creation at the joint surface, and 4) increase in the size and population of those cavities.

Crack initiation at the joint surface is primarily caused by the shearing mechanisms leading to shear failures. Propagation of these fractures is then prevalently impelled by the tensile failure of the joint and host rock material. The severity of fractures instigated through shear failure is significantly higher than that caused by tensile failure. This trend is associated with the movement of the joint planes as they slide against each other. A rise in joint dilatancy intensifies the generation and growth of both tensile and shear fractures. Where the joint dilatancy remains consistent, increments in the frictional resistance inversely and significantly affect the fracturing process. The degree of this effect appreciates at the high range of friction values; within these bounds, the contribution of low joint dilation angles is negligible.

For joints with high frictional resistance, the extent of fracturing near the joint area decreases as dilatancy increases; however, this phenomenon only holds within the ambit encompassing low to medium dilation angles. Furthermore, for medium to highly dilatant joints, which are also greatly frictional, a rise in joint frictional resistance reduces the intensity of fracturing.

The work presented here is primarily based on regular-spaced single planar joints observed under plane strain conditions. It will be worthwhile to examine the contributions to the fracturing phenomenon at instances where 1) there are irregular joint spacings, and 2) there is a more complex network of joints with geometries interacting at diverse angles. The framework for future works will hinge on these aspects. 


\section{Nomenclature}

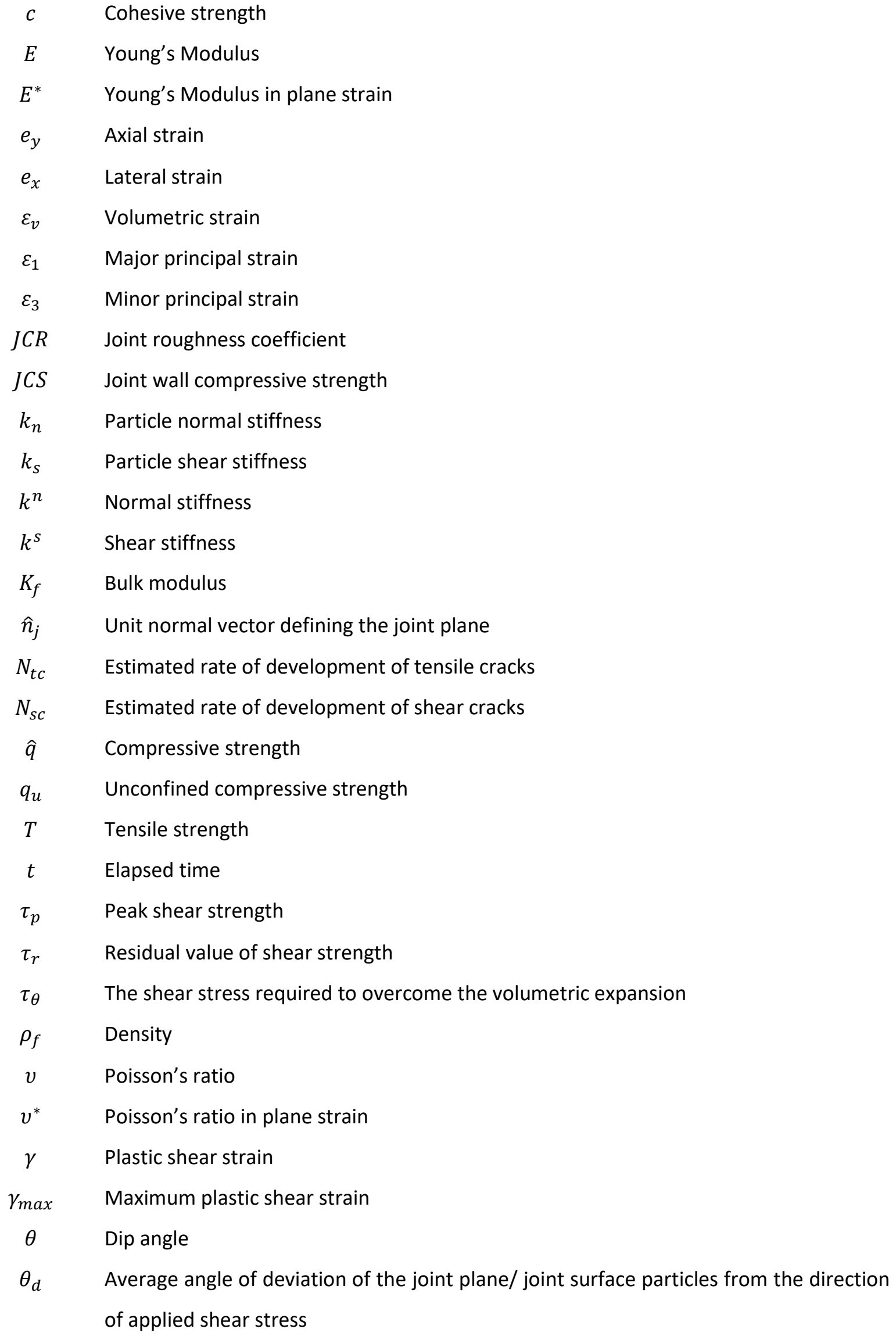




$\begin{array}{cl}\vartheta & \text { Dip direction } \\ \sigma_{D} & \text { Deviatoric stress } \\ \sigma_{n} & \text { Normal stress } \\ \sigma_{y} & \text { Axial stress } \\ \sigma_{x} & \text { Lateral stress } \\ \sigma_{1}^{\prime} & \text { Major effective principal stress } \\ \sigma_{3}^{\prime} & \text { Minor effective principal stress } \\ \phi & \text { Angle of internal friction (friction angle) } \\ \phi_{r} & \text { Residual value of friction angle } \\ \phi_{b} & \text { Basic friction angle } \\ \phi_{c r i t} & \text { Critical friction angle } \\ \phi_{f} & \text { Interparticle friction angle corrected for work done or energy dissipated due to } \\ & \text { expansion } \\ \phi_{t} & \text { The true angle of friction between the mineral surfaces of the particles } \\ \phi_{c v} & \text { Angle of friction under constant volume } \\ \varphi & \text { Dilation of a material, joint or discontinuity } \\ \varphi_{p} & \text { Peak dilation, which is the same as the maximum dilation } \\ \mu & \text { Viscosity }\end{array}$

\section{References}

Amadei, B. and Saeb, S. 1990. Constitutive models of rock joints. Proceedings of the international symposium on rock joints. Leon, Norway, p. 581-594.

Athavale, A. S. and Miskimins, J. L. 2008. Laboratory hydraulic fracturing on small homogeneous and laminated blocks. 42nd US Rock Mechanics Symposium, San Francisco June 29-July 2.

Barton, N. 2013. Shear strength criteria for rock, rock joints, rockfill and rock masses: Problems and some solutions. Journal of Rock Mechanics and Geotechnical Engineering 5: 249-261. DOI: https://doi.org/10.1016/j.jrmge.2013.05.008

Barton, N. 1973. Review of a new shear-strength criterion for rock joints. Engineering Geology, 7, 287-332.

Barton, N. 1976. The shear strength of rock and rock joints. international Journal of Rock Mechanics and Mining Sciences and Geomechanics Abstracts, 19 (9), 255-279.

Barton, N. and Choubey, V. 1977. The shear strength of rock joints in theory and practice. Rock Mechanics, 10, 1-54. 
Bolton, M. D. 1986. The strength and dilatancy of sands. Geotechnique, 36 (1), 65-78.

Byerlee, J. 1978. Friction of Rocks. In: BYERLEE, J. \& WYSS, M. (eds.) Rock Friction and Earthquake Prediction. Birkhäuser Basel.

Cacace, M. and Blocher, G. 2015. Meshlt - a software for three dimensional volumetric meshing of complex faulted reservoirs. Environmental Earth Sciences 74 (6), 5191-5209.

Cai, M. and Horii, H. 1992. A constitutive model of highly jointed rock masses. Mechanics of Materials, 13, 217-246.

Casas, L., Miskimins, J. L., Black, A. and Green, S. 2006. Laboratory hydraulic fracturing test on a rock with artificial discontinuities. SPE Annual Technical Conference and Exhibition, San Antonio, Texas, USA, 24-27 September

Chang, C. S. and Misra, A. 1990. Packing structure and mechanical properties of granulates. Journal of Engineering Mechanics, 116 (5): 1077-93

Cieslik, J. 2018. Dilatancy as a measure of fracturing development in the process of rock damage. Open Geosci. 10: 484-490

Chuprakov, D. A., Akulich, A. V., Siebrits, E. and Thiercelin, M. 2010. Hydraulic fracture propagation in a naturally fractured reservoir. SPE Oil and Gas India Conference and Exhibition in Mumbai, India, 20-22 January.

De Josselin de Jong, G. 1976. Rowe's stress-dilatancy relation based on friction. Geotechnique, 26 (1), 527-534.

Desai, C. S., Zaman, M. M., Lightner, J. G. and Siriwardane, H. J. 1984. Thin-layer element for interfaces and joints. Int J Numer Anal Meth Geomech, 8 (1), 19-43.

Eshiet, K. and Sheng, Y. 2014. Investigation of geomechanical responses of reservoirs induced by carbon dioxide storage. Environmental Earth Sciences, 71, 3999-4020.

Eshiet, K. I. and Sheng, Y. 2015. Inter-relationship between joint dilatancy and frictional resistance: impact on fracture behaviour. IOP Conf. Series: Earth and Environmental Science, 26 (2015) 012053.

Eshiet, K. I. and Sheng, Y. 2017. The role of rock joint frictional strength in the containment of fracture propagation. Acta Geotechnica, 12 (4), 897-920. https://doi.org/10.1007/s11440016-0512-2

Eshiet, K. I-I, Welch, M. and Sheng, Y. 2018. Numerical modelling to predict fracturing rock (Thanet chalk) due to naturally occurring faults and fluid pressure. Journal of Structural Geology, 116: 12-33; DOI: https://doi.org/10.1016/i.jsg.2018.07.021 
Han, G., Jing, H., Jiang, Y., Lui, R. and Wu, J. 2020. Effect of Cyclic Loading on the Shear Behaviours of Both Unfilled and Infilled Rough Rock Joints Under Constant Normal Stiffness Conditions. Rock Mech Rock Eng 53, 31-57. DOI: https://doi.org/10.1007/s00603-019-01866-w

Hossaini, K. A., Babanouri, N. and Nasab, S. K. 2014. The influence of asperity deformability on the mechanical behavior of rock joints. International Journal of Rock Mechanics \& Mining Sciences 70: 154-161

Huang, H. Y. 1999. Discrete element modeling of tool-rock interaction. PhD thesis, University of Minnesota, Minneapolis, MN.

Huang, Q. and Angelier, J. 1989. Fracture spacing and its relation to bed thickness. Geological Magazine, 126, 355-362.

Huang, H., Lecampion, B. and Detournay, E. 2013. Discrete element modeling of tool-rock interaction I: rock cutting. Int. J. Numer. Anal. Meth. Geomech., 37: 1913-192

Indraratna, B., Oliveira, D. and Jayanathan, M. 2008. Revised shear strength model for infilled rock joints considering overconsolidation effect. Proceedings of the 1st Southern Hemisphere International Rock Mechanics Symposium SHIRMS, 16-19 September, Perth.

Itasca Consulting Group Inc. 2014. Particle Flow Code - PFC (2 and 3 dimension), Version 5.0, User's Manual. Mineapolis, Minesota

Ivars, D. M., Pierce, M. E., Darcel, C., Reyes-Montes, J., Potyondy, D. O., Young, R. P. and Cundall, P. A. 2011. The synthetic rock mass approach for jointed rock mass modelling. International Journal of Rock Mechanics and Mining Sciences, 48, 219-244.

Jacquey, A. B., Cacace, M. and Blocher, G. 2017. Modelling coupled fluid flow and heat transfer in fractured reservoir; description of a 3D benchmark numerical case. Energy Procedia 125, 612-621.

Ji, S. and Suruwatari, K. 1998. A revised model for the relationship between joint spacing and layer thickness. Journal of Structural Geology, 20, 1495-1508.

Ji, S., Zhu, Z. and Wang, Z. 1998. Relationship between joint spacing and bed thickness in sedimentary rocks: effect of interbed slip. Geological Magazine, 135, 637-655.

Johansson, F. 2016. Influence of scale and matedness on the peak shear strength of fresh, unweathered rock joints. International Journal of Rock Mechanics \& Mining Sciences 82: 3647. DOI: http://dx.doi.org/10.1016/i.ijrmms.2015.11.010

Johansson F. and Stille, H. 2014. A conceptual model for the peak shear strength of fresh and unweathered rock joints. International Journal of Rock Mechanics \& Mining Sciences 69: 3138. DOI: https://doi.org/10.1016/j.ijrmms.2014.03.005

Kachanov, M. 1980. Continuum model of medium cracks. Journal of the Engineering Mechanics Division. ASCE, Vol. 106, No. EM5. Proc. Paper 15750, October 1980, 1039-1051. 
Kachanov, M. 1982a. Microcrack Model of Rock Inelasticity. Part I: Frictional Sliding on Pre-existing Microcracks. Mechanics of Materials, 1, 19-27

Kachanov, M. 1982b. Microcrack Model of Rock Inelasticity. Part II: Propagation of Microcracks. Mechanics of Materials, 1, 29-41.

Kachanov, M. 1982c. Microcrack Model of Rock Inelasticity. Part III: Time-Dependent Growth of Microcracks (Stress Corrosion Cracking). Mechanics of Materials, 1, 123-129.

Kachanov, M., Montagut, E. L. E. and Laures, J. P. 1990. Mechanics of crack - microcrack interactions. Mechanics of Materials 10, 59-71.

Kachanov, M., Prioul, R. and Jocker, J. 2010. Incremental linear-elastic response of rocks containing multiple rough fractures: Similarities and differences with traction-free cracks. Geophysics, 75 (1), D1-D11.

Kulatilake, P. H. S. W., Malama, B. and Wang, J. 2001. Physical and particle flow modeling of jointed rock block behaviour under uniaxial loading. International Journal of Rock Mechanics and Mining Sciences, 38, 641-657.

Kamonphet, T., Khamrat, S. and Fuenkajorn, K. 2015. Effects of cyclic shear loads on strength, stiffness and dilation of rock fractures. Songklanakarin J. Sci. Technol. 37 (6): 683-690

Ladiera, F. L. and Price, N. J. 1981. Relationship between fracture spacing and bed thickness. Journal of Structural Geology, 3.

Lambert, C and Coli, C. 2014. Discrete modeling of rock joints with a smooth-joint contact model. Journal of Rock Mechanics and Geotechnical Engineering, 6: 1-12.

DOI: https://dx.doi.org/10.1016/j.jrmge.2013.12.003

Lee, H., Moon, T. and Haimson, B. C. 2016. Borehole breakouts induced in Arkosic sandstones and a discrete element analysis. Rock Mechanics and Rock Engineering, 49 (4): 1369-1388

Lehner, F. and Kachanov, M. 1996. On modelling of "winged" cracks forming under compression. International Journal of Fracture, 77, R69-R75.

Lei, Q., Latham, J-P. and Xiang, J. 2016. Implementation of an empirical joint constitutive model into finite-discrete element analysis of the geomechanical behaviour of fractured rocks. Rock Mechanics and Rock Engineering. DOI: https://doi.org/10.1007/s00603-016-1064-3

Li, Y., Wu, W., Tang, C. and Liu, B. 2019. Predicting the shear characteristics of rock joints with asperity degradation and debris backfilling under cyclic loading conditions. International Journal of Rock Mechanics and Mining Sciences, 120: 108-118. DOI: https://doi.org/10.1016/i.ijrmms.2019.06.001

Maciejewski, J., Bąk, S. and Ciężkowski, P. 2020. Modelling of rock joints interface under cyclic loading. Studia Geotechnica et Mechanica, 42 (1): 36-47.

DOI: https://doi.org/10.2478/sgem-2019-0030 
Mohammadnejad, T. and Khoei, A. R. 2013. An extended finite element method for hydraulic fracture propagation in deformable porous media with the cohesive crack model. Finite Elements in Analysis and Design, 73, 77-95.

Narr, W. and Suppe, J. 1991. Joint spacing in sedimentary rocks. Journal of Structural Geology, 13: 9, 1037-1048.

Newland, P. L. and Allely, B. H. 1957. Volume changes in drained triaxial tests on granular materials. Geotechnique, 7, 17-34.

Ohnishi, Y., Chan, T. and Jing, L. 1996. Constitutive models for rock joints. Developments in Geotechnical Engineering, 79, 57-92.

Park, J.-W. and Song, J.-J. 2009. Numerical simulation of a direct shear test on a rock joint using a bonded-particle model. International Journal of Rock Mechanics and Mining Sciences, 46, 1315-1328.

Philipp, S., Gudmundsson, A., Meier, S. and Reyer, D. 2009. Field studies and numerical models of hydrofracture propagation layered fractures reservoirs. . Geophysical Research Abstracts 11.

Plesha, M. 1987. Constitutive models for rock discontinuities with dilatancy and surface degradation. International Journal of Numerical and Analytical Methods in Geomechanics, 11, 345-362.

Plesha, M. 1995. Rock joints: Theory, constitutive equations. Studies in Applied Mechanics, 42, $375-$ 393.

Potyondy, D. O. and Cundall, P. A. 2004. A bonded-particle model for rock. International Journal of Rock Mechanics and Mining Sciences, 41 (8), 1329-64.

Potyondy, D. O. and Cundall, P. A. 2004. A bonded-particle model for rock. International Journal of Rock Mechanics and Mining Sciences, 41 (8), 1329-64

Priest, S. T. 1993. Discontinuity analysis for rock mechanics, London: Chapman \& Hall [chapter 10].

Puntel, E. and Saouma, V. E. 2008. Experimental behavior of concrete joint interfaces under reversed cyclic loading. J. Struct. Eng. 134(9): 1558-1568

Roko, R. O., Daemen, J. J. K. and Myers, D. E. 1997. Variogram characterization of joint surface morphology and asperity deformation during shearing. Int. J. Rock Mech. Min. Sci. 34 (1): $71-$ 84

Rowe, P. W. 1962. The stress-dilatancy relation for static equilibrium of an assembly of particles in contact. Proceedings of the Royal Society of London, Series A - Mathematical and Physical Sciences, 269, 500-527.

Rowe, P. W. 1969. The relation between the shear strength of sands in triaxial compression, plane strain and direct shear. Geotechnique, 19 (1), 75-86.

Saadat, M. and Taheri, A. 2020. A cohesive grain based model to simulate shear behaviour of rock joints with asperity damage in polycrystalline rock. Computers and Geotechnics, 117, 103254. DOI: https://doi.org/10.1016/j.compgeo.2019.103254 
Saadat, M. and Taheri, A. 2019. A cohesive discrete element based approach to characterizing the shear behavior of cohesive soil and clay-infilled rock joints. Computers and Geotechnics, 114, 103109. DOI: https://doi.org/10.1016/j.compgeo.2019.103109

Salgado, R. 2006. The Engineering of Foundations, McGraw-Hill Education.

Schopfer, M. P. J., Arslan, A., Walsh, J. J. and Childs, C. 2011. Reconciliation of contrasting theories for fracture spacing in layered rocks. Journal of Structural Geology, 33, 551-565.

Segura, J. M. and Carol, I. 2004. On zero-thickness interface elements for diffusion problems. International Journal for Numerical and Analytical Methods in Geomechanics 28 (9), 947962.

Segura, J. M. and Carol, I. 2008. Coupled HM analysis using zero-thickness interface elements with double nodes. Part I: Theoretical model. International Journal for Numerical and Analytical Methods in Geomechanics 32 (18), 2083-2101.

Shimizu, H., Murata, S. and Ishida, T. 2011. The distinct element analysis for hydraulic fracturing in hard rock considering fluid viscosity and particle size distribution. International Journal of Rock Mechanics and Mining Science \& Geomechanics, 48, 712-727.

Tang, C. A., Liang, Z. Z., Zhang, Y. B., Chang, X., Tao, X., Wang, D. G., Zhang, J. X., Liu, J. S., Zhu, W. C. and Elsworth, D. 2008. Fracture spacing in layered materials: a new explanation based on two-dimensional failure process modeling. American Journal of Science, 308, 49-72.

Thiercelin, M. and Makkhyu, E. 2007. Stress field in the vicinity of a natural fault activated by the propagation of an induced hydraulic fracture. Proc., First Canada-US Rock Mechanics Symposium-Rock Mechanics Meeting Society's Challenge and Demands, 2 1617-1624.

Trivedi, A. 2010. Strength and dilatancy of jointed rocks with granular fill. Acta Geotechnica, 5 (1), 15-31.

Vallejos, J. A., Suzuki, K., Brzovic, A. and Ivars, D. M. 2016. Application of Synthetic Rock Mass modeling to veined core-size samples. International Journal of Rock Mechanics and Mining Sciences, 81: 47-61.

Wang, J. G., Ichikawa, y. and Leung, C. F. 2003. A constitutive model for rock interfaces and joints. International Journal of Rock Mechanics and Mining Sciences, 40, 41-53.

Welch, M. J., Souque, C., Davies, R. K. and Knipe, R. J. 2015. Using mechanical models to investigate the controls on fracture geometry and distribution in chalk. Geological Society, London, Special Publications, 406, 281-309.

Wen, Z. J., Wang, X., Li, Q. H., Lin, G., Chen, S. J. and Jiang, Y. J. 2016. Simulation analysis on the strength and acoustic emission characteristics of jointed rock mass Technical Gazette, 23 (5): $1277-1284$ 
Wu, H. and Pollard, D. D. 1995. An experimental study of the relationship between joint spacing and layer thickness. Journal of Structural Geology, 17.

Yang, B., Jiao, Y. and Lei, S. 2006. A study on the effects of microparameters on macroproperties for specimens created by bonded particles. Internation Journal for Computer-Aided Engineering and Software, 23, 607-631.

Yang, B., Jiao, Y. and Lei, S. 2006. A study on the effects of microparameters on macroproperties for specimens created by bonded particles. International Journal for Computer-Aided Engineering and Software, 23, 607-631.

Zare, M., Kakaie, S. R. and Jalali, S. M. E. 2008. A new empirical criterion for prediction of the shear strength of natural infilled rock joints under constant normal load (CNL) conditions. ISRM International Symposium - 5th Asian Rock Mechanics Symposium (ARMS5), 24-26 November, Tehran, Iran.

Zhang, X. and Jeffrey, R. G. 2006 The role of friction and secondary flaws on deflection and reinitiation of hydraulic fractures at orthogonal pre-existing fractures. Geophysical Journal International, 166, 1454-1465.

Zhang, X. and Jeffrey, R. G. 2008. Reinitiation or termination of fluid-driven fractures at frictional bedding interfaces. Journal of Geophysical Research, 113, B08416, 16 PP.

Zhao, X. G. and Cai, M. 2010. A mobilized dilation angle model for rocks. International Journal of Rock Mechanics and Mining Sciences 47: 368-384.

DOI: https://doi.org/10.1016/i.ijrmms.2009.12.007 